\title{
Los morlacos \\ y las redes sociales
}

Ángel Torres-Toukoumidis / Andrea De Santis (Coordinadores)

Adriel Shicay, Camila Villacis, Verónica Sigcha, Diego Vintimilla, Jonnathan Morocho, Jasson Marca, Alex Mejía, Christian Picón, Amanda Guzmán, Tábata Figueroa, Evan Arias, Viviana Calle, Ximena Méndez, Freddy Parra, Johny Cabrera, Paolo Romero, Jhonathan Cuesta, Esteban Calderón, Wendy Pugo, Melissa Mora, Mishell Jiménez, Cristopher Pesántez, Fabrizzio Sánchez y Nicolás Moscoso

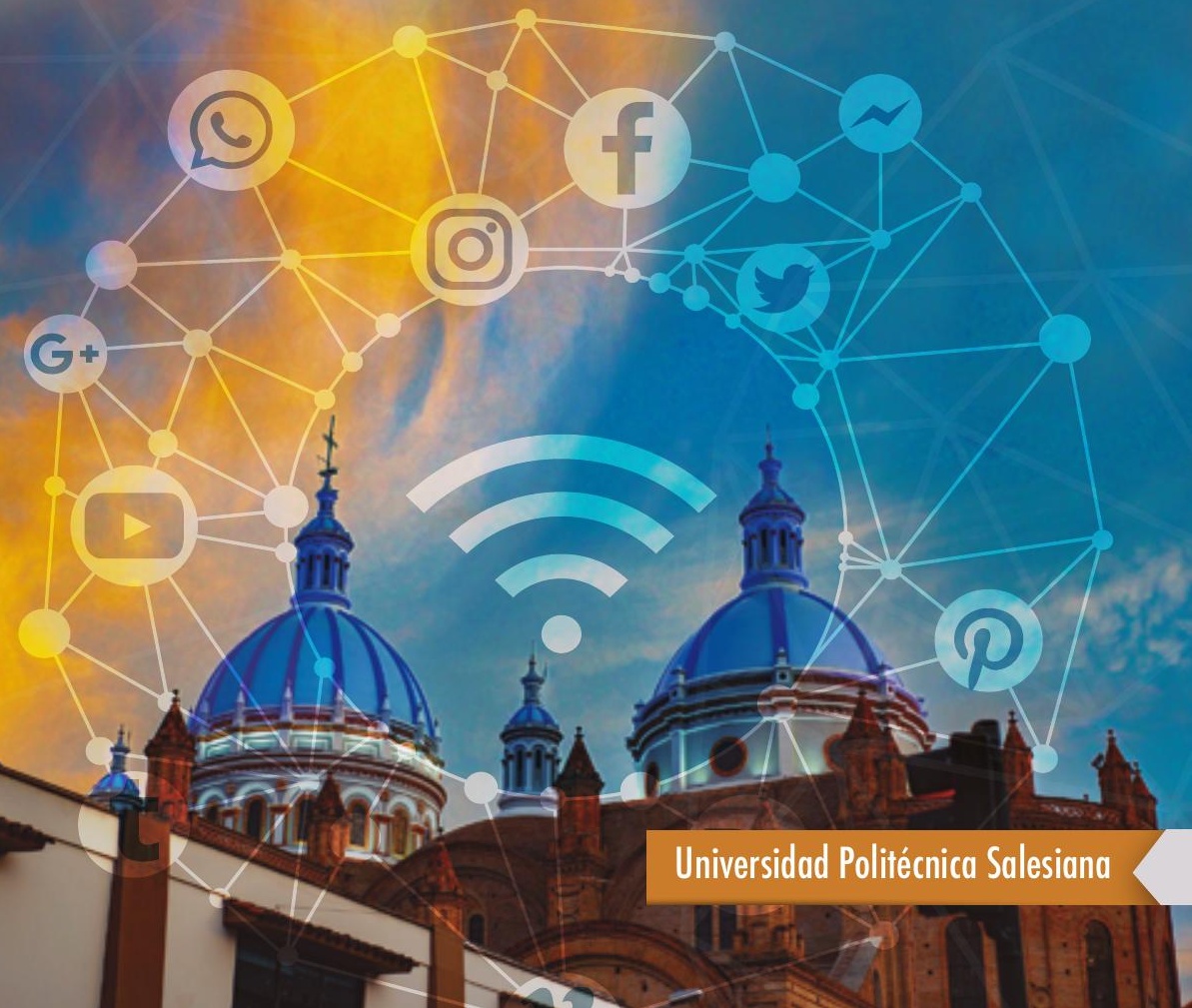


$\underline{\text { Los morlacos y las redes sociales }}$

Ángel Torres-Toukoumidis

Andrea De Santis

(coords.)

\section{SciELO Books / SciELO Livros / SciELO Libros}

TORRES-TOUKOUMIDIS, Á., and DE SANTIS-PIRAS, A., coord. Los

morlacos y las redes sociales [online]. Quito: Editorial Abya-Yala, 2020, 212 p. ISBN: 978-9978-10-534-4.

http://doi.org/10.7476/9789978105771.

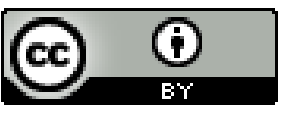

All the contents of this work, except where otherwise noted, is licensed under a Creative Commons Attribution 4.0 International license. Todo o conteúdo deste trabalho, exceto quando houver ressalva, é publicado sob a licença Creative Commons Atribição 4.0. Todo el contenido de esta obra, excepto donde se indique lo contrario, está bajo licencia de la licencia Creative Commons Reconocimento 4.0. 


\section{Los morlacos y las redes sociales}



Ángel Torres-Toukoumidis, Andrea De Santis-Piras

(Coordinadores)

\section{Los morlacos y las redes sociales}

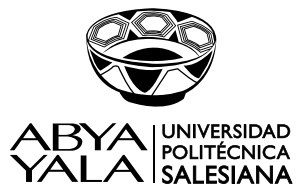

2020 


\section{Los morlacos y las redes sociales}

(C)Ángel Torres-Toukoumidis, Andrea De Santis-Piras (Coordinadores)

Autores: Adriel Shicay-Quezada, Camila Villacís-Mendoza, Verónica Sigcha-Pacheco, Diego Vintimilla-León, Jonnathan Morocho-García, Jasson Marca-Quituizaca, Alex Mejía-Loza, Christian Picón-Cedillo, Amanda Guzmán-Heras, Tábata Figueroa-Sacoto, Evan Arias-Sánchez,Viviana Calle-Salinas, Ximena Méndez-Calle, Freddy Parra-Sigüencia, Johny Cabrera-Ruiz, Paolo Romero-Arévalo, Jhonathan Cuesta-Cuesta, Esteban Calderón-Méndez, Wendy Pugo-Arévalo, Melissa Mora-Gordillo, Mishell Jiménez-Pineda, Cristopher Pesantez-Maxi, Fabrizzio Sánchez-García, Nicolás Moscoso-Loaiza

1ra edición:

(C) Universidad Politécnica Salesiana Av. Turuhuayco 3-69 y Calle Vieja

Cuenca-Ecuador

Casilla: 2074

P.B.X. (+593 7) 2050000

Fax: (+593 7) 4088958

e-mail: rpublicas@ups.edu.ec www.ups.edu.ec

\section{CARRERA DE COMUNICACIÓN}

Diagramación: Editorial Universitaria Abya-Yala

Quito-Ecuador

ISBN UPS:

978-9978-10-448-4

Impresión: $\quad$ Editorial Universitaria Abya-Yala

Quito-Ecuador

Tiraje:

300 ejemplares

Impreso en Quito-Ecuador, septiembre 2020

Publicación arbitrada de la Universidad Politécnica Salesiana 
INTRODUCCIÓN

Cuenca y las redes sociales ........................................ 7

Ángel Torres-Toukoumidis, Andrea De Santis

CApítulo I

El antes y después de las redes sociales en Cuenca ......

Adriel Shicay-Quezada, Camila Villacís-Mendoza

\section{Capítulo II}

Dicotomía rural-urbana sobre el uso

de las redes sociales en Cuenca-Ecuador.....

Verónica Sigcha-Pacheco, Diego Vintimilla-León,

Jonnathan Morocho-García

\section{Capítulo III}

Lo rural y urbano: influencia

de las redes sociales.................................................... 73

Jasson Marca-Quituizaca, Alex Mejía-Loza,

Christian Picón-Cedillo

\section{Capítulo IV}

Redes sociales en jóvenes

y adultos mayores cuencanos 


\section{Capítulo V}

Lenguaje cuencano en las redes sociales...................... 109 Evan Arias-Sánchez

\section{Capítulo VI}

Influencers en la ciudad de Cuenca

Viviana Calle-Salinas, Ximena Méndez-Calle

\section{Capítulo VII}

Cultura cuencana y redes sociales

Freddy Parra-Sigüencia, Johny Cabrera-Ruiz,

Paolo Romero-Arévalo

Capítulo VIII

El comercio cuencano y las redes sociales

Jhonathan Cuesta-Cuesta, Esteban Calderón-Méndez

Capítulo IX

Los cuencanos en el exterior

y las redes sociales

Wendy Pugo-Arévalo, Melissa Mora-Gordillo

Capítulo X

Los emigrantes en Cuenca

y las redes sociales. 185

Mishell Jiménez-Pineda, Cristopher Pesantez-Maxi

Capítulo XI

El futuro de las redes sociales en Cuenca 201 Fabrizzio Sánchez-García, Nicolás Moscoso-Loaiza 


\title{
INTRODUCCIÓN Cuenca y las redes sociales
}

\author{
Ángel Torres-Toukoumidis \\ Universidad Politécnica Salesiana, Ecuador \\ https://orcid.org/0000-0002-7727-3985 \\ Andrea De Santis \\ Universidad Politécnica Salesiana, Ecuador \\ https://orcid.org/0000-0002-7441-3794
}

En tiempos de pandemia, las redes sociales se han posicionado como las principales plataformas de entretenimiento, acrecentando de igual modo su uso en otros propósitos como es el caso del educativo (Torres-Toukoumidis \& De Santis, 2020a). En tanto, reconociendo la importancia de estos espacios de interacción, los estudiantes de Comunicación, en la asignatura Investigación de la Comunicación impartida en segundo ciclo por la Universidad Politécnica Salesiana ha compendiado un análisis sobre el uso de las redes sociales en diferentes contextos, generando una visión holística sobre su implicación en la ciudad de Cuenca.

Si bien la Universidad Politécnica Salesiana tiene sedes en Quito, Guayaquil y Cuenca, el estudio se concentró 
en Cuenca por tres razones, la primera claramente porque la asignatura era impartida en dicha sede, la segunda, porque las limitaciones de desplazamiento generadas por la Covid-19 dificultaban la accesibilidad directa a la información de las otras dos sedes y en tercera instancia, la Alcaldía de Cuenca, a través de Camila Corral, Coordinadora del Proyecto Editorial y de Fomento a la Lectura de la Dirección Municipal de Cultura, Recreación y Conocimiento apoyó el accionar y desarrollo de esta iniciativa.

La obra combina diferentes enfoques cualitativos y cuantitativos permitiendo así abordar con múltiples diseños y herramientas metodológicas destacando ciberetnografías, investigación-acción, estudios descriptivos y narrativos que utilizaron entrevistas en profundidad, documentación, encuestas entre otras herramientas de recopilación de datos. Específicamente, el libro se organiza en 11 capítulos estructurados de la siguiente manera:

El primer capítulo, "El antes y después de las redes sociales en Cuenca" realizado por Adriel Shicay-Quezada y Camila Villacís-Mendoza, aplican un diseño narrativo para determinar la incidencia secuencial de Facebook en la comunicación interpersonal, demostrando la aceptación de los cuencanos hacia esta plataforma como herramienta de uso diario, debido a sus facilidades comunicativas, su simplicidad de manejo y su versatilidad superando con creces a los canales tradicionales de comunicación.

Verónica Sigcha-Pacheco, Diego E. Vintimilla-León y Jonnathan Morocho-García elaboraron el capítulo de- 
nominado "Dicotomía rural-urbana sobre el uso de las redes sociales en Cuenca-Ecuador", en el que adaptaron un estudio cuantitativo descriptivo correlacional sobre las redes sociales en la dicotomía rural-urbana asentando que WhatsApp se utiliza más que Facebook.

En complemento, el tercer capítulo, "Lo rural y urbano: influencia de las redes sociales" realizado por Jasson Marca-Quituizaca, Alex Mejía-Loza y Christian Picón- Cedillo profundizan en este contexto desde el punto de vista más general, argumentando el despunte de TikTok en el contexto urbano.

Seguidamente, Amanda Guzmán-Heras y Tábata Figueroa-Sacoto publican "Redes sociales en jóvenes y adultos mayores cuencanos" en el que llevaron a cabo 50 entrevistas en profundidad haciendo eco la desigualdad evidenciada por la comparativa entre las personas mayores y jóvenes cuencanos en cuanto al conocimiento y uso de las redes sociales.

El próximo capítulo, "Lenguaje cuencano en las redes sociales" elaborado por Evan Gabriel Arias-Sánchez, se enfoca en el empleo de coloquialismos y spanglish por usuarios en cuentas de Facebook propiamente cuencanas, demostrando que pese a la masiva migración digital potencial aculturación, el lenguaje aun no se encuentra amenazado por cambios drásticos producidos por el influjo de las nuevas generaciones.

En el sexto capítulo, Viviana Calle-Salinas y Ximena Méndez-Calle han redactado "Influencers en la ciudad 
10

de Cuenca”, en el cual han analizado perfiles mediáticos observando las estrategias de comunicación en Instagram demostrando su importancia para las marcas en el entorno publicitario.

Continuando con los capítulos, se encuentra "Cultura cuencana y redes sociales" en el que Freddy Parra-Sigüencia, Johny Cabrera-Ruiz y Paolo Romero-Arévalo demuestran el uso de las redes sociales para enaltecer la difusión de la cultura de Cuenca mediante la incursión de herramientas audiovisuales.

En el octavo capítulo, Jhonathan Cuesta-Cuesta y Esteban Calderón-Méndez se dedicaron a entretejer la situación del comercio cuencano y las redes sociales, exhibiendo la relevancia del comercio electrónico generada por las fans page de Facebook, en el que se denota una flexibilización de los procesos de compraventa y aumento de la promoción de su oferta de productos y servicios.

Wendy Pugo-Arévalo y su compañera, Melissa Mora-Gordillo ordenan de manera coherente un análisis exploratorio sobre la práctica comunicativa de los cuencanos en el exterior, recalcando el uso de las redes sociales para satisfacer la necesidad de interacción y contacto virtual con sus familiares, además de escuchar noticias sobre su ciudad de nacimiento.

En su contraparte, la otra cara de la moneda fue otorgada por Mishell Jiménez- Pineda y Cristopher Pesantez-Maxi, quienes se orientaron a conocer la posición de los extranjeros en Cuenca respecto a las redes sociales, evi- 
denciando patrones similares al capítulo anterior, donde la mayoría se conecta para ver noticias, trabajar y contactar a sus conocidos y parientes.

Para culminar, un capítulo simbólico es "El futuro de las redes sociales en Cuenca" realizado por Fabrizzio Andree Sánchez-García y Nicolás Moscoso-Loaiza, quienes consultaron a 15 expertos de las carreras de Comunicación e Informática manifestando en general, la prospectiva de optimización de las redes sociales actuales, el cual será aprovechado por la publicidad para maximizar el desarrollo económico de la ciudad.

Estos 11 capítulos buscan complementar una colección que inició al principio del 2020 con el libro titulado: "Cuando los instagrammers son los adultos" (Torres-Toukoumidis \& De Santis, 2020b) en el que participaron estudiantes de carrera de Comunicación en la asignatura "Investigación de la Comunicación" de la Universidad Politécnica Salesiana, sede Cuenca.

Admitimos que lo vivido en el ciclo anterior con esa obra ha sido sumamente fructífera para los estudiantes, de allí que esta vez, se extrapole el proceso hacia otra investigación manteniendo los mismos propósitos: proveer una experiencia simulada del modus vivendi académico y adentrarse en la aprehensión de conocimientos relacionados con la investigación, conociendo así las formas de sistematizar la realidad y generar resultados a partir de los mismos. En definitiva, en nombre de todo el equipo, esta obra es un regalo que le hacemos a Cuenca y a todos sus ciudadanos por la conmemoración de su Bicentenario de Independencia. 
Ángel Torres-Toukoumidis, Andrea De Santis-Piras (Coordinadores)

12

\section{Bibliografía}

Torres-Toukoumidis, A., \& De Santis, A. (2020a). YouTube y la comunicación del siglo XXI. Ciespal.

(2020b). Cuando los instagrammers son los adultos. Abya-Yala. 


\title{
CAPítulo I El antes y después de las redes sociales en Cuenca
}

\author{
Adriel Shicay-Quezada \\ Universidad Politécnica Salesiana, Ecuador \\ https//orcid.org/0000-0001-9218-3200 \\ Camila Villacís-Mendoza \\ Universidad Politécnica Salesiana, Ecuador \\ https://orcid.org/0000-0002-1364-8290
}

\section{Resumen}

El impacto comunicacional que ha generado las redes sociales en la vida de las personas es una verdad indiscutible de nuestros días; su uso progresivo a la par de los avances tecnológicos y de comunicaciones, las ha convertido en una herramienta clave para los procesos comunicativos y sociales. Pero, ¿cómo ha sido esta transición a la comunicación virtual de la sociedad cuencana en los últimos años? El objetivo de este estudio es analizar las formas de comunicación interpersonal mediante la red social Fa- 
cebook y observar los efectos que ha tenido en las relaciones sociales en Cuenca en comparación con los antiguos medios de comunicación tradicionales. Las preguntas de esta investigación se respondieron a través de entrevistas a profundidad a 30 residentes de Cuenca, Ecuador mediante plataformas en línea. Las respuestas obtenidas demuestran la cantidad de usuarios activos de esta red social que se encuentran satisfechos con sus facilidades, su aprovechamiento para el acceso y difusión de la información tanto para promocionar y publicitar sus negocios, como para informarse sobre noticias de actualidad. Se comprendió también la aceptación que tiene la plataforma dentro de la sociedad considerando la opinión de la muestra en lo referente a si la integración de redes sociales ha mejorado o empeorado las relaciones sociales en la población de Cuenca. Estos resultados indicaron el cambio comunicacional que ha tenido el paso de redes sociales en la ciudad y las diferencias más destacables entre el antes y después de su inmersión en la vida cotidiana.

Palabras clave: Cuenca, Facebook, red social, comunicacional, relaciones sociales, usuarios, cuencanos, comunicación interpersonal.

\section{Abstract}

The communicational impact that social networks have generated in people's lives is an indisputable truth of our times; their progressive use, along with technological and communication advances, has made them a key tool for communicative and social processes. But, how has 
this transition to the virtual communication in the society of Cuenca occurred in the last years? The purpose of this study is to analyze the forms of interpersonal communication through the social network Facebook and to observe the effects it has had on social interactions in Cuenca in comparison with the former traditional methods of communication. The questions in this investigation were responded to through in-depth interviews with 30 residents of Cuenca, Ecuador using online platforms. The answers obtained show the number of active users of this social network who are satisfied with its facilities, its use for access and spreading of information in order to promote and advertise their businesses, and to stay informed about current news. The answers collected contributed to a better understanding of the acceptance of the platform within society, considering the opinion of the sample as to whether the integration of social networks has improved or worsened social relations in the population of Cuenca. These results indicated the communicational change that the passing of social networks in the city has had and the most remarkable differences between before and after its immersion in daily life.

Keywords: Cuenca, Facebook, social network, communication, social relations, users, interpersonal communication.

El impacto de las redes sociales y su inmersión en nuestra vida cotidiana es, sin duda, una realidad innegable a nivel global en nuestros días. El nacimiento del internet se sitúa en la década de 1960, en el contexto contemporáneo de la Guerra Fría, como una herramienta militar de los 
Estados Unidos; pero no fue hasta 20 años después cuando revolucionó al mundo con su libre comercialización. Sin embargo, la llegada de la "red" a Cuenca, Ecuador se hizo esperar hasta mediados de los años 90 y se popularizó a inicios del nuevo milenio.

La historia de cómo la web y las redes sociales se insertaron en el marco cultural de nuestra sociedad es una amplia fuente de análisis; no obstante, el objetivo de esta investigación no se basa únicamente en una narrativa lineal de la evolución de las redes sociales en la Ciudad de los Cuatro Ríos, sino más bien en contrastar su impacto y la influencia que ha tenido en los ámbitos de la comunicación personal y social, antes y después de su incorporación en realidad colectiva cuencana.

Cuenca es la tercera ciudad más grande en población ecuatoriana, con un total de 505585 habitantes según expone el Instituto Nacional de Estadística y Censos (INEC, 2020). A través de una indagación realizada en 2015 y publicada por el Diario El Comercio, se demostró que: "A escala nacional, un 41,4\% de las personas encuestadas tienen una cuenta en una red social. Entre las opciones presentadas por el INEC están Facebook, Twitter, YouTube, WhatsApp, Skype y otras redes" (Sandoval, 2015).

En la era de la digitalización, existen tres principales factores que moldean las relaciones de adaptación entre las redes sociales y los actores de la sociedad: componer, compartir y difundir (García-Galera \& Valdivia, 2014). 


\section{7}

Este primer componente permite a los usuarios ser partícipes activos de la interacción y publicación de contenido dentro de la red; las posibilidades y la facilidad de producir sobrepasan las limitaciones de generaciones pasadas; haciendo sencillo para el internauta convertirse en "prosumidor", concepto desarrollado por el profesor de literatura Marshall Herbert McLuhan en 1972.

El prosumo tiene su esencia en la unión de dos conceptos: productor y consumidor. Al principio no se refería al campo tecnológico sino al campo económico ya que señalaba al prosumidor a aquella persona que elaboraba sus propios productos y los consumía, con la ausencia de intermediarios. (McLuhan \& Nevitt en Arribas-Urrutia et al., 2019, p. 52)

El concepto de compartir información se basa en la asequibilidad de las redes sociales "al alcance de todos". Cualquier individuo es capaz de generar y compartir contenido a través de sus redes sociales, fin fundamental de esta acción: "Crear sin compartir no tiene sentido" (García-Galera \& Valdivia, 2014). Es gracias a la sencillez de este proceso, como surge el término "periodismo móvil" que consiste en la utilización de un dispositivo portátil para redactar o filmar sucesos y luego compartirlos en redes sociales, hecho que en el contexto social cuencano se ha visto presente varias veces en sucesos político-sociales, donde debido al quebrantamiento de la confianza del pueblo con la prensa nacional, este personaje, el ciberperiodista, adquirió veracidad. "El periodismo no muere, muta" dijo la autora Carmela Ríos en 2012 en la entrega del Premio Ortega y Gasset. 
En referencia al factor de difusión, las redes sociales permiten llegar a un público más amplio sin límites de tiempo y espacio, son útiles para crear relaciones interpersonales entre interesados sobre un tema en común; debido a esto, en el marketing, cumplen un rol fundamental para la divulgación publicitaria.

La relación entre la sociedad y las redes sociales, no es estática, se encuentra en constante evolución, razón por la cual las empresas de nuestro medio se han visto en la necesidad de adaptarse para satisfacer el nuevo estilo de los demandantes, en particular los emergentes microemprendimientos han visto en esta disponibilidad de fácil difusión una oportunidad para hacer conocer sus productos y servicios, logrando llegar a un mayor público en menor tiempo y así acelerando su crecimiento. Por tanto, es posible afirmar que las redes sociales y las aplicaciones móviles han consolidado una relación bilateral más cercana entre productor y consumidor mediante la retroalimentación o feedback (Aucay \& Herrera, 2017).

\section{Metodología}

Objetivo general: Analizar las relaciones de comunicación interpersonal antes y después de la incorporación de las redes sociales, en Cuenca, Ecuador.

Objetivos específicos: Observar las formas de interacción interpersonal en redes sociales, específicamente en la plataforma Facebook; Comparar las relaciones de comunicación interpersonal antes y después las redes so- 
ciales como parte de la cotidianeidad de la sociedad cuencana, tomando como referencia la plataforma Facebook; Contrastar el cambio comunicacional en las relaciones interpersonales, influenciadas por redes sociales, tomando como referencia las plataformas Facebook en Cuenca, con relación a los medios tradicionales de comunicación.

\section{Enfoque}

Esta investigación tiene un enfoque cualitativo al estudiar las características del paso de las redes sociales en la sociedad cuencana. Cuenta con un análisis deductivo partiendo de las generalidades de las redes sociales a nivel histórico hacia la particularidad de los efectos de las mismas en las relaciones interpersonales en Cuenca.

\section{Diseño}

Este proyecto está basado en un diseño narrativo al exponer nociones generales sobre las redes sociales y el impacto de las mismas, a través de conceptos previos presentados por autores nacionales e internacionales; con la finalidad de contrastar las características de la comunicación interpersonal, relatando el antes y después de la introducción de las redes sociales en la comunidad cuencana, mediante documentación y entrevistas en profundidad.

\section{Herramientas de recopilación de datos}

Las herramientas a utilizar en el desarrollo de este estudio son entrevistas a profundidad de opinión, expre- 


\section{0}

sión de sentimientos y especialmente de antecedentes, pues buscamos contrastar y observar los cambios que han provocado las redes sociales en las relaciones interpersonales en los ciudadanos cuencanos. El formato de las preguntas será: general para crear un ambiente de confianza con el entrevistado, de ejemplificación, estructurales y de contraste. La segunda técnica de recolección de datos se cimenta en documentos, materiales y registros al revisar artículos e investigaciones previas sobre el tema a trabajar.

\section{Criterios de análisis}

\section{Viabilidad de medios comunicativos:}

- Canales para la comunicación: Forma en que los individuos efectúan distintos procesos comunicativos, indispensablemente de la intención del mensaje, a través de un canal. Los canales pueden ser abstractos o concretos, es decir, digitales (televisión, teléfono, radio, portales de medios electrónicos, etc.) o físicos (Periódicos, diarios, cartas, etc.)

- Medios de comunicación tradicionales: Televisión, radio, prensa escrita, llamadas telefónicas convencionales, Mensajes de texto, correo electrónico, entre otros.)

Inversión y distribución de tiempo: Desde las expresiones de la muestra seleccionada se realiza un cuestionamiento al tiempo desde que pasaron a formar parte de la digitalidad, la cantidad de tiempo que estos invierten para 


\section{1}

el uso de las redes sociales, específicamente Facebook, y la forma en cómo se organizan con el resto de actividades sistemáticas de su cotidianidad para crear un espacio dedicado al uso y consumo de la virtualidad, que ofrecen este tipo de redes sociales.

Percepción del aprovechamiento comunicacional: Juicios de valor emitidos en referencia a la factibilidad del uso de redes sociales como herramienta de procesos comunicativos, así como también las sensaciones o sentimientos, denotados en las versiones de los entrevistados en cuanto al aprovechamiento funcional de la red social.

\section{Resultados}

A continuación, presentamos nuestros resultados como parte esencial de nuestro capítulo, mediante la interpretación de las opiniones vertidas por los entrevistados, que corresponden a la muestra; apoyados en gráficos estadísticos que están relacionados a los criterios de análisis planteados en nuestra metodología. Es importante mencionar que en algunos casos hemos redactado textualmente opiniones cortas, emitidas por los entrevistados, como datos extras que caben ser destacados en nuestra investigación.

\section{Viabilidad de medios comunicativos}

Los entrevistados declararon que, las llamadas mediante un teléfono convencional o celular eran las más utilizadas al momento de comunicarse con los demás (38\%), 


\section{2}

seguido por los mensajes de texto pagados (29\%), luego estaban otras redes sociales como MySpace, Hi5, Windows Live Messenger, entre otros (19\%). Mientras que, de manera personal a través de la oralidad, las personas también se comunicaban, pero de una forma menos frecuente (10\%), y finalmente, los correos electrónicos, que, a pesar de ser una vía de comunicación virtual, eran los menos usados (4\%).

\section{Figura 1}

Cambio generado por Facebook al momento de comunicarse con el círculo social

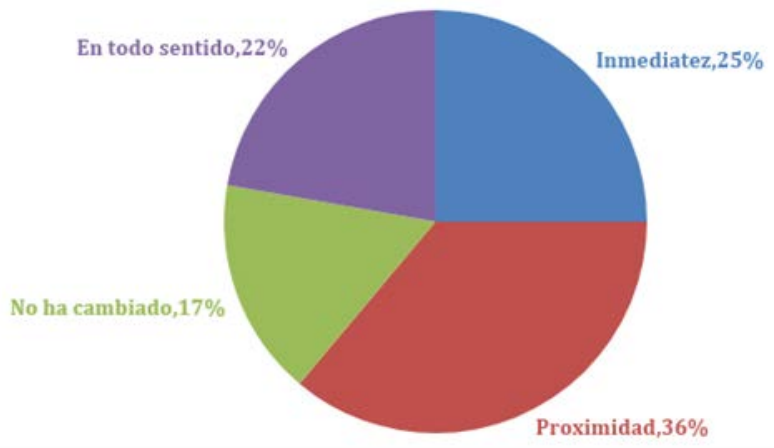

Fuente: Elaboración propia.

La proximidad ha sido la característica más nombrada al momento de evidenciar el cambio comunicacional por el uso de Facebook (36\%), seguido por la inmediatez $(25 \%)$ que no difiere mucho en cuanto a las personas que piensan que, simplemente ha cambiado en todo sentido (22\%); para finalmente referir una cantidad considerable, y no menos importante, de quienes piensan que no ha cambiado su manera de comunicarse (17\%). 


\section{3}

Ha facilitado la comunicación sin barreras físicas, nos ha permitido estar al tanto de nuestro entorno incluso de manera informativa, pero también ha perjudicado las relaciones interpersonales con el entorno, además ha dado paso al cyberbullying y la exposición de información personal (Anónimo).

\section{Figura 2}

Medios de información que, según los entrevistados, han sido desplazados por la aparición de Facebook

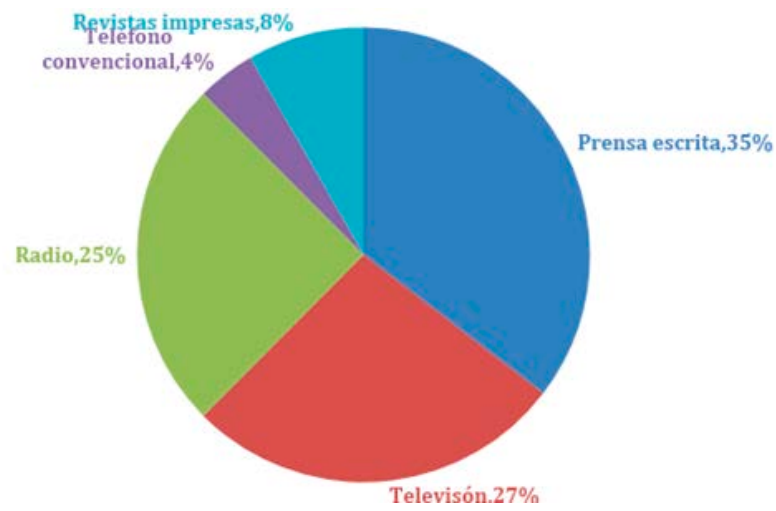

Fuente: Elaboración propia.

Si hay algo en que gran parte de los entrevistados están de acuerdo es que, varios medios de comunicación/ información han sido desplazados por Facebook por sus distintas características. Así es el caso de la prensa escrita (diarios y periódicos), que se posiciona como el medio que primero ha sido desplazado por esta red social al momento de informar (36\%), seguido por la televisión que a pesar de tener una eficaz manera de transmitir mensajes a 


\section{4}

través de material audiovisual, lo posicionan como el segundo medio desplazado (27\%), luego está la radio, que siendo un medio tradicional, aún se mantiene en pie por el consumo de grupos sociales específicos (25\%), ocupan el cuarto lugar de desplazamiento las revistas impresas, los entrevistados consideraron que no es una buena manera de comunicar un mensaje; sin embargo, no formó parte ni siquiera de los tres primeros medios desplazados por Facebook $(8 \%)$ y por último está el teléfono convencional, medio que aún se usa para una comunicación no constante (4\%). Adicional a esto, las personas que cumplieron con la entrevista expresan que, los medios convencionales no desaparecerán fácilmente, como es el caso de la radio, que, por su facilidad de sintonización en distintos lugares, ha permanecido en actividad y con una acogida considerable.

\section{Inversión y distribución de tiempo}

La mayoría de los entrevistados indicaron que se unieron como usuarios de Facebook con una cuenta activa, desde hace seis a diez años (55\%), seguido por otra representativa cantidad que lo hicieron en un intervalo de once a quince años (41\%), y finalmente una cantidad pequeña que refiere hace uno a cinco años (4\%).

Es decir que, Facebook mantiene actividad desde que llegó al Ecuador hace quince años, pero hace diez años es donde registra mayor acogida por parte de usuarios cuencanos. 


\section{5}

\section{Figura 3}

Tiempo desde que la persona se unió a Facebook y lo usa de manera activa

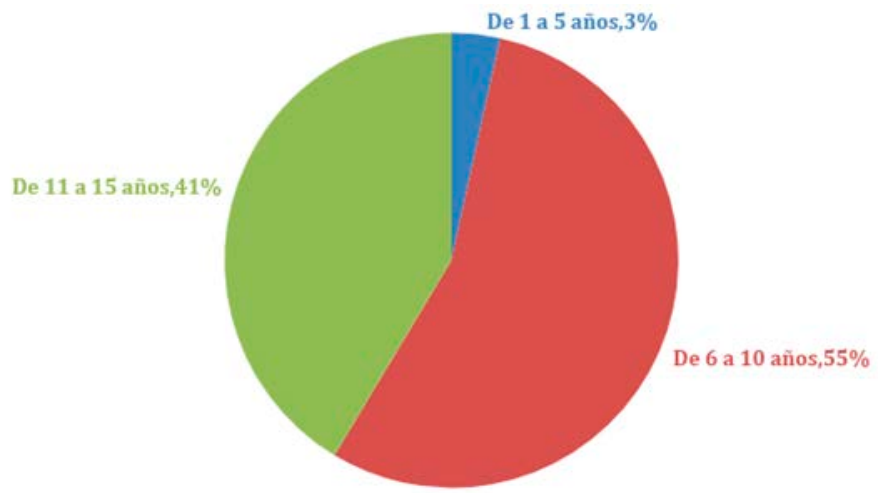

Fuente: Elaboración propia.

Figura 4

Número de horas invertidas en el uso

de la red social Facebook

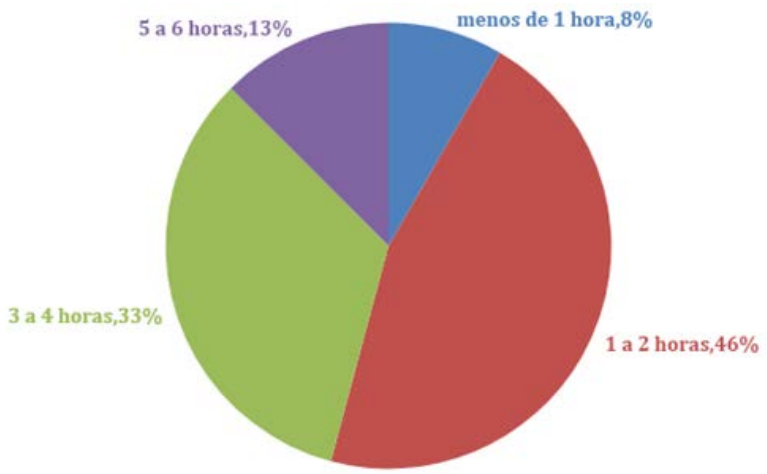

Fuente: Elaboración propia. 


\section{6}

Gran parte de los usuarios de Facebook en Cuenca dijeron que ocupan alrededor de una a dos horas en el uso de esta red social (46\%), seguido por otros que gastan de tres a cuatro horas al navegar en esta plataforma web (33\%), luego en tercer lugar, están los usuarios que ocupan alrededor de cinco a seis horas (13\%); y finalmente están quienes se toman menos de una hora para revisarlo $(8 \%)$.

Algunos individuos que se ubican en aquel grupo que consumen Facebook durante una a dos horas, expresaron que lo hacen durante la noche, dato que nos pareció importante destacar.

\section{Figura 5}

Manera en que Facebook ha vulnerado la distribución del tiempo destinado a la realización de actividades diarias

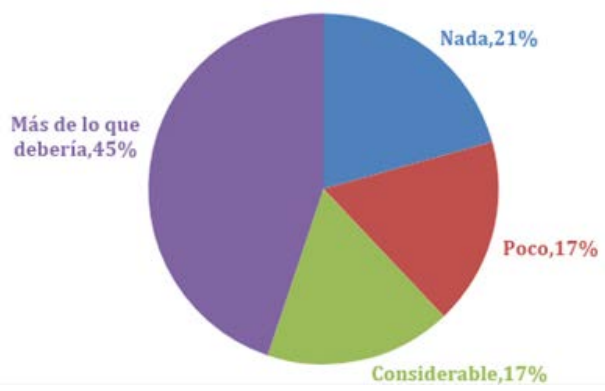

Fuente: Elaboración propia.

En el análisis de este criterio hemos encontrado que la mayoría de la gente (45\%) piensa que ha cambiado mucho la manera de distribuir su tiempo, al otorgar más 
tiempo de lo debido, seguido de quienes piensan que no ha cambiado para nada al usarlo (21\%), y finalmente están quienes dijeron que, es poco y considerable, la manera en que ha cambiado la manera en que distribuían su tiempo por usar Facebook (17\%).

\section{Percepción del aprovechamiento comunicacional}

\section{Figura 6}

La facilidad que Facebook ha proporcionado a la muestra entrevistada, misma que antes no poseían sino hasta su uso

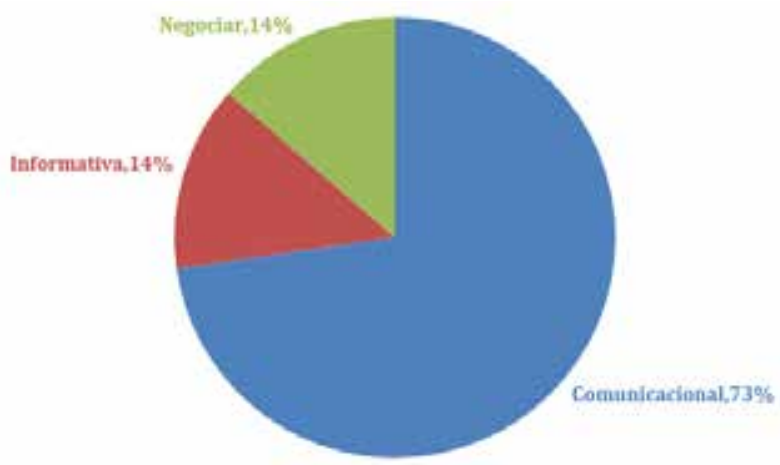

Fuente: Elaboración propia.

La mayoría de las personas entrevistadas supieron indicar que Facebook mayormente brinda una facilidad comunicacional al momento de estar en contacto y pendientes de lo que sucede en las vidas de sus conocidos (73\%), seguida por la facilidad de hacer negocios a través de pequeños y grandes emprendimientos difundidos por 
medio de esta red social (14\%); luego que la facilidad informativa no se queda atrás y se la efectúa por parte de un cierto público considerable (13\%).

Respecto a la obtención de información de actualidad a través de Facebook, a comparación de los medios tradicionales (radio, televisión y prensa escrita), varias personas dicen sentirse satisfechos, ya sea por su poca disponibilidad de tiempo para informarse y poder hacerlo mientras se comunican con terceros, así también por tener mayor dinamismo en contenido multimedia.

\section{Figura 7}

Expresiones del efecto que tiene Facebook en las relaciones de comunicación interpersonal en Cuenca

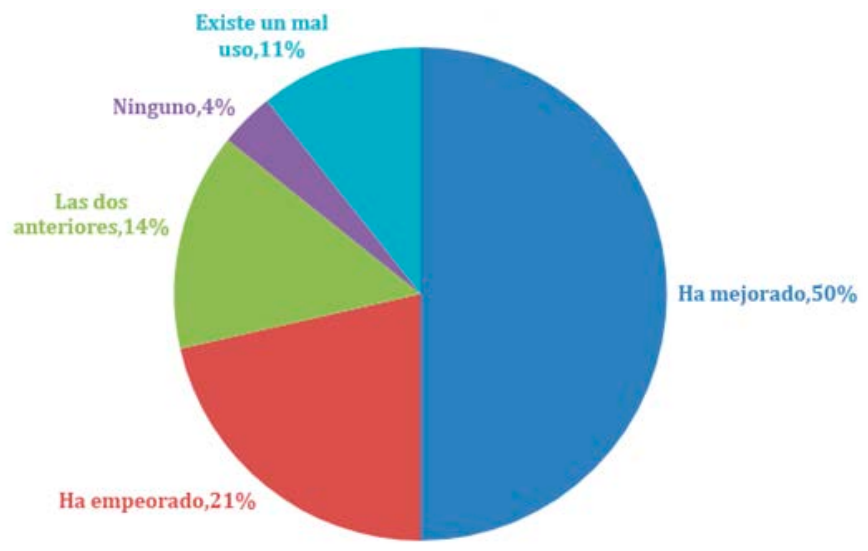

Fuente: Elaboración propia.

Por otra parte, pocas personas están conscientes y sienten preocupación al saber que existe la posibilidad de 
encontrarse con información falsa o distorsionada, que únicamente genera confusión y desinformación.

Finalmente, una parte minúscula de la muestra expresó que no le causa ninguna emoción, ya que no se informan a través de Facebook.

La mitad de nuestros entrevistados han sabido reconocer que Facebook ha mejorado el nivel de comunicación interpersonal existente en Cuenca (50\%), mientras que una quinta parte ha dicho lo contrario (21\%), seguido de otra cantidad pequeña la cual expresó que tiene aspectos positivos y negativos (14\%), mientras que una décima parte señala un aspecto importante como lo es el mal uso que se le da a esta red social (11\%); y finalmente una minúscula cantidad de personas que piensa que no ha tenido ningún efecto (4\%).

Una de las expresiones que vale exponerla es la siguiente: "Si bien es cierto, las redes sociales acercaron a los que están lejos, pero es cierto que también han alejado a los que están cerca, porque existe una preferencia hacia la tecnología antes que a lo tradicional".

\section{Conclusiones}

La comunicación es un proceso que se encuentra en constante evolución, se adapta a los avances tecnológicos, a los cambios sociales y variaciones culturales. Tras un profundo análisis de los estudios presentados, y en base a los objetivos propuestos, se logró comprender las formas en que las redes sociales, tomando como referencia Facebook, 
han moldeado las relaciones interpersonales en Cuenca en los últimos años.

Mediante las entrevistas en profundidad se observó la aceptación de la generalidad de la población hacia la plataforma como herramienta de uso diario, debido a sus facilidades comunicativas, su simplicidad de manejo y su versatilidad hacia diversas actividades de interés de los entrevistados, como: el acceso a noticias, información, publicidad, actualidad de sus contactos y del mundo. Sin embargo, es conveniente mencionar que un considerable porcentaje de la muestra encontró que la red social "ha empeorado las relaciones interpersonales" en la ciudad de estudio, además que reconocieron el mal uso de esta plataforma y la existencia de falsa información dentro de la misma.

El estudio previamente presentado permitió observar, analizar y comparar las relaciones de comunicación interpersonal antes y después la inmersión de las redes sociales como parte de la cotidianeidad de la sociedad cuencana.

Gran parte de las preguntas de la entrevista fueron de opinión, por lo tanto, inferimos también en que las respuestas de la presente investigación proporcionan resultados regidos a la subjetividad y percepción personal de cada uno de los entrevistados. Para mayor contraste de datos, es recomendable para futuros investigadores considerar una mayor cantidad de personas dentro de la muestra a analizar. Esta indagación se realizó en el periodo mayo-julio, 2020; en contemporaneidad con la pandemia Covid-19 y las medidas de distanciamiento social implementadas por 
el gobierno ecuatoriano, razón por la cual se alcanzó una menor cercanía de diálogo con la muestra entrevistada.

\section{Bibliografía}

Arribas-Urrutia, A., Islas-Carmona, O., \& Cortés, F.G. (2019). From prosumers to observers: an emergent trend on the Internet and among Young Ecuadorians. Results from the World Internet Project study, Ecuador. Revista Latina de Comunicación Social, (74), 969-996. http:// dx.doi.org/10.4185/RLCS-2019-1367

Aucay-Piedra, E., \& Herrera-Torres, P. (2017). Nivel de uso de las redes sociales en el proceso de comunicación en las MIPES de Cuenca. Retos. Revista de Ciencias de la Administración y Economía, 7(14), 81-98. http://dx.doi. org/10.17163/ret.n14.2017.04

García- Galera, \& Valdivia, A. (2014). Prosumidores mediáticos: Cultura participativa de las audiencias y responsabilidad de los medios. Comunicar: Revista científica de Comunicación y Educación, (43), 10-13. https://bit. ly/3hbMoy 2

INEC (2020). Instituto Nacional de Estadística y Censos. https:// bit.ly/3hlrH2M

Sandoval, C. (15 de abril de 2015). El Comercio. https://bit. ly/2YkNHUa

\section{Anexos}

Cuestionario para la aplicación de las entrevistas:

1. ¿Hace cuánto tiempo se unió a la red social Facebook?

2. ¿Cómo se comunicaba con su círculo social antes del uso de Facebook? 
3. ¿Cómo considera usted que Facebook ha cambiado la manera de comunicarse con su círculo social?

4. ¿Cuál cree que es la facilidad que le ha proporcionado Facebook, misma que no poseía antes del uso de esta red social?

5. ¿Cuánto tiempo invierte diariamente en Facebook? (subir contenido, compartir, comunicarse con sus contactos)

6. ¿De qué manera piensa usted que Facebook ha cambiado la distribución del tiempo que invierte en diferentes actividades de su día a día?

7. ¿Cómo se siente usted cuando obtiene información de actualidad a través de Facebook a comparación de los medios tradicionales (radio, tv, prensa escrita)?

8. ¿Qué medios de información considera usted que han sido desplazados por Facebook?

9. Desde su punto de vista ¿Las redes sociales, específicamente Facebook, han mejorado o empeorado las relaciones de comunicación interpersonal en Cuenca? 


\title{
CAPÍtulo II Dicotomía rural-urbana sobre el uso de las redes sociales en Cuenca-Ecuador
}

\author{
Verónica Sigcha-Pacheco \\ Universidad Politécnica Salesiana, Ecuador \\ https://orcid.org/0000-0002-8404-2579 \\ Diego Vintimilla-León \\ Universidad Politécnica Salesiana, Ecuador \\ https://orcid.org/0000-0002-8127426X \\ Jonnathan Morocho-García \\ Universidad Politécnica Salesiana, Ecuador \\ https://orcid.org/0000-0002-2424-5809
}

\section{Resumen}

La dicotomía rural-urbana sobre uso de las redes sociales en Cuenca, se prescribe como una temática actual y la influencia que tiene la zona geográfica en el uso de las redes sociales. Para ello, se aplicó un estudio cuantitativo, de enfoque 
deductivo, utilizando el alcance correlacional y descriptivo-interpretativo, a través de encuestas, aplicadas a la población urbana y rural del cantón Cuenca. Los resultados demuestran que la red social más utilizada es WhatsApp, mientras que la red social menos utilizada es Twitter. El sector urbano-rural, utiliza redes sociales diariamente entre 2-4 horas, accediendo en su mayoría a través de dispositivos móviles inteligentes en un $98 \%$, cabe recalcar que la principal actividad en redes sociales en el sector urbano es la búsqueda de entretenimiento y mantener contacto con familiares y amigos. Por otro lado, en el sector rural, las principales actividades se basan en la búsqueda de entretenimiento, mantener contacto con familiares, amigos y por temas relacionados con el trabajo. Se pudo concluir que la zona geográfica, influye en uso de las redes sociales, en el cual se evidencia que la dicotomía de las manifiestas zonas, influyen en el uso, propósito, tiempo y frecuencia con la que se utilizan las redes sociales, con el fin de demostrar las diferencias y similitudes en el uso de las redes sociales.

Palabras clave: Urbano, rural, medios sociales, Cuenca, Ecuador.

\section{Abstract}

The rural-urban dichotomy on the use of social networks in Cuenca is prescribed as a current issue and the influence that the geographical area has on the use of social networks. For this purpose, a quantitative study was applied, with a deductive approach, using the correlational and descriptive-interpretative scope, through surveys, applied to the urban and rural population of the canton 
of Cuenca. The results show that the most used social network is WhatsApp, while the least used social network is Twitter. The urban-rural sector, uses social networks daily between 2-4 hours, accessing mostly through intelligent mobile devices in $98 \%$, it should be emphasized that the main activity in social networks in the urban sector is the search for entertainment and maintaining contact with family and friends, on the other hand, in the rural sector, the main activities are based on the search for entertainment, maintaining contact with family, friends and for work-related issues. It could be concluded that the geographical area, influences the use of social networks, in which it is evident that the dichotomy of the manifest areas, influence the use, purpose, time and frequency with which social networks are used, in order to demonstrate the differences and similarities in the use of social networks.

Keywords: Urban, rural, social networks, Cuenca, Ecuador.

Durante siglos, estudios urbanísticos y rurales han buscado dar respuestas a diferentes interpelaciones. La delimitación de estas áreas ha permitido organizar distintas zonas otorgando funciones específicas (Cimadevilla, 1997). Si bien, al pensar en lo rural, se imagina grandes territorios dedicados a la agricultura, conocimiento empírico, educación elemental o básica, el verdadero rol tras el asentamiento de políticas neoliberales y económicas, fue la multifuncionalidad de las áreas rurales con una visión no agraria, estructuras organizacionales más complejas, estrechando la brecha existente con su contraparte urbana. Por otra parte, lo urbanístico con connotaciones de paradig- 
mas dominantes, industrialización, amplio comercio, educación avanzada, conocimiento académico y científico que se desarrolla de manera acelerada y constante, generando la expansión paulatina de las áreas urbanas; cabe subrayar que, debido a dicha ampliación, la urbanidad ha absorbido varios sectores antes considerados rurales, llevando consigo los beneficios de la urbanidad (Burgos \& Bocco, 2020).

Desde su categorización, las diferencias entre las áreas urbanas y rurales han permitido desarrollar un sinfín de recursos, tanto naturales como industriales y económicos. Sin embargo, la peor parte siempre ha recaído en el área rural; según el censo poblacional y de vivienda, Ecuador 2010, el índice de pobreza del país es del 60.1\% del cual, el 93.4\%, se ubica en zonas no delimitadas, este indicador se calculó mediante la metodología de Necesidades Básicas Insatisfechas (NBI). De acuerdo con estos datos, las zonas rurales y no delimitadas mantienen una gran desigualdad de cara a las zonas urbanas.

Por otra parte, en el ámbito fáctico y social sobre las redes sociales y la función que esta tiene en las áreas urbano-rurales, se determinó mediante estudios latinoamericanos que cada día se suman nuevos usuarios a las diferentes redes sociales, progresivamente, estas plataformas aumentaron no solo la cantidad de usuarios, sino también se registró un aumento etario, dejando de ser una plataforma monopolizada por adultos jóvenes, para ser utilizadas por personas con edades entre los 10 y 70 años. 
Tomando en cuenta los precedentes en la dicotomía urbana y rural del Ecuador, este estudio se centra en encontrar la valoración interpretativa del uso de las redes sociales en el cantón Cuenca, analizando las redes de mayor alcance mediático, su uso, credibilidad y factores de riesgo, el segmento de edades que más presencia activa tiene en estas plataformas y sobre todo la facilidad de acceso a los mismos entre las áreas urbano-rurales.

\section{Precedentes de la dicotomía rural y urbana}

Con relación a los sectores rurales y urbanos, pensar en la existencia de un ambiente único e indiferenciado, por mucho, resultaría una utopía; si bien es cierto, en un tiempo remoto pudo ser su realidad, pero con el pasar de los años, la delimitación no solo se concedió para diferenciar un ambiente de otro, sino también para categorizarlos y que cada uno cumpliera una función específica. Como resultado de esta fragmentación, el sector rural quedó marginado por los grandes modelos de desarrollo dominantes en los sectores económico, político, académico, público; albergando pobreza e inexorables desventajas (Cimadevilla, 1997).

Por lo que se refiere al término urbano "Tiene un atractivo de entrada, especial por su diversidad temática, donde se tratan aspectos de carácter social, económico, cultural, infraestructural e institucional, todo desde una perspectiva globalizadora y sintética" (Noguer, 2010, p. 98). Sin embargo, en la década de los 90 se reconoce una multifuncionalidad no solo en el tema agrícola, sino en diversas funciones ambientales e intangibles, conservando 
en el sector rural sus lenguas, dialectos, modo de vida familiar, etc. (Espín, 2010).

Desde la sociedad rural este tratado es visto como una real amenaza en tanto que se privilegia la economía global sobre la local, la dimensión empresarial sobre la campesina, el conocimiento tecnológico de última generación sobre el conocimiento tradicional, todo lo cual apunta a un proceso sin retorno que implicaría el fin de la sociedad rural tal y como hoy la percibimos. (Martínez, 2006, p. 25)

\section{De la dicotomía rural y urbana en América Latina}

La Iniciativa Global para la Investigación Urbana ${ }^{1}$ (GURI), ha desarrollado una amplia investigación de carácter social y crítico en países del tercer mundo, esto, debido a la necesidad de entender los cambios económicos y sociales en la cultura urbana de dichos países. Pesquisa que cubrió países de África, Asia y un amplio grupo de países de América Latina, dentro de este último, la investigación se dividió en tres subregiones; México, Colombia y Centro América; Brasil y Venezuela; y, Países del Sur entre los que se encuentran Perú, Ecuador y Bolivia.

GURI arrojó resultados ${ }^{2}$ de 12 equipos subregionales, en un inicio este estudio se dio, debido a la percepción,

1 El proyecto GURI, fue financiado por la empresa FORD y coordinado por la Universidad de Toronto (Canadá), cuyo análisis se basó en tres etapas empezando en el año de 1992 y concluyendo en 1998.

2 Los resultados de esta investigación fueron publicados en inglés por la Universidad de Toronto. 
que los estudios urbanísticos en países subdesarrollados habían caído tanto a nivel cuantitativo como cualitativo, sin embargo, esta investigación, al contrario de lo que se creía, demostró que los estudios urbanísticos habían aumentado considerablemente tanto en cantidad, como en la calidad que éstos presentaban, excepto en países de África Oriental, donde la extrema pobreza, relegaba a gran cantidad de personas a las áreas rurales, estancando el crecimiento urbano (Schteingart, 2000).

En la primera subsección de países, México ya poseía vanos estudios realizados por investigadores estadounidenses entre las décadas de los 40 y 50, pero en la década de los 60 empieza un estudio urbano más detallado que en consecuencia disparó el desarrollo urbano más importante en los años 70. Por su parte Centroamérica, es de este primer subsegmento, el más tardío en desarrollo urbano, pues dados los constantes cambios y conflictos políticos, económicos y guerras, no fue, sino hasta finales de los años 70 e inicio de los 80, que por primera vez se dan estudios y planificación urbana. En Colombia, las investigaciones y proyectos urbanísticos se dan de forma lenta comparado con México, dado que, en los mismos años, toda la atención estaba puesta en los estudios agrarios.

En la segunda subsección, Brasil, es el país que más cambios ha sufrido dentro del campo de análisis y planificación urbanística, por un lado, pese a haber empezado su investigación en los años 40 junto con México, este país presentaba estudios más detallados y de alta calidad técnica, gracias a la ayuda de geógrafos y sociólogos esta- 
dounidenses, tiempo después, en la misma década, investigadores franceses también empezarían amplios estudios en este campo. En los años 60 y 70, el gobierno empieza un plan de financiamiento y la creación de una importante cantidad de instituciones dedicadas a la investigación, multiplicando los centros de estudio y apostando en cursos de posgrado. Sin embargo, en los años 80 se dan procesos complejos debido al recorte del apoyo estatal, generando una crisis no solo en la investigación y el estudio, sino también poniendo en riesgo el desarrollo urbano. ${ }^{3}$ En los países de Perú, Bolivia y Ecuador la investigación empieza en los años 60 con instituciones extranjeras, dando inicio a estudios y planificaciones técnicos urbanos; en Ecuador, ${ }^{4}$ solo instituciones de origen estadounidense se encargan de dicho estudio, mientras que en Perú y Bolivia hubo presencia de investigadores franceses. Se crean universidades con departamentos especializados en docencia y en investigación en el tema urbano y rural (Stren,1995).

La ruralidad por su parte, pese a ser reconocida como tal, solo fue considerada, cuando las zonas urbanas ya poseían estudios y planificaciones teóricos y prácticos para lograr el desarrollo y expansión de las zonas comerciales e industriales. En este punto, las políticas Neolibe-

3 Tras el recorte presupuestario en Brasil, las instituciones vinculadas al desarrollo urbano y de vivienda casi desaparecen en su totalidad.

4 Debido al estudio de estas organizaciones estadounidenses, Ecuador realiza su segundo censo en 1962, contando con el único censo en el que se dividen no solo por provincias y cantones sino también delimitando las áreas urbanas y rurales del país. 
rales económicas, aceleraron varios procesos de transformación, que no solo afectaron a las zonas urbanas, sino también a las zonas rurales, convirtiéndolas en la "nueva ruralidad” (Llambí \& Pérez, 2007). Por esta razón, los diferentes estudios se enfocaron en el análisis de la ampliación de la visión de los campos y su sistema agrario, para expandir sus funciones a sistemas no agrarios y multifuncionales, creando una brecha cada vez menor entre la urbanidad y la ruralidad, en dichas investigaciones también se intentaba explicar el cambio en los patrones culturales de la nueva vida rural debido a la expansión no solo del sector urbano, sino también del sector rural, estas intervenciones, se llevaron a cabo en la década de los 90 (Kay, 2007).

En la figura 1, podemos observar el crecimiento demográfico de América Latina desde el año 1950 y su proyección hasta el año 2020.

\section{Figura 1}

Crecimiento demográfico en América Latina

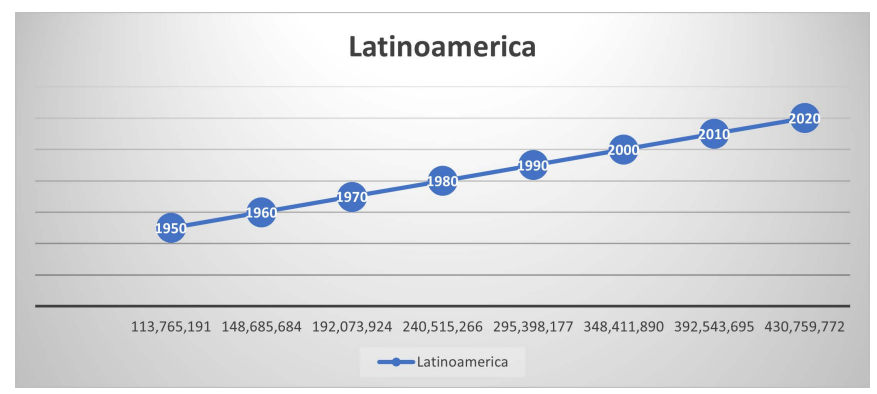

Fuente: Elaboración propia a partir de PopulationPyramid.net 2019 


\section{Dicotomía urbana y rural en Ecuador}

Ecuador ${ }^{5}$ ha contado con un amplio crecimiento demográfico a partir de la segunda mitad del siglo XX, con la "acelerada" modernización política, económica y social que el país atravesaba, se necesitaban cifras demográficas oficiales, pero no fue, sino hasta la presidencia de Galo Plaza Lasso que se recopilan los primeros datos estadísticos (García, 2007). Hasta la fecha, Ecuador cuenta con 7 censos poblacionales y de vivienda, los cuales están representados en la figura 2, siendo el primer censo en el año 1950 con un resultado de 3 202757 habitantes, 1962 con 4476007 habitantes, 1974 con 6521710 habitantes, 1982 con 8060712 habitantes, 1990 con 9648189 habitantes, 2001 con 12156608 habitantes y en 2010 con 14483499 habitantes, estas son las cifras oficiales del Instituto Nacional de Estadísticas (INEC).

Figura 2

\section{Crecimiento demográfico en Ecuador}

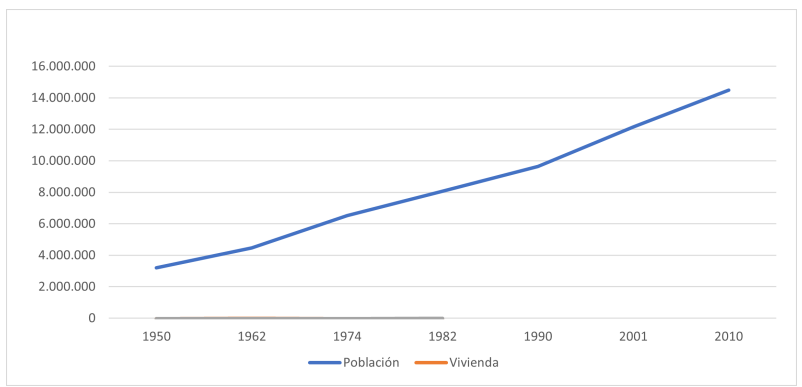

Fuente: Elaboración propia a partir de INEC 2020

5 Ecuador representa el $0.2 \%$ de la población mundial y representa el 2\% de la población en América Latina. 
Según los datos demográficos del Ecuador, la desigualdad en la distribución territorial de la población es un factor evidente. Pascual (2007) afirma que "la distribución de la población ecuatoriana ha mostrado y muestra en estos inicios de la nueva centuria- un claro signo de desequilibrio tanto a escala regional como en términos urbano- rurales" (p. 80). Estas, junto a la asignación de recursos, desarrollo de infraestructuras, diferencias económicas, políticas, culturales y étnicas, permiten comprender la desigualdad ecuatoriana en el ámbito rural. La ruralidad ecuatoriana, al igual que en gran número de los países latinoamericanos presenta fuertes problemas de desigualdad económica y social, de acuerdo a los datos del Instituto Nacional de Estadísticas y Censos (INEC) alrededor del $93.4 \%$ de la pobreza se encuentra en zonas no delimitadas. Dichas estadísticas recopiladas en el año 2010, revelaron que el índice de pobreza, fue calculado en base a las Necesidades Básicas Insatisfechas (NBI), siendo las principales, agua, luz, alcantarillado, salud y educación. En la tabla 1, se mencionan las 5 provincias con mayor índice de pobreza en el Ecuador.

\section{Tabla 1}

\section{Índice de pobreza NBI por provincias}

\begin{tabular}{|l|l|}
\hline Sucumbíos & $87,0 \%$ \\
\hline Orellana & $85,0 \%$ \\
\hline Los Ríos & $79,5 \%$ \\
\hline Napo & $78,6 \%$ \\
\hline Esmeraldas & $78,3 \%$ \\
\hline
\end{tabular}

Fuente: Elaboración propia a partir de INEC 2020 
Dentro de esta tabla de pobreza, la provincia del Azuay se sitúa en penúltimo lugar con un $48.3 \%$ de pobreza por necesidades básicas insatisfechas, solo superado por la provincia de Pichincha con un $33.55 \%$. Pese a los diferentes esfuerzos por reducir el índice de pobreza en las zonas no delimitadas, es evidente que la modernización social, económica y los avances tecnológicos no han contribuido en el sector rural en cuanto a disminuir la desigualdad urbano-rural (Herrán-Gómez et al., 2017).

En el área urbana, Madera (2012) asegura que "lo urbano está representado en el ciudadano promedio que busca simplemente vivir el día a día" (p.177). Explicando la estrecha relación que existe entre lo urbano-social. Por otra parte, sistemas económicos, políticos, estéticos, raciales y étnicos, se encuentran en un cambio continuo, construyendo y reconstruyéndose de manera compleja y a la vez acelerada. Dentro de las estadísticas del censo poblacional en los diferentes años, al igual que en el ámbito demográfico, también se ha podido evidenciar un crecimiento en la delimitación urbano-rural. En la figura 3, se observa que, en 7 décadas, las provincias del Ecuador pasaron de 15 a 24. Los cantones, de 87 a 221. En el censo del año 1962 se marca por primera y única vez la delimitación de las áreas urbanas y rurales, siendo el único año en el que dicho estudio estadístico se toma de manera individual para formar parte del estudio GURI, realizado a nivel de Latinoamérica. 


\section{Figura 3}

Avances estadísticos obtenidos en censos poblacionales

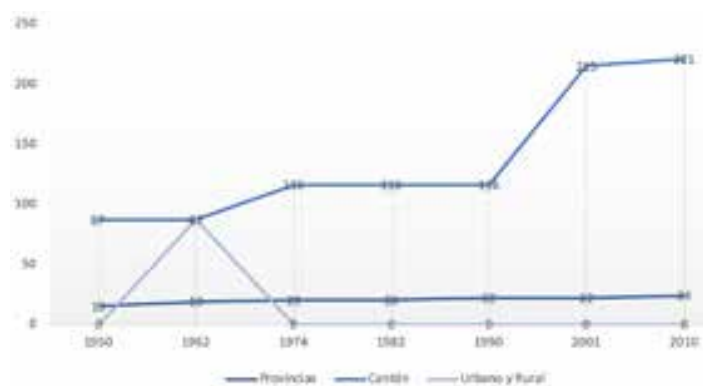

Fuente: Elaboración propia a partir de INEC 2020

En la tabla 2, podemos observar la tasa de crecimiento según el área, dentro de éste, el crecimiento urbano es del 2,24\% con relación a su contraparte rural con 1,47\%, dando un promedio de crecimiento de $1,95 \%$ en margen total de las áreas urbano-rural.

\section{Tabla 2}

Crecimiento demográfico en áreas urbanas y rurales

\begin{tabular}{|l|r|r|r|}
\hline Censo & \multicolumn{2}{|l|}{ 2001 } & \multicolumn{2}{|l|}{ Tasa de crecimiento } \\
\hline Urbano & 7431355 & 9.090 .786 & $2,24 \%$ \\
\hline Rural & 4725253 & 5392713 & $1,47 \%$ \\
\hline Total & 12156608 & 14483499 & $1,95 \%$ \\
\hline
\end{tabular}

Fuente: Elaboración propia a partir de INEC 2020

\section{Redes sociales en América Latina}

Si bien es cierto, que la llegada del internet cambió por completo el mundo, masificando la información e 
instalándola al alcance de todos, búsquedas más rápidas, productivas $\mathrm{y}$, por último, la comunicación. Esta revolución mediática, a su vez, da paso a una de las plataformas más utilizadas hoy en día, las redes sociales, cuya aparición, transformó la manera en la que los seres humanos nos relacionamos, ya que pasamos de seres presenciales a digitales. Ya sean plataformas de mensajería instantánea, redes digitales, la facilidad de compartir impresiones, pensamientos, emociones, buscar archivos, imágenes, videos y noticias en tiempo real, es la característica más importante que ofrecen las redes sociales. Las posibilidades con este tipo de sistemas, son infinitas y sus efectos, aunque son ampliamente estudiados, también son variados, pues se han investigado en la mayoría de áreas, desde la comunicación, salud, psicología, psiquiatría, sociología y lingüística. El número de usuarios, crece de manera inimaginable cada día, albergando un rango extenso de edades que van desde los 10 años, hasta los 70 años en promedio; esta diversificación se ha dado gracias a la facilidad de agruparse por edades, gustos, preferencias (Redó, 2014).

En el caso médico, Nass de Ledo (2011), expone el éxito de varios experimentos en dichas redes, pues crearon una página dentro de la plataforma Facebook, donde los pacientes podían recurrir en busca de información sobre sus enfermedades y no solo eso, sino encontrar personas con sus mismas afecciones, lo que provocó que dichos pacientes se reagruparan, formando una nueva comunidad de apoyo, donde compartían experiencias, información y recomendaciones sobre su enfermedad en común. 
En la figura 4, encontraremos que las redes con más afluencia de usuarios en América Latina son: YouTube 95\%, Facebook 93\%, WhatsApp 87\%, Facebook Messenger $64 \%$ y Twitter $57 \%$.

\section{Figura 4}

Redes con mayor afluencia en América Latina

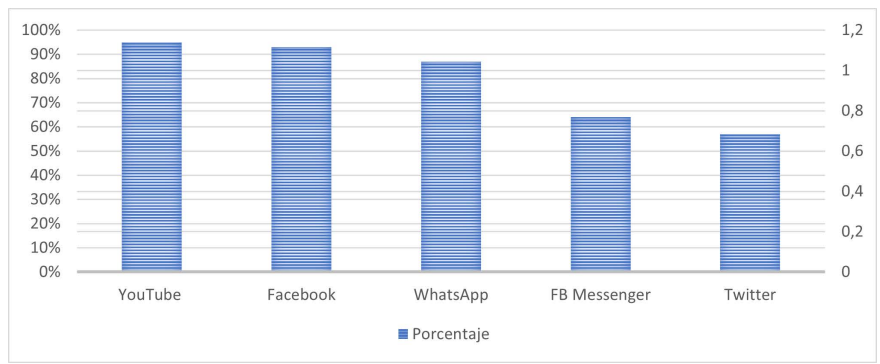

Fuente: Elaboración propia a partir de TreceBits

En América Latina, el número de usuarios en internet, es de 4021 mil millones, con un aumento del 7\% interanual, mientras que los usuarios de redes sociales ascienden a 3196 millones, con un aumento del 13\% anual.

En la figura 5, se pueden observar las actividades más comunes que los usuarios realizan en redes sociales. 
48

Figura 5

Actividades frecuentes en redes sociales

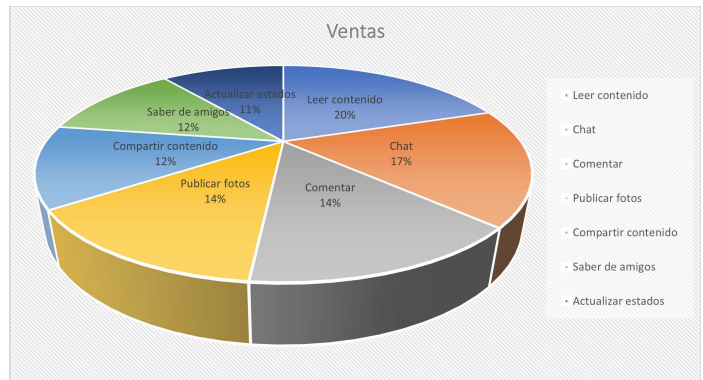

Fuente: Elaboración propia a partir de TendenciasDigitales

En la figura 6, se expone una estadística de los dispositivos más usados para acceder a redes sociales, siendo las computadoras de escritorio o portátiles con un $43 \%$, teléfonos celulares $52 \%$, Tablet $4 \%$ y otros dispositivos $0,14 \%$.

Figura 6

Dispositivos utilizados para generar tráfico web

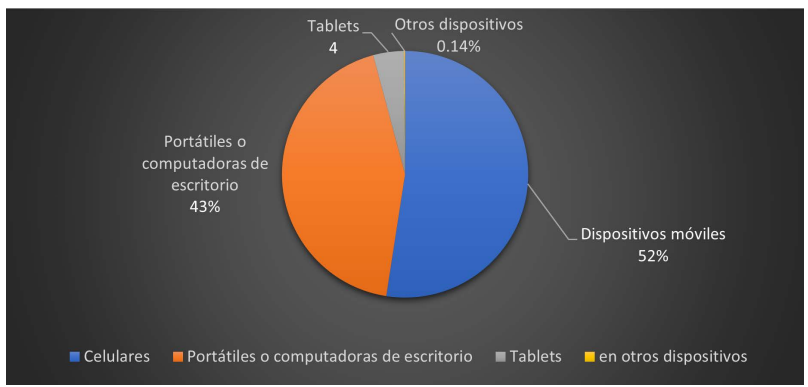

Fuente: Elaboración propia a partir de Trecebits 
Redes sociales en Ecuador

En Ecuador, "el uso de las redes sociales es cada vez más común en el ámbito personal” (López et al., 2018, p.3). Su utilización en aspectos: sociales, económicos y laborales se ha vuelto indispensable, logrando que el mayor porcentaje de personas utilicen dispositivos móviles dentro y fuera del hogar, dejando atrás a los medios tradicionales, como la radio y televisión, obligando a éstos, a evolucionar para mantenerse a la par con la vanguardia de la tecnología (Montoya, 2017).

Alrededor de 13.8 millones de personas tienen acceso a internet, de los cuales 13 millones son usuarios de redes sociales. Según el informe de Ecuador estado digital 2020, la mayor cantidad de usuarios de redes sociales están localizados en Quito y Guayaquil, sumando el 33\% del territorio nacional, de los cuales el $63 \%$ es un público mayor a 24 años. Este informe también menciona las plataformas con mayor número de usuarios entre los cuales destacan: Facebook, Instagram, Linkedln, TikTok, Pinterest y Snapchat.

En la figura 7, se puede visualizar el número de usuarios de las 4 redes sociales más concurridas según estas estadísticas, de las cuales Facebook acaudilla la lista con 12040000 de usuarios, Instagram con 4020000 de usuarios, Linkedln con 2580000 y TikTok con 1400000. 
50

\section{Figura 7 \\ Usuarios por red social}

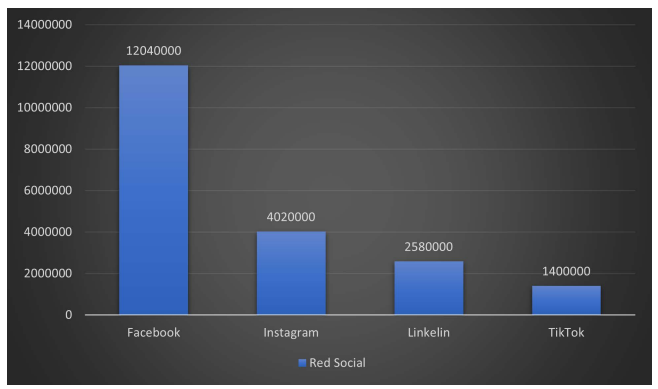

Fuente: Elaboración propia a partir de Primicias.ec

Como se observa, Facebook posee gran preeminencia en relación a las remanentes redes sociales y las cifras en torno a sus segmentos los podemos observar en la figura 8 , donde a pesar de ser la red social más concurrida, la mayor cantidad de sus usuarios, rodea los 25 y 35 años, mientras que el rango de edades que menos utiliza esta plataforma son personas de 55 años en adelante.

Figura 8

Usuarios de Facebook por edades

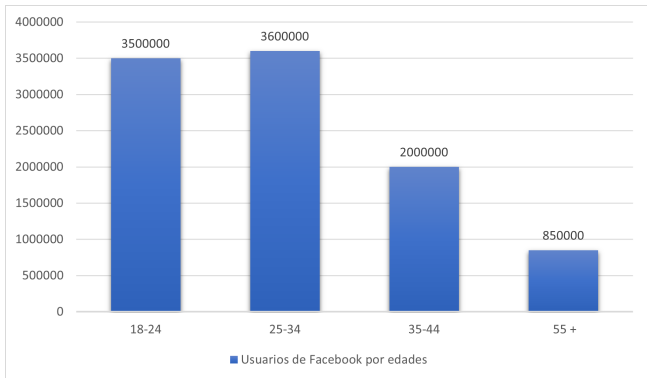

Fuente: Elaboración propia a partir de Primicias.ec 
Por su parte el Ministerio de Telecomunicaciones del Ecuador, afirma que hasta el año 2015, el 91\% de ecuatorianos ya eran usuarios de al menos una red social. Según datos del Observatorio TIC, esta cifra se basa en el estudio de personas que utilizan dispositivo móvil inteligente, en 2011, los registros ingresados de usuarios de redes sociales, fueron de $69.9 \%$, obteniendo un aumento de $21 \%$ en tan solo 4 años.

En zonas urbanas de la ciudad de Quito se registraron $92.4 \%$ de usuarios de cara a zonas rurales con un $82.88 \%$, estos datos también revelaron que los hombres son quienes más utilizan las redes sociales, así también, la provincia del Azuay es la que más registros obtuvo con $95.45 \%$ de usuarios de redes de acuerdo al número de habitantes.

En la figura 9, se observa el total de las líneas telefónicas, usuarios de internet y usuarios de redes sociales en relación a la población del Ecuador.

\section{Figura 9}

\section{Usuarios digitales del Ecuador}

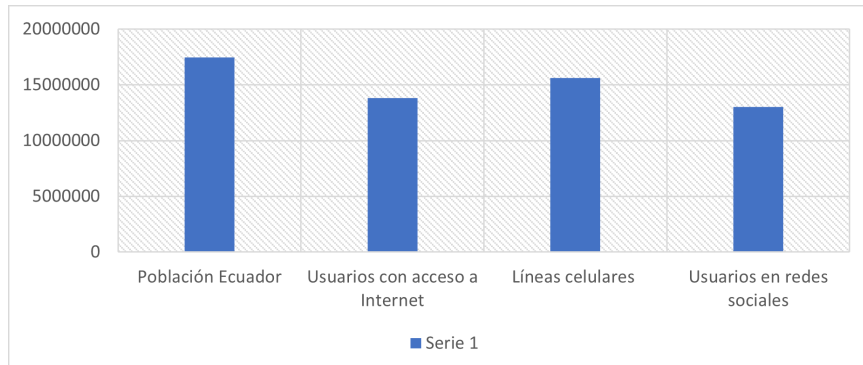

Fuente: Elaboración a partir de Mentinno-Innovation \& Lifetime Value Partners 2020 


\section{Cuenca. Dicotomía rural urbana}

Cuenca se encuentra localizada en los Andes neotropicales del Ecuador, es decir, está asentada sobre la antigua ciudad del Inca Tomebamba. Se ubica geográficamente de $39^{\prime}$ a $3^{\circ} 00^{\prime}$ de latitud sur y $78^{\circ} 54^{\prime}$ a $79^{\circ} 26^{\prime}$ de longitud oeste, con una altura sobre el nivel del mar que varía de 100 a $4560 \mathrm{msnm}$, por otra parte, el cantón Cuenca está dividido en 15 parroquias urbanas, que conforma la ciudad de Cuenca con un área alrededor de $72.32 \mathrm{~km}^{2}$, por lo que el cantón, cuenta con una dimensión de $3086 \mathrm{~km}^{2}$, cuyo $2.34 \%$ está ocupado por la ciudad de Cuenca. Por el contrario, el cantón Cuenca, cuenta con 21 parroquias rurales, cuyo movimiento y comercio se centra en zonas aledañas a parques, centros parroquiales, iglesias y mercados. Cuen$\tan$ con construcciones que sirven de viviendas y de locales comerciales donde generalmente un día de fin de semana, se genera la actividad comercial, turística y la población rural alejada, viaja a los centros con sus productos para comercializarlos, por el contrario, en el sector urbano, existe una dispersión de cada elemento y los limites parroquiales son descuidados, formando un solo conjunto que es la ciudad de Cuenca. Tras la Independencia de Cuenca el 3 de noviembre de 1820 , se genera un crecimiento de la población y la expansión urbana.

En la década de los 90, la tasa de crecimiento promedio anual de la zona urbana fue del $3.10 \%$. Sin embargo, la tasa de crecimiento promedio anual en los últimos 10 años (2001 a 2010) en la zona urbana es del 1.93\%. Presentándose una diferencia del $1.17 \%$ que indica la disminución 
del índice de crecimiento poblacional en la zona urbana. En la zona rural la tasa de crecimiento promedio anual de 1990 al 2001 tiene un valor del $0.41 \%$ y desde el 2001 al 2010 es del $2.50 \%$. Se puede apreciar que ha aumentado el crecimiento en la zona rural en 2,09 puntos. Dentro del porcentaje, en la zona urbana, el $47.72 \%$ son hombres y el $52.28 \%$ mujeres. En la zona rural el $47.37 \%$ son hombres y 52.62\% mujeres (Bermeo, 2013).

Para conocer los datos del uso de las redes sociales en zonas urbanas y rurales de Cuenca, realizamos una investigación cuantitativa, con la ayuda de encuestas, que revelaron las redes sociales más populares, el fin con el que se usan, el promedio de edades que utilizan estas plataformas y las diferencias entre su uso en las zonas rurales y urbanas de Cuenca.

\section{Metodología}

Hipótesis general: El cantón Cuenca, tiene la misma accesibilidad y frecuencia de uso de redes sociales, tanto en el sector urbano como en el rural.

Hipótesis específicas: Los habitantes de zonas urbanas, utilizan mayor cantidad de redes sociales que habitantes de las zonas rurales; Facebook es la aplicación más utilizada en el cantón Cuenca; Los habitantes de zonas rurales invierten más tiempo en redes sociales que el sector urbano.

A partir de una metodología cuantitativa se pretende ratificar si el territorio geográfico del cantón Cuenca, 
influye en el uso de las redes sociales. El paradigma cuantitativo orienta a una investigación correlacional y descriptiva-interpretativa, en efecto pretende constatar si las personas que viven en las zonas urbanas y rurales, asignan el mismo uso a sus redes sociales.

La técnica utilizada para recopilación de datos fue encuestas, basadas en validez de contenido, la cual fue corregida y validada por profesionales en el área académica e investigativa de la Universidad Politécnica Salesiana sede Cuenca, conformada por el Dr. Ángel Torres-Toukoumidis, Dr. Andrea de Santis Piras y Dr. Blas Garzón-Vera.

Se aplicaron 120 encuestas online, de las cuales el $50 \%$ estuvo dirigida al sector urbano y el otro $50 \%$ al sector rural. Las encuestas realizadas, incluyeron una pregunta básica de segmentación para dividir a los habitantes de las zonas urbanas y rurales, por otro lado, el tiempo que el encuestado vive en el sector, verifica que tratamos con personas cuyo desarrollo se ha visto afectado ya sea positiva o negativamente por la dicotomía urbano-rural. De esta forma, las preguntas validadas para la encuesta, tienen el fin de identificar cuántas redes sociales utilizan y con qué fin, la plataforma más y menos utilizada, su frecuencia de uso, la cantidad de tiempo que se invierte diariamente en redes sociales, qué dispositivo es el más utilizado para navegar por dichas plataformas y la consideración de la importancia de estas redes en la sociedad actual. Los cambios sugeridos, fueron realizados en el cuestionario que posteriormente se validó como herramienta de recopilación de datos. 
La encuesta consta de 10 preguntas realizadas bajo la escala de Likert de cuatro puntos y las bases fundamentales de cuestionarios; conviene subrayar que las escalas que se utilizaron, se basaron según el grado de concordad, que corresponde a: 1 . Muy acuerdo, 2. De acuerdo, 3. En desacuerdo, 4. Muy en desacuerdo. Otro tipo de escala que se utilizó fue el de frecuencia, que corresponde a: 1. Siempre, 2. La mayoría de veces sí, 3 . La mayoría de veces no, 4 . Nunca. Por otra parte, también se utilizó preguntas dicotómicas y multivalentes.

Las encuestas se realizaron del 14, hasta el 16 de julio de 2020, a partir de esa fecha los datos fueron procesados mediante Excel, permitiendo volcar la información obtenida, generando patrones contenidos dispuestos hacia el análisis del resultado.

\section{Resultados}

En base a la investigación realizada, se generó una muestra de 120 encuestas, 60 en la zona urbana y 60 en la zona rural, las respuestas a las encuestas realizadas, pueden visualizarse en la tabla 3, cuya estructura se segmentó acorde a la zona geográfica previamente delimitada.

\section{Tabla 3}

\section{Resultados de la muestra}

1. Su vivienda se ubi-

ca en el sector:

$$
\begin{array}{cccc}
\begin{array}{c}
\text { Entre } 5 \text { a } 10 \\
\text { años }
\end{array} & \text { Más de 10 } & \text { Menos de } 5 & \text { Total } \\
\text { años } & \text { años } &
\end{array}
$$




\section{6}

\begin{tabular}{|ccccc|} 
Rural & 14 & 29 & 17 & 60 \\
Urbano & 9 & 42 & 9 & 60 \\
\hline \multicolumn{1}{r}{ Total, general } & $\mathbf{2 3}$ & $\mathbf{7 1}$ & $\mathbf{2 6}$ & $\mathbf{1 2 0}$ \\
\hline
\end{tabular}

\section{2. ¿Cuánto tiempo tiene aproximada- mente viviendo en esa zona?}

\begin{tabular}{lcccc} 
& $\begin{array}{c}\text { Entre } \mathbf{5} \text { a 10 } \\
\text { años }\end{array}$ & $\begin{array}{c}\text { Más de } \mathbf{1 0} \\
\text { años }\end{array}$ & $\begin{array}{c}\text { Menos de 5 } \\
\text { años }\end{array}$ & Total \\
\hline Rural & 14 & 29 & 17 & 60 \\
Urbano & 9 & 42 & 9 & 60 \\
\hline \multicolumn{1}{c}{ Total, general } & $\mathbf{2 3}$ & $\mathbf{7 1}$ & $\mathbf{2 6}$ & $\mathbf{1 2 0}$
\end{tabular}

\section{3. ¿Cuántas de estas redes} sociales usa?

\begin{tabular}{|c|c|c|c|}
\hline & Rural & Urbano & Total \\
\hline Facebook & 1 & & 1 \\
\hline Facebook, Instagram & 1 & & 1 \\
\hline Facebook, WhatsApp & 2 & & 2 \\
\hline $\begin{array}{l}\text { Facebook, WhatsApp, } \\
\text { Facebook Messenger }\end{array}$ & 5 & 2 & 7 \\
\hline $\begin{array}{l}\text { Facebook, WhatsApp, Fa- } \\
\text { cebook Messenger, Twitter }\end{array}$ & 1 & 2 & 3 \\
\hline $\begin{array}{l}\text { Facebook, WhatsApp, } \\
\text { Instagram }\end{array}$ & 9 & 7 & 16 \\
\hline $\begin{array}{l}\text { Facebook, WhatsApp, } \\
\text { Instagram, Facebook } \\
\text { Messenger }\end{array}$ & 12 & 16 & 28 \\
\hline $\begin{array}{l}\text { Facebook, WhatsApp, Ins- } \\
\text { tagram, Facebook Messen- } \\
\text { ger, Twitter }\end{array}$ & 3 & 6 & 9 \\
\hline
\end{tabular}




\section{7}

Facebook, WhatsApp,

Instagram, TikTok

4

4

Facebook, WhatsApp, Instagram, TikTok, Facebook

Messenger

8

10

18

Facebook, WhatsApp, Instagram, TikTok, Facebook

Messenger, Twitter

69

15

Facebook, WhatsApp,

Instagram, Twitter

1

1

Facebook, WhatsApp,

TikTok

1

WhatsApp

1

1

WhatsApp, Facebook

Messenger

3

3

WhatsApp, Instagram

1

1

2

WhatsApp, Instagram,

Facebook Messenger

1

1

WhatsApp, Instagram,

TikTok

2

2

WhatsApp, Instagram, Tik-

Tok, Facebook Messenger

11

2

WhatsApp, Instagram,

Twitter

1

1 2

WhatsApp, TikTok 1 1 
58

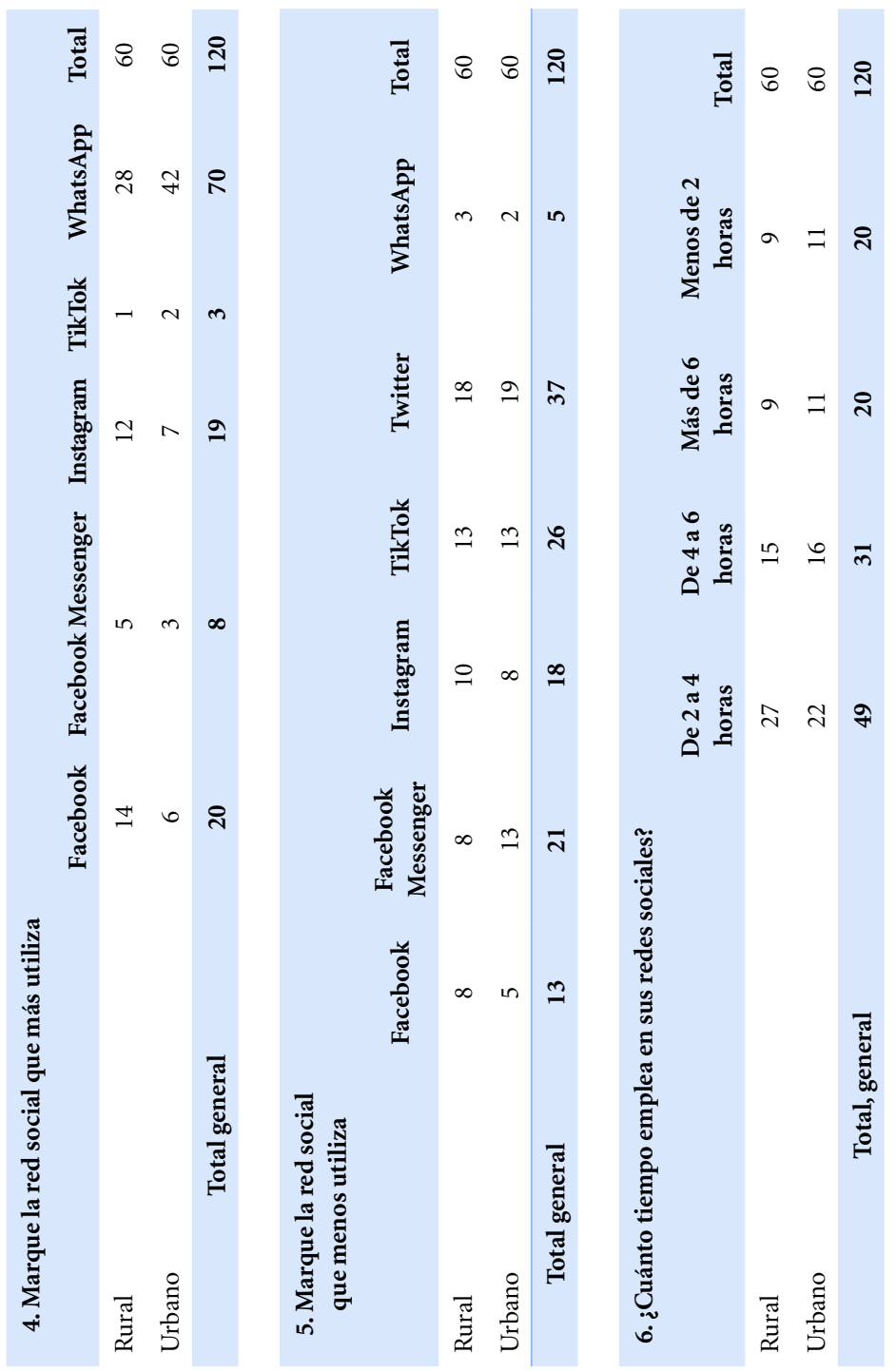


59

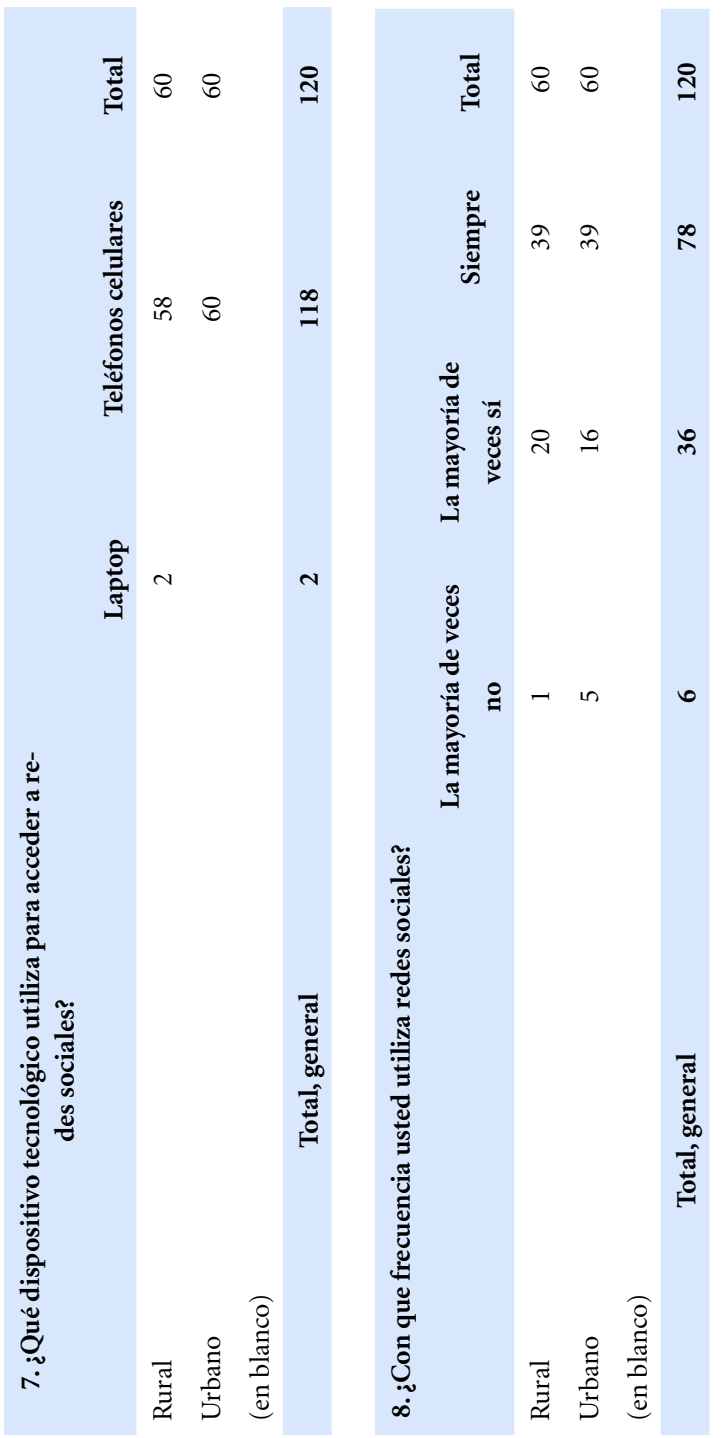




$$
60
$$

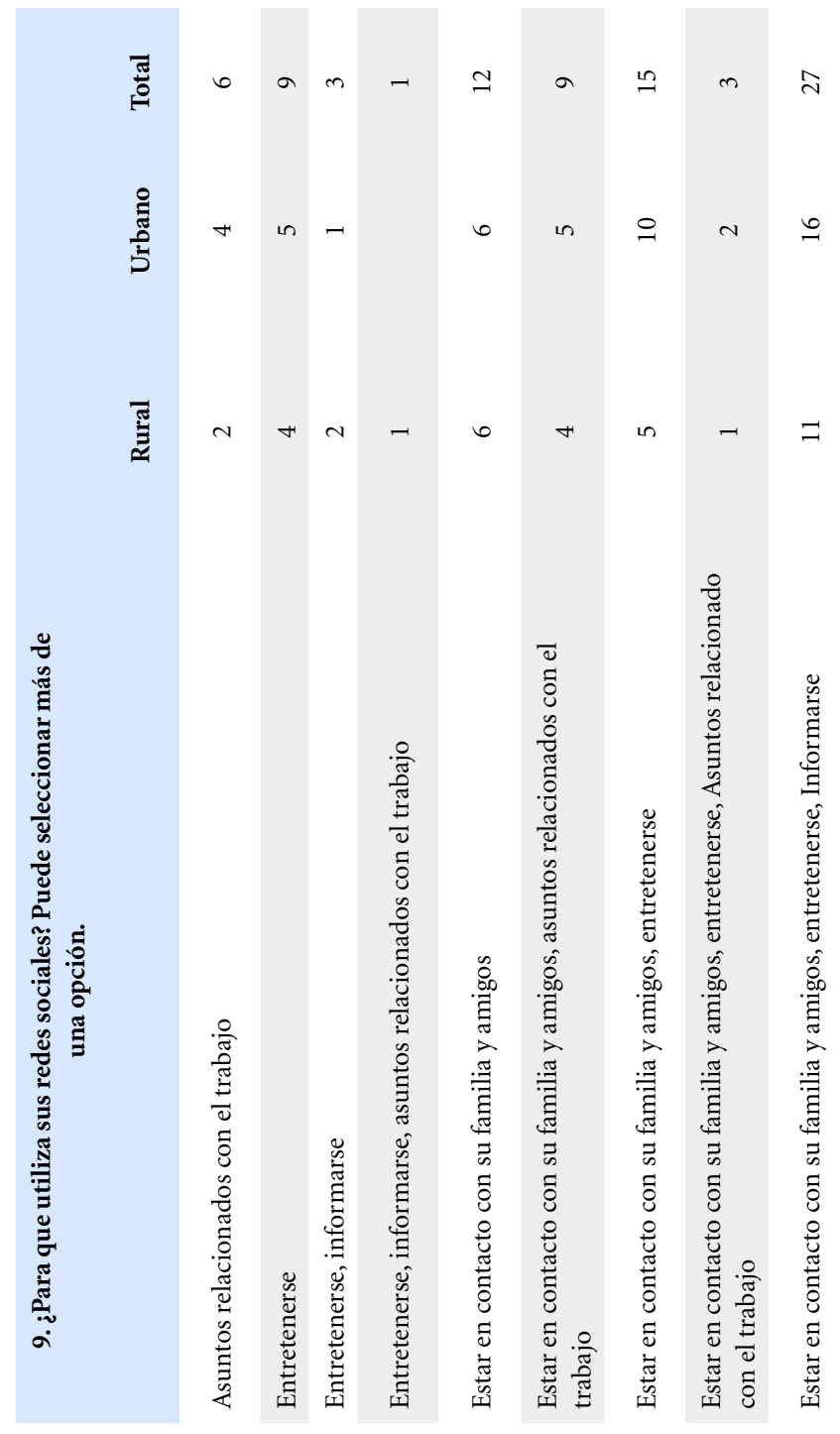



61

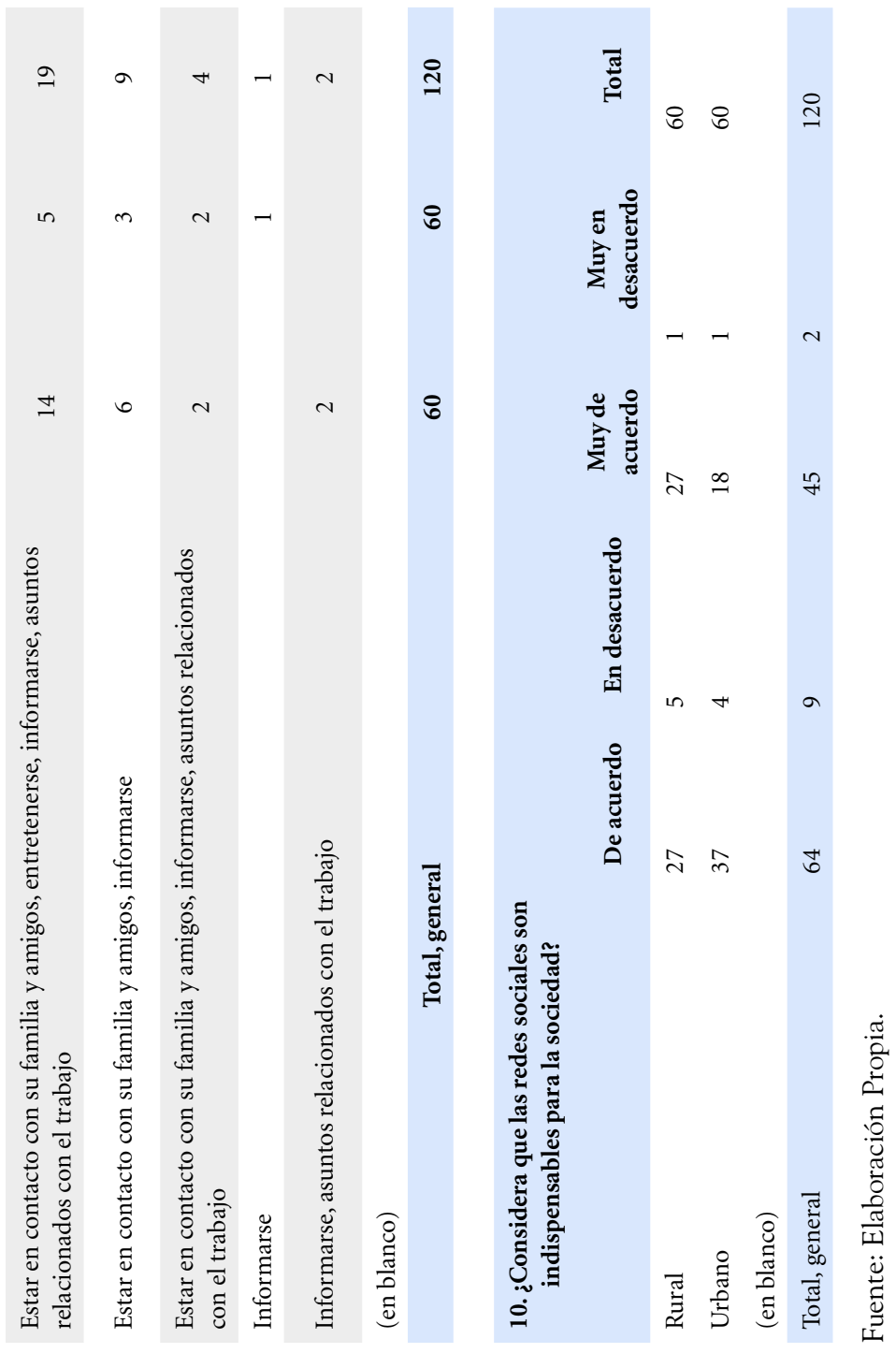


Como se observa en la tabla 3, pregunta 2. La mayor parte de los encuestados, vive más de 10 años en la misma ubicación, con el $70 \%$ en la zona urbana y el $48.33 \%$ en la zona rural. En las preguntas 3 y 6 , se concluye que la cantidad de redes utilizadas en las zonas urbanas y rurales son las mismas en cantidad, pero difieren en el tiempo empleado, la mayor cantidad de encuestados utilizan sus redes un promedio de 2 a 4 horas diarias, con $45 \%$ en el área rural y el $36.66 \%$ en el área urbana, sin embargo, en el rango de 6 horas o más, el sector urbano concluye con $18.33 \%$ de cara al sector rural con $15 \%$, siendo el área que más tiempo emplea en sus redes sociales.

En la pregunta 4 y 5 se reconoce como la red más utilizada a WhatsApp con $70 \%$ en la zona urbana y $46.66 \%$ en la zona rural, siendo por otro lado Twitter la aplicación menos utilizada con un $0 \%$. La pregunta 7 , demuestra que el dispositivo tecnológico más utilizado es el teléfono móvil con $96.66 \%$ en la zona rural y el $100 \%$ en la zona urbana. En la pregunta 8 y su frecuencia de uso, el $65 \%$ de encuestados admite que siempre utilizan sus redes sociales. La pregunta 9, concluye que en el sector urbano, los encuestados utilizan sus redes con el fin de entretenerse y mantener contacto con familiares y amigos, mientras que en el sector rural se incluyen asuntos relacionados con el trabajo en un $26.66 \%$ y $23.33 \%$ respectivamente. A continuación, se vislumbrarán los resultados detalladamente.

\section{Análisis del resultado}

Con respecto a las redes sociales más utilizadas por los habitantes del cantón Cuenca, la figura 10, muestra los 
resultados generales de las 120 encuestas realizadas, de las cuales se obtienen los siguientes porcentajes: WhatsApp concluye como la red social más utilizada con un 58\%, Facebook en segundo lugar con $17 \%$, Instagram con $16 \%$, Facebook Messenger con $7 \%$, TikTok con $2 \%$ y en último lugar, quedando como la red social menos utilizada, se encuentra Twitter con $0 \%$.

Figura 10

Porcentajes de Redes sociales que son más y menos utilizadas

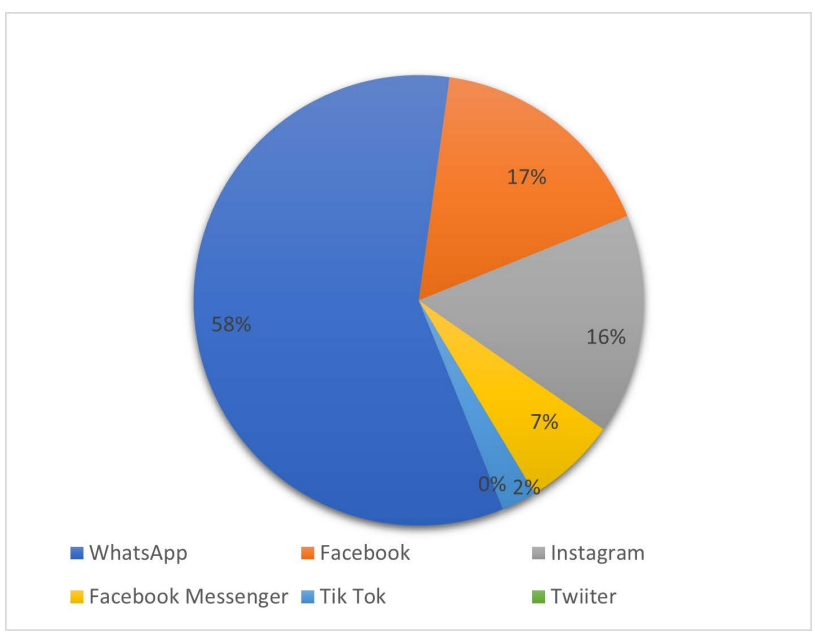

Fuente: Elaboración propia

Como se observa en la figura 11, tanto en el sector urbano como en el rural, se utiliza la misma cantidad de redes sociales. 


\section{4}

Las redes más utilizadas en los sectores urbano-rurales se diferencian a partir de la segunda red con más afluencia, sin embargo, pese a que WhatsApp es la red más utilizada de manera global, en el área urbana el amplio margen entre WhatsApp con un 70\% e Instagram con $11.66 \%$ mayormente visible que, en el área rural, cuyos porcentajes concluyen con un margen de diferencia más estrecho, otorgándole a WhatsApp un $46.66 \%$, seguido de Facebook con $23.33 \%$.

Figura 11

Cantidad de redes sociales usadas en el cantón Cuenca

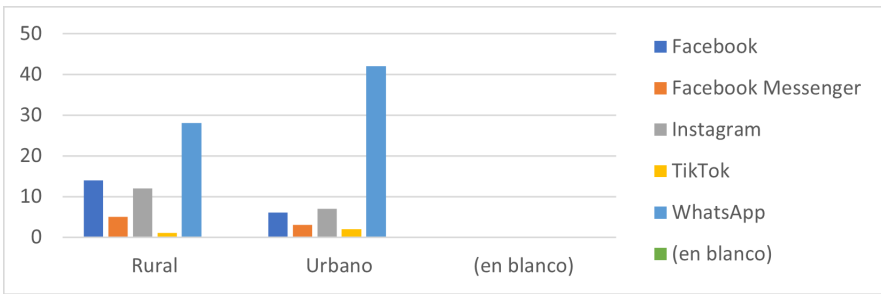

Fuente: Elaboración propia

En tercer lugar, en la zona urbana Facebook concluye con $10 \%$, en la zona rural, Instagram se ubica en tercer lugar con $20 \%$ por su parte, Facebook Messenger se ubica en cuarto lugar con $5 \%$ en la zona urbana y $8.33 \%$ en la zona rural; TikTok, se ubica en último lugar con $3.333 \%$ en la zona urbana y $1.66 \%$ en la zona rural.

En la figura 12, se observa la cuantía de redes utilizadas en estos mismos sectores, distinguiendo la zona ur- 
bana con color naranja y con azul la zona rural, como se aprecia, la zona urbana es la que mayor cantidad de redes sociales utiliza.

\section{Figura 12}

Cuantía de redes utilizadas en zona urbana y rural

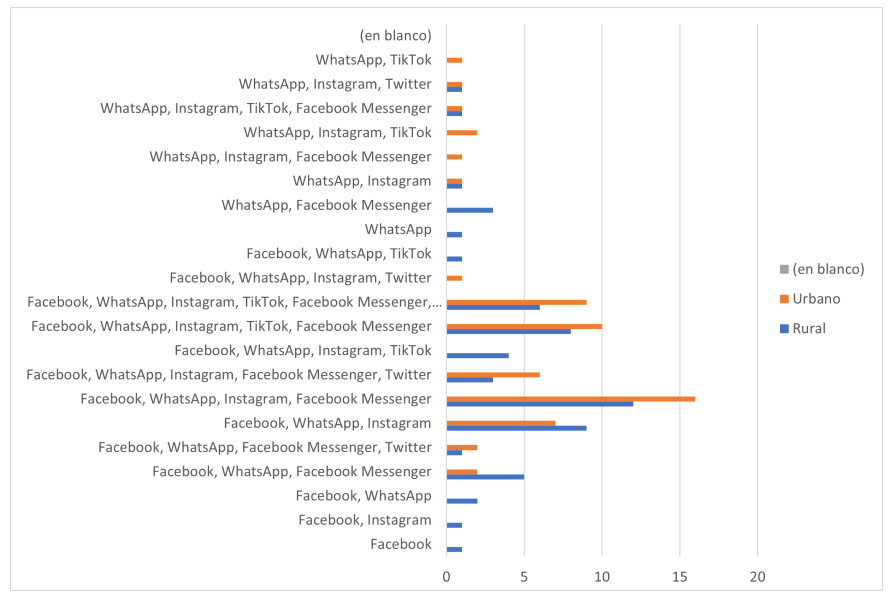

Fuente: Elaboración propia

En la figura 13, se observa el tiempo que dedican los encuestados a sus redes sociales, consumando la encuesta a favor de la zona urbana, donde el 18.33\% utiliza sus redes sociales más de 6 horas diarias, por su parte, en la zona rural un $15 \%$ de encuestados, utiliza sus redes sociales más de 6 horas diarias.

Esta pregunta, concluyó con una igualdad en torno a las personas que utilizan sus redes menos de 2 horas al día y más de 6 horas al día, dando un resultado de $15 \%$ en el sector rural y $18,33 \%$ en el sector urbano. 
66

Figura 13

Tiempo en redes sociales

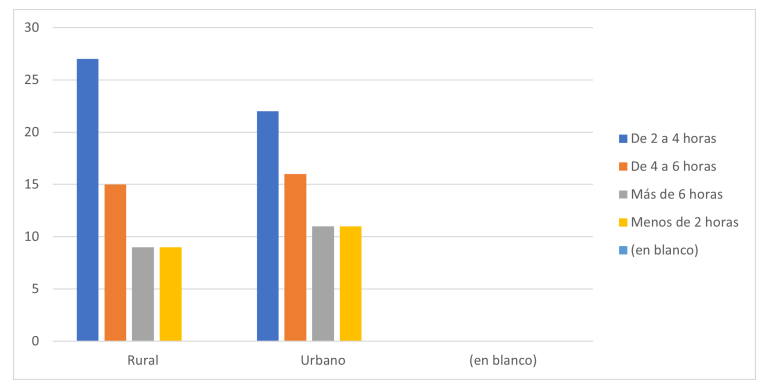

Fuente: Elaboración propia.

\section{Conclusiones}

Finalmente, concluido el trabajo de investigación, el referente general, es la influencia de la zona geográfica en el uso de las redes sociales del cantón Cuenca, en el cual se evidencia que la dicotomía de las manifiestas zonas, influyen en el uso, propósito, tiempo y frecuencia con la que utilizan las redes sociales.

En cuanto a las hipótesis específicas, la recopilación de datos a través de una muestra online de 120 encuestas, que dieron como resultado la comprobación de una de las tres hipótesis específicas planteadas con respecto de la dicotomía urbana-rural, en consecuencia, se pudo comprobar que en la primera hipótesis de la investigación, los habitantes de las zonas urbanas utilizan la misma cantidad de redes sociales que habitantes de las zonas rurales, sin embargo, los habitantes de las zonas rurales, utilizan estas redes en me- 
nor porcentaje que los de la zona urbana; en consecuencia, a través de los resultados obtenidos, no se pudo comprobar esta hipótesis; con respecto a la segunda hipótesis y debido a la investigación previa y demostrada en el marco teórico, se planteó la hipótesis, afirmando que Facebook sería la aplicación más utilizada en el cantón Cuenca, al igual que los márgenes de Quito y Guayaquil, sin embargo, los resultados obtenidos demuestran que la aplicación más utilizada en el cantón Cuenca es WhatsApp con 70\% en el área urbana y $46,66 \%$ en el área rural; en torno a la última hipótesis, ésta se planteó con la afirmación de que los habitantes de zonas rurales invierten más tiempo en redes sociales que los habitantes del sector urbano, los resultados sin embargo, demostraron que son los habitantes de las zonas urbanas, quienes emplean más tiempo navegando por las distintas redes sociales.

El uso de redes sociales se ha convertido en una acción indispensable en nuestro medio, tanto así, que personas naturales e incluso los medios tradicionales, se han visto en la obligación de actualizarse e involucrarse con los medios digitales. El uso de dichas plataformas ha pasado de ser un acto de vanguardia, a ser una necesidad en ámbitos como el comercial, laboral, informativo y de entretenimiento.

Una de las limitaciones más importantes para culminar este estudio investigativo y que infirió en el número de la muestra, fue la emergencia sanitaria por la Covid-19. Por este motivo, las encuestas se plantearon de forma digital, siendo en un inicio un trabajo de campo, otro de los 
factores importantes fue el corto tiempo para aplicar las encuestas y la demora en la obtención de la validación de contenido, provocando atrasos inesperados.

Para los próximos estudios consideramos que la muestra no solo debe ser aplicada en el cantón Cuenca se recomienda, utilizar el modelo aplicado en ciudades como Quito, Guayaquil, Ambato, Machala. También se considera que el modelo de las encuestas puede ser reiterado en otro contexto de estudio.

\section{Bibliografía}

Bermeo, H. (2013). Implementación de la metodología de análisis de vulnerabilidad a nivel cantonal-Cuenca. https://bit. ly/3hh8Vtu

Burgos, A., \& Bocco, G. (2020). Contribuciones a una teoría de la innovación rural. Cuadernos de Economía, 39(79), 219-247.

Cimadevilla, G. (1997). De la dicotomía urbano-rural a la emergencia urbana. Momentos y movimientos. Do Programa De Pos Graduacao Em Historia Da Ufsc, 52-70. https://bit.ly/34t6QH3

Espín, M.A. (2010). Reseña de "Historia social urbana: Espacios y flujos" de Eduardo Kigman, compilador. Iconos. Revista de Ciencias Sociales, (36), 175-178. https://bit. ly/3jf7lbR

García, F. (2007). ¿Un nuevo modelo rural en Ecuador? Cambios y permanencias en los espacios rurales en la era de la globalización. Iconos. Revista de Ciencias Sociales, (29), 77-93. https://bit.ly/2Et0rRx

Herrán-Gómez, J., Sastre-Merino, S., \& Torres-Toukoumidis, Á. (2017). Radio mensaje para la gestión del sistema 
de riego en comunidades rurales indígenas de Ecuador. Equidad y Desarrollo, 1(28), 43-60. https://doi. org/10.19052/ed.4212

Instituto Nacional de Estadísticas y Censos (INEC). (2014). Evolución de las variables investigadas en los censos de población y vivienda del Ecuador 1950, 1962, 1974, 1982, 1990, 2001, 2010. https://bit.ly/3aUZSM9

Kay, C. (2007). Algunas reflexiones sobre los estudios rurales en América Latina. Íconos. Revista de Ciencias Sociales, (29), 31-50. https://doi.org/10.17141/iconos.29.2007.230

Llambí, L., \& Pérez, E. (2007). Nuevas ruralidades y viejos campesinos. Agenda para una nueva sociología rural Latinoamericana. Cuadernos de desarrollo rural, (59), 3761. https://bit.ly/3jf3tYF

López, O., Beltrán, C., Morales, R., \& Cavero, O. (2018). Estrategias de marketing digital por medio de redes sociales en el contexto de las PYMES del Ecuador. CIencIAmérica, 7(2), 1-18. https://bit.ly/318Ne13

Mentinno-Innovation \& Lifetime Value Partners (2020). Ecuador Estado Digital Ene/20. https://bit.ly/3aTzTVJ

Madera, S. (2012). El pensamiento filosófico: clave del desarrollo social y urbano. Sophia, Colección de Filosofía de la Educación, (12), 169-179. https://bit.ly/2Edm9cv

Martínez-Valle, L. (2006). La perspectiva local-global en el medio ecuatoriano. Íconos. Revista de Ciencias Sociales, (24), 89-99. https://bit.ly/2Yx0DWR

Ministerio de Telecomunicaciones y de la Sociedad de la Información (2015). 91\% de ecuatorianos utiliza las redes sociales en su teléfono inteligente. https://bit.ly/3gtLb3U

Montoya, A. (2017). La guerra virtual: La televisión vs. El internet

(tesis de pregrado). Universidad de Palermo, Argentina. Nass De Ledo, I. (2011). Las redes sociales. Revista Venezolana de Oncología, 23(3),133. https://bit.ly/2EwNTbP 


\section{0}

Noguer. J., (2010). Análisis de un área urbana. Revista de Girona, 214(151), 98-98.

Schteingart, M. (2000). La Investigación urbana en América Latina. Papeles de Población, 6(23), 9-25. https://bit. ly/3gnvTh7

Stren, R. (1995). Towards a Research Agenda for the 1990. An Introduction. In R. Stren, Latin America, Urban Research in the Developing World. Universidad de Toronto, Canadá.

Tendencias digitales (26 de junio 2017). Uso de las redes sociales en Latinoamérica. Datos y reflexiones. Tendencias Digitales. https://bit.ly/3jfcgcP

\section{Anexos}

\section{Encuesta aplicada}

\section{Uso de las redes sociales en el cantón Cuenca}

Con el objetivo de comprobar la diferencia del uso de redes sociales en el cantón Cuenca, agradecemos su aporte, al llenar la siguiente encuesta que ha sido realizada a partir de la escala de actitud de Likert y las bases fundamentales de cuestionarios. Para responder, haga clic en la opción que más se adapte a su respuesta.

\section{Su vivienda se ubica en el sector:}

Urbano

Rural

2. ¿Cuánto tiempo tiene aproximadamente viviendo en esa zona?

Menos de 5 años

Entre 5 a 10 años

Más de 10 años 
3. ¿Cuántas de estas redes sociales usa? Puede seleccionar más de una.

Facebook

WhatsApp

Instagram

TikTok

Facebook Messenger

Twitter

4. Marque la red social que más utiliza:

Facebook

WhatsApp

Instagram

TikTok

Facebook Messenger

Twitter

5. Marque la red social que menos utiliza:

Facebook

WhatsApp

Instagram

TikTok

Facebook Messenger

Twitter

6. ¿Con que frecuencia usted utiliza redes sociales?

Siempre

La mayoría de veces si

La mayoría de veces no

Nunca 
7. ¿Cuánto tiempo emplea en sus redes sociales?

Menos de 2 horas

De 2 a 4 horas

De 4 a 6 horas

Más de 6 horas

8. ¿Qué dispositivo tecnológico utiliza para acceder a redes sociales?

Teléfonos celulares

Tablet

Laptop

Computadora de escritorio

9. ¿Pará qué utiliza sus redes sociales? Puede seleccionar más de una opción.

Estar en contacto con su familia y amigos.

Entretenerse

Informarse

Asuntos relacionados con el trabajo

10. ¿Considera que las redes sociales son indispensables para la sociedad?

Muy de acuerdo

De acuerdo

En desacuerdo

Muy en desacuerdo 


\title{
CApítulo III Lo rural y urbano: influencia de las redes sociales
}

\author{
Jasson Marca-Quituizaca \\ Universidad Politécnica Salesiana, Ecuador \\ https://orcid.org/0000-0001-9638-0148 \\ Alex Mejía-Loza \\ Universidad Politécnica Salesiana, Ecuador \\ https://orcid.org/0000-0002-9788-0715 \\ Christian Picón-Cedillo \\ Universidad Politécnica Salesiana, Ecuador \\ https://orcid.org/0000-0002-5081-3240
}

\section{Resumen}

La tecnología se ha transformado en un instrumento indispensable en todos los sectores del mundo ya sea social o cultural, el acceso y uso de ellas son, hoy en día, herramientas irremplazables para el logro de los objetivos de desarrollo, crecimiento y bienestar, así como las redes sociales han avanzado y ver cómo el mundo ahora está regido virtualmente, un indicio de la popularidad que ad- 


\section{4}

quirió el uso de internet fue la aparición de sitios específicamente pensados para la transmisión, opinión y creación de información por parte de la población y recientemente el tema de las redes sociales se ha convertido en el boom del mundo en el que vivimos y suele ser asociado a la vida urbana, donde millones de personas se la pasan con la cabeza enterrada en sus computadoras y celulares, enchufados al mundo virtual. Pero la explosión de las conexiones a través de la Red no solo ha cambiado la manera de interactuar en las grandes ciudades. También las zonas rurales, tradicionalmente más remotas y desconectadas, están siendo transformadas por la aparición de estas nuevas herramientas tecnológicas. Este impacto se siente con claridad en todo el mundo y debido a esto, se ha llevado a cabo el siguiente estudio con recopilación de datos relacionado a la "Dicotomía rural-urbana sobre el uso de las redes sociales", en la ciudad de Cuenca.

Palabras clave: Herramientas irremplazables, redes sociales, virtualmente, vida urbana, zonas rurales.

\section{Abstract}

Technology has become an indispensable tool in all sectors of the world, whether social or cultural, access to and use of them are now irreplaceable tools for achieving the goals of development, growth and well-being, just as social networks have advanced and seen the world now governed virtually, An indication of the popularity acquired by the use of the Internet was the emergence of sites specifically designed for the transmission, opinion and creation 
75

of information by the population and recently the issue of social networks has become the boom of the world in which we live and is often associated with urban life, where millions of people spend their heads buried in their computers and cell phones, plugged into the virtual world. But the explosion of connections through the Net has not only changed the way of interacting in big cities. Rural areas, traditionally more remote and disconnected, are also being transformed by the emergence of these new technological tools. This impact is clearly felt all over the world and because of this, the following study has been carried out with data collection related to the "Rural-urban dichotomy on the use of social networks", in the city of Cuenca.

Keywords: Irreplaceable tools, social networks, virtually, urban life, rural areas.

Desde que internet ha estado al alcance de las personas, se ha vuelto una prioridad para la mayoría en tener un medio de comunicación para estar conectados, mientras que otros no disponen de los recursos necesarios para obtener una red social. Esto se ha convertido en una necesidad para las personas en su día a día como: los estudiantes, maestros, empresas, padres de familia etc. Como dijo Litwin (2005) "Desde las escuelas elementales hasta las unidades académicas universitarias, las tecnologías se utilizan como herramientas para favorecer las comprensiones" (p. 5). Debido a estos cambios, las redes han llegado a influir en nuestra forma de pensar e interactuar. 


\section{6}

Como hace énfasis Sluzki (1996) ha considerado a la red social como una estructura capaz de influir sobre la satisfacción individual y la calidad de vida; al parecer, las redes funcionales y socialmente sensible producen mayores sentimientos de satisfacción en sus integrantes, mientas que aquellas redes reducidas, con pocos niveles de participación social y un margen estrecho de intentar cambios, implica una reducción de la posibilidad de acceder a recursos sociales provechosos para los individuos, desde los cuales se pueda favorecer a la adaptación y contrarrestar las adversidades (1996).

Esto ha creado en la sociedad nuevas culturas, debido a que al estar en un constante contacto con los demás, nos alimenta de nuevos conocimientos. Así también las redes sociales sirven como un instrumento para identificarse en el ámbito de la comunicación, todas las personas de diferentes edades han conseguido sus propias cuentas de Facebook, Instagram, Twitter, YouTube, y ahora Tiktok, que en estos tiempos ha tomado una popularidad inmensa, por ser una herramienta fácil de usar, intuitiva e interactiva entre otras, como dijo Van Dijck (2019) "Estos son inventos que presentan de manera sencilla algoritmos complejos que presentan una inmensa cantidad de datos sobre gustos, preferencias y afectos" (p. 2), pero no todos saben utilizar bien estas aplicaciones, unos lo hacen por diversión, necesidad o popularidad. Ya que la manera en las que usamos las redes sociales varía entre los jóvenes, adultos, y personas de la tercera edad. 


\section{7}

Lo que se puede tornar complicado es el hecho de que no todos tienen el mismo poder adquisitivo que los demás, siendo este el caso de personas que habitan en las zonas rurales y muchas veces por cuestiones personales no han logrado progresar en su ámbito económico, como describe José Ávila "La utilidad de las redes sociales consiste en las aplicaciones de sus fundamentos sobre los patrones de salud, bienestar y desarrollo de la calidad de vida de los individuos que pertenecen a comunidades o poblaciones en condiciones de desventaja" (2012, p. 49), esto les genera una manera completamente distinta de pensar y entender las redes sociales, muchos de ellos lo ven como algo innecesario en sus vidas, lo tienen en un punto secundario no relevante, a consecuencia que nunca le han dado mucha importancia. Esto puede ser positivo o negativo tanto en lo rural y urbano por sus diferencias.

La zona rural por el simple hecho de que viven con más plenitud y pueden mantener alejados de la tecnología, pero al mismo tiempo están desinformados de los hechos más relevantes en la sociedad. La zona urbana que se mantiene en constantes actualizaciones de información y tecnología, siendo así, nos limita a tener vidas muchas de las veces encerrados en casa sin experimentar todo lo que nos ofrece el mundo exterior, por pasar muchas horas sentados junto a la computadora o estar todo el día con nuestros celulares a la mano, enchufados a un mundo virtual.

\section{Uniendo lo rural y urbano}

Observando más allá de cómo las redes sociales han afectado nuestras vidas y el cómo nos hemos dejado in- 
fluenciar por la tecnología, hay situaciones en las que se produce todo lo contrario tal es el caso de muchas personas que se han visto beneficiadas y han mejorado sus estilos de vida, se puede relacionar con lo que dice José Ávila "La pertenencia a la red social garantiza un mejor nivel de adaptación ante las adversidades y mayores posibilidades de afrontamiento de las condiciones difíciles a las cuales se enfrenta el individuo" (2012, p. 50). Este fenómeno ha transformado el comercio rural permitiendo que hombres y mujeres del campo también usen las redes para educarse e informarse sobre nuevas tecnologías y métodos de trabajo, formas de venta y ganancias expandiendo sus negocios a nuevas fronteras y dándose a conocer en la sociedad. La educación en las zonas rurales han permitido que niños y jóvenes accedan a escuelas con la intención de tener una mejor educación más apropiada para su futuro, se ve reflejado hoy en día, debido a que influye en nuestra sociedad mejorando la vida de muchos campesinos que han logrado adaptarse a los cambios culturales como la tecnología y las redes sociales, quizás es donde más se siente este impacto de la comunicación del día a día de un bien necesario para muchas personas que estuvieron desconectadas del mundo por demasiado tiempo.

Incluso muchas empresas de la zona urbe han llegado a tener acuerdos con personas provenientes del campo, en el ámbito de alimentos que es una necesidad primordial para la sociedad, a través de acuerdos que benefician a ambas partes, gracias a las nuevas tecnologías y redes sociales. $\mathrm{Si}$ bien es notable cómo internet y las redes sociales han modificado nuestro estilo de vida, en muy poco tiempo, lo 
cierto es que esta transformación no es uniforme con toda la población, habiendo sociedades que evitan la tecnología por costumbres o una ética moral.

\section{Metodología}

La metodología que se implementó en este estudio se basa en un enfoque cuantitativo, donde se implementaron varias encuestas, a partir de una hipótesis específica, esto ayudó a poner en práctica el estudio, se desarrolló un diseño etnográfico o también llamado Netnografia, los resultados obtenidos serán interpretados más adelante para analizar el comportamiento de un grupo social. Para la recopilación de datos se utilizó una muestra estratificada mediante un cuestionario de preguntas cerradas, en un periodo de diez días que se llevaron a cabo del 2 de julio hasta el 12 de julio, se optó por esta opción por el hecho de que se buscan respuestas directas y concretas, que fueron formuladas en un cuestionario de once preguntas, y se tomó siete de ellas para su debido análisis, en la que se revisa si Facebook es la red social con mayor incidencia, solo con revisar sus cuentas locales más concurridas o WhatsApp es otro modo simple de comunicarse, ampliamente utilizado, que progresivamente ha ido sustituyendo a las llamadas cortas y a la mensajería celular, se optó por realizar la encuesta ya mencionada a veinticinco personas de la zona rural y veinticinco personas de la zona urbana, la cual trata sobre las redes sociales más utilizadas en las respectivas zonas, nuestras hipótesis son las siguientes: 
- Los habitantes de la zona urbana utilizan con más frecuencia TikTok.

- Instagram es la red social más frecuentada por la zona rural y urbana.

- Facebook es la red social más utilizada en la zona rural.

\section{Resultados}

La puesta en práctica y el periodo en que se realizó este estudio fueron cruciales para la obtención de datos, en la zona rural y urbana de Cuenca, elaborado a través de una minuciosa encuesta a cincuenta personas, veinticinco de ellos/as pertenecientes a su respectivo sector ya mencionado, se ve reflejado en el gráfico de barras que realizamos, en donde obtuvimos los siguientes resultados.

Figura 1

Aplicación de edad (personas)

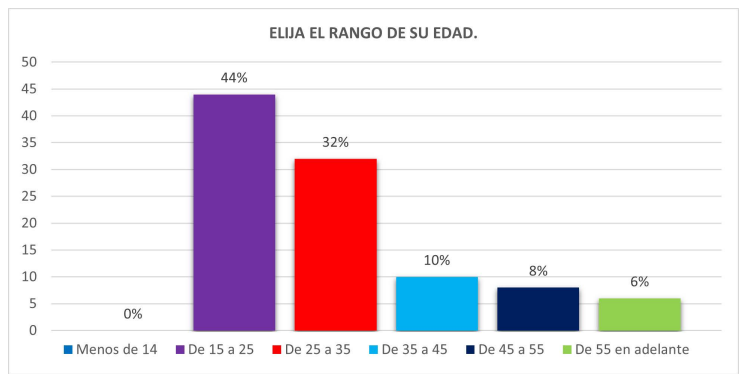

Fuente: Elaboración propia

El seguimiento que se realizó, da como resultado el rango de edad de varios usuarios que frecuentan una red 


\section{1}

social, la gran mayoría oscila entre los 15 a 25 años, esta cuenta con un porcentaje del 44\%, y los que lo usan con menor frecuencia son las personas que sobrepasan los 55 años de edad, cuentan con un $6 \%$ respectivamente, se observa la disminución en el uso de redes dependiendo el rango de la edad de personas jóvenes a persona mayores.

\section{Figura 2}

Disponibilidad de red inalámbrica

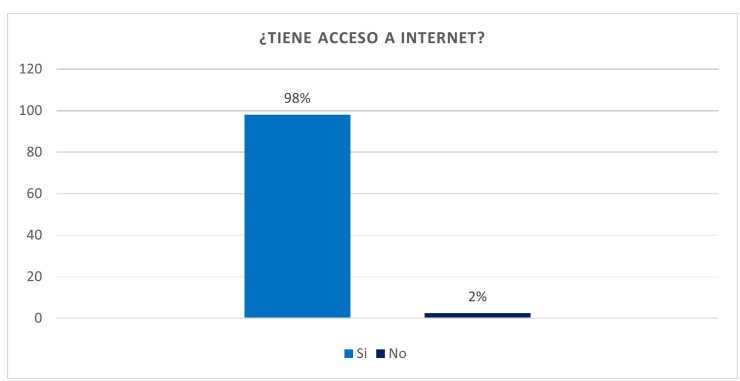

Fuente: Elaboración propia

Los resultados obtenidos manifiestan en el presente gráfico, un 98\% de resultados y que las personas encuestadas, tienen la posibilidad y disponibilidad de acceder a redes inalámbricas la cual puede ser utilizada en cualquier aparato electrónico que posean, el otro $2 \%$ no dispone de esta debido a su avanzada edad, o no ven necesidad de optar por una red inalámbrica. 
Figura 3

Porcentaje de usuarios con red social

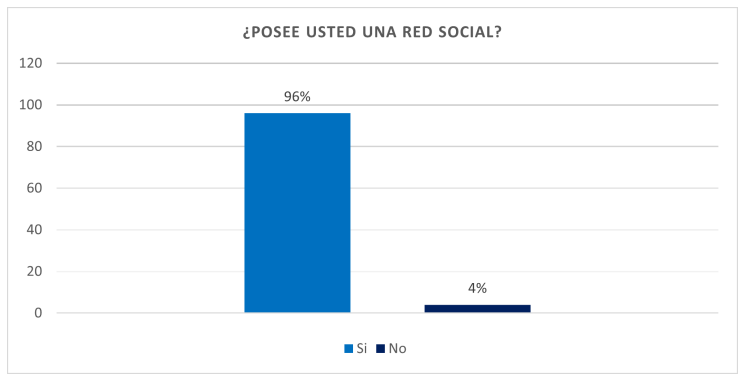

Fuente: Elaboración propia

La puesta en práctica ante el uso de Facebook, Instagram, YouTube etc. demuestra un porcentaje mayor del $96 \%$ de personas que utilizan las redes sociales, y un $4 \%$ que no la poseen, como se mencionó anteriormente, esto se debe a que no disponen una red inalámbrica o son personas mayores que no ven la necesidad de optar por conseguir una red social o desconocer las funciones de esta.

Figura 4 Aplicación de actividades en redes sociales

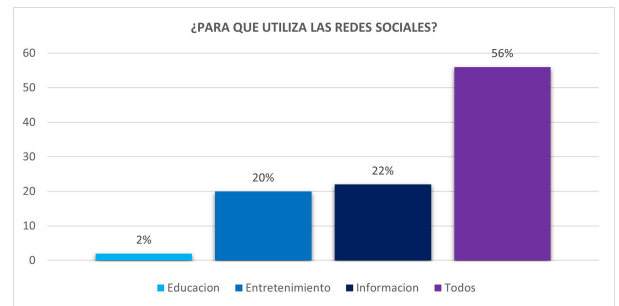

Fuente: Elaboración propia 


\section{3}

Este gráfico se dividió en 4 partes, educación, entretenimiento, información y la opción de todos, la gran mayoría opto por seleccionar la última opción, que englobaba todas las opciones ya mencionadas contando con un 56\%, mientras que la minoría que es un $2 \%$ eligió la opción de educación únicamente.

En la hipótesis general, se partió de la idea de conocer cuáles de las siguientes redes sociales (Facebook, Instagram, YouTube, Twitter, TikTok, WhatsApp) son de las más utilizadas en la urbe cuencana, a partir de este estudio se consiguieron los siguientes datos.

\section{Figura 5}

\section{Porcentaje de redes sociales en zona urbana}

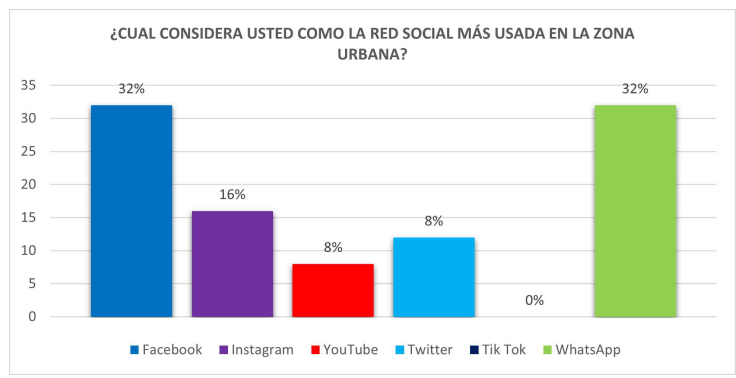

Fuente: Elaboración propia

Se mencionó que Tiktok es la red social más frecuentada en la zona urbana de Cuenca, y se obtuvo el siguiente resultado, en el que Facebook con un 32\% y WhatsApp con $32 \%$ son las redes sociales más utilizadas en la respectiva zona, teniendo en cuenta que están empatadas y sobrepasan por mucho a TikTok $0 \%$. 


\section{4}

Figura 6

\section{Red social más utilizada en Cuenca}

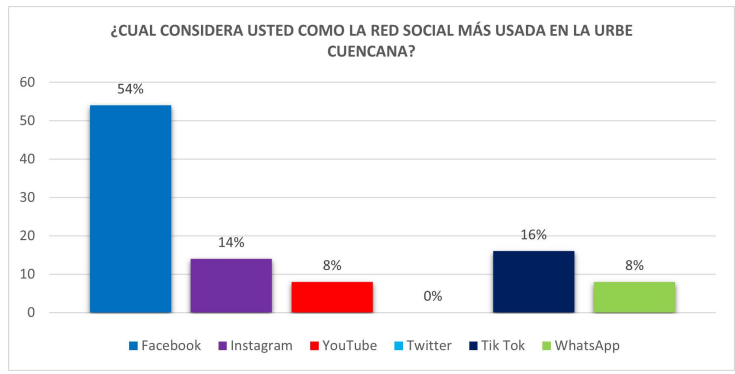

Fuente: Elaboración propia

Según lo analizado, en toda la urbe cuencana, gran parte de esta considera que Facebook es la que se frecuenta en su mayoría contando con un 54\% de las respuestas obtenidas, mientras que la menos considerada por parte de los ciudadanos cuencanos es Twitter que cuenta con un $0 \%$ de las respuestas obtenidas.

\section{Figura 7}

Porcentaje de redes sociales en zona rural

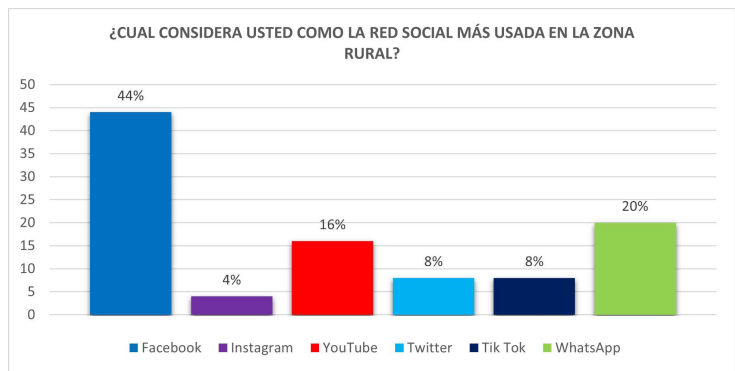

Fuente: Elaboración propia 


\section{5}

Con la última hipótesis y su primicia de que Facebook es la red social más utilizada en la zona rural, estos fueron los resultados obtenidos, se observa que la red social más frecuentada por las comunidades aledañas de Cuenca es la aplicación Facebook con un 44\%, mientras que las menos consideradas son Twitter y TikTok contando con el porcentaje más bajo de $8 \%$.

\section{Conclusiones}

Frente a los datos recaudados de esta investigación, pudimos conocer cómo se da el uso en las diferentes redes sociales, de los distintos sectores de la ciudadanía cuencana, concluimos que, en la primera hipótesis general, la mayor parte posee internet con un $98 \%$, el otro $2 \%$ no contaba con este recurso dada a su avanzada edad, mientras que, en la zona rural y urbana se cuenta con un $96 \%$ de personas que tienen acceso a una red social, el $4 \%$ faltante no cuenta con la misma, debido al problema ya mencionado con anterioridad. Este estudio nos llevó a la conclusión de que por su longevidad no saben utilizar estos medios, mientras que la gran mayoría que sí cuentan con una red social, utilizan esto para educarse, entretenerse e informarse, cada una de estas con un fin específico.

En la primera hipótesis específica, esta tenía la finalidad de demostrar que Tiktok estaba recibiendo un apoyo inmenso de la zona urbana, luego del análisis se pudo constatar que nuestra idea planteada anteriormente concluyó siendo errónea, debido al hecho de que es la menos usada, esta cuenta con un 0\%, y es Facebook con un 32\% la 
más popular, con estos porcentajes constatamos que nuestra idea propuesta estaba equivocada. Con estos resultados obtenidos, no quiere decir que esta aplicación no cuente con ningún usuario cuencano.

La segunda, con el análisis ya hecho se llegó a los siguientes resultados, con la premisa ya planteada con anterioridad, no se obtuvo el resultado esperado, siendo que Instagram no es la red social más usada en las distintas zonas, así pues, se obtuvieron estos resultados en la zona rural un $4 \%$, y en la zona urbana un $16 \%$. Aquí también se consiguió el mismo resultado, en el que Facebook sigue con su popularidad y cuenta con $44 \%$ en la zona rural y un $32 \%$ en la zona urbana.

El último punto se logró comprobar y fue la única premisa que sí se cumplió, ya que Facebook sí es la red social más usada en la zona rural, contando con un $44 \%$ de aprobación. En los resultados obtenidos, la mayor parte de la zona urbana acuden a esta aplicación por la gran diversidad que ofrece.

Recomendamos para un futuro estudio del mismo, que se deberá tomar en cuenta la cantidad de muestras realizadas, buscar una amplia cantidad de información en libros e incluso el método de encuestas presenciales deberá ser necesario, constatar que los contenidos no sean densos, utilizar un lenguaje estándar. Las limitaciones que presentó este estudio se debe principalmente por la pandemia del Covid-19 que el mundo atraviesa actualmente, debido a que las encuestas se tuvieron que aplicar de manera online, 


\section{7}

mediante Google formularios, si estas se hubieran llevado a cabo de manera presencial el estudio se hubiera visto más enriquecido, algo que afectó aún más el estudio realizado fue el hecho de que no todos somos habitantes de Cuenca y esto nos limitó al momento de realizar las encuestas.

\section{Bibliografía}

Ávila, J. (2012). Las redes sociales en el contexto comunitario: Redes sociales y análisis de redes. Azul y violeta Editores Ltda.

Litwin, E. (2005). Tecnologías educativas en tiempos de Internet. Amorrortu.

Sluzki, C. (1996). La red social: frontera de la práctica sistémica. Gedisa Editorial.

Van Dijck, J. (2019). La cultura de la conectividad: una historia crítica de las redes sociales. Siglo XXI Editores. 



\section{CApítulo IV Redes sociales en jóvenes $y$ adultos mayores cuencanos}

Amanda Guzmán-Heras

Universidad Politécnica Salesiana, Ecuador https://orcid.org/0000-0002-2822-8387

Tábata Figueroa-Sacoto Universidad Politécnica Salesiana, Ecuador https://orcid.org/0000-0001-8798-7036

\section{Resumen}

Las redes sociales como medio masivo de interacción tienen una gran audiencia, pero varía su uso en la edad de los usuarios. Este trabajo busca sobre todo mostrar el uso de las redes sociales en los jóvenes y adultos mayores conociendo el rango de incompatibilidad existente. Se basa en el análisis cualitativo que fue realizado a través de las 50 entrevistas usadas como técnica de recopilación de datos, aplicadas a una muestra de 25 jóvenes y 25 adultos mayores cuencanos. El análisis presenta la existencia de una desigualdad de uso y conocimiento en Facebook, Instagram y 
90

WhatsApp de los adultos mayores en comparación a los jóvenes. Esta investigación refleja que en la comunidad cuencana los jóvenes son los que predominan en el ámbito de las redes sociales mientras que los adultos mayores sufren una desventaja; este fue un estudio necesario, debido a que la falta de documentos similares impidió hacer la comparación de resultados.

Palabras clave: Internet, medios sociales, información, comunicación, joven, vejez.

\section{Abstract}

Social networks as a mass medium of interaction have a large audience, but their use varies according to the age of the users. This work seeks above all to show the use of young and old people in social networks knowing the range of incompatibility that exists. It is based on the qualitative analysis that was carried out through the 50 interviews used as a data collection technique, applied to a sample of 25 young people and 25 older adults from Cuenca. The analysis presents the existence of an inequality of use and knowledge in Facebook, Instagram and WhatsApp of older adults in comparison to younger adults. This research reflects that in the Cuenca community, young people are the ones who predominate in the social networking arena while older adults are at a disadvantage; this was a necessary study because the lack of similar documents prevented the comparison of results. 


\section{1}

Keywords: Internet, social media, information, communication, youth, old age.

El internet ha revolucionado la forma en que las personas se comunican y los procedimientos de interacción a nivel interpersonal se modificaron en los últimos años, sin embargo ¿es el internet el epicentro del acceso a contenidos inapropiados?, o quizás ¿son espacios complejos que excluyen a los faltos de conocimiento en esta área? Nuestro trabajo pretende segmentar estas reacciones desde la perspectiva adulta como la juvenil, e identificar los posibles resultados de la capacidad para utilizar las nuevas tecnologías, como herramienta de trabajo o por puro placer. Al mismo tiempo que se presentará una atmósfera comparativa, puesto que los adultos mayores generan una notable diferencia de uso a contraste con los jóvenes, estos efectos que justificarán nuestra investigación serán sustentados bajo el nivel emocional y físico, secuela directa de la conexión interactiva digital (Torres-Toukoumidis \& De Santis, 2020).

La acción investigativa aplicada también accederá a las diversas plataformas sociales, que a pesar de que coexisten dentro de una misma estructura, será fundamental diferenciar algunas de las más importantes plataformas, para la correcta descripción del uso e impacto en los adultos y jóvenes, pues sus funcionalidades corresponden a diversas operaciones digitales que adquieren cierto nivel de dificultad. Entre ellas estará Facebook, compañía de servicios de redes sociales, Instagram que se basa mucho más en la identidad personal del sujeto en vez de en la identidad relacional. WhatsApp de la misma forma corresponderá a la 
lista de redes que entran en secuencia de análisis de impacto, debido a que forma parte del medio digital en potencia entre las redes sociales más destacas, complementando su relación con los sujetos de estudio.

La comunicación móvil resultante de encapsular todo este proceso interactivo digital de redes en diversos dispositivos, también formarán parte del estudio de escenarios, sobre las que se apoyan muchas de las dimensiones que caracterizan a las culturas juveniles que conservan más destreza para desenvolverse dentro de estas redes, a comparación de los adultos mayores; sin embargo, este no será un impedimento pues existen expertos que han generado redes de apoyo enfocadas a esta población, formando así un grupo capaz de interactuar y formar parte de este acelerado mundo de las relaciones vía internet, haciendo que su rango de edad no sea un limitante.

\section{Redes digitales y su carácter de uso en los jóvenes}

El planteamiento de diversas fuentes facilita el estudio respectivo por medio de algunos resultados ya existentes, estos aspectos se van a desenvolver en un orden secuencial, partiendo desde internet, la base de todo este conjunto abarcado desde los estudios realizados por la Universidad de Rosario "propuso que la existencia de déficits en autoestima y una elevada impulsividad predecirían el uso problemático de internet" (Moral-Jiménez \& Fernández- Domínguez, 2018, p. 113). 
Desvinculándonos del uso personal, el internet ha suministrado facilidades al progreso del aprendizaje interactivo, con nuevas herramientas que promueven la realidad virtual en diversas esferas de conocimiento, un estudio exploratorio de la Universidad Oberta de Cataluña explica que "la posibilidad de beneficiarse debido a habilidades de uso, tan solo se da en entornos educativos altamente favorables a la tecnología y dónde se fomenta la interacción como parte del proceso de enseñanza-aprendizaje" (Castaño et al., 2015, p. 33).

La división de cuestionamientos centra los estudios en dos posibilidades de uso, el académico progresista digital y la aplicación individual problemática juvenil, no obstante, en Ecuador se aprecia una variabilidad en sus dimensiones pues "ha bajado el porcentaje de uso de redes sociales de jóvenes de 13 a 18 años que antes representaba el 28\% en el 2014 y ahora el 18\% para fines de 2016 e inicios 2017" (Guaña-Moya et al., 2018, p. 229).

Continuando con esta secuencialidad, se mostró las variables positivas y negativas que ofrece el internet, y a esto se incorporan las diferentes redes sociales, la razón por la que los jóvenes acceden a internet; por lo cual se encontró un estudio publicado por el Tecnológico de Monterey que explica el de uso que le dan los jóvenes a la red social de Facebook. "Los resultados obtenidos indican que el 77.5\% de la muestra utiliza Facebook todos los días de la semana; un $48.5 \%$ lo utiliza de 1 a 3 horas diarias y un $27.0 \%$ menos de una hora" (Valerio \& Serna 2018, p. 23). 


\section{4}

En relación con el manejo de Facebook por parte de los jóvenes, otro estudio publicado por la Universidad de Alicante indica las variables por las que esta red social se puede ver abandonada por sus usuarios, entre ellas están "La competencia de otras redes sociales como Instagram y TikTok resultan más atractivas para el público joven, asimismo, existe un elevado riesgo de ciber-crimen para la obtención de cierta información y otros delitos" (Palao-Pedrós \& Baez-Devesa, 2020, p. 43).

Con respecto a WhatsApp, un estudio realizado por la Revista Internacional de Psicología del Desarrollo y la Educación, detalla las formas de uso diferenciadas por géneros, en donde "Un 40,9\% de las mujeres señalan que están muy enganchadas a esta aplicación, frente a un 25,4\% de los varones" (del Barrio-Fernández \& Ruiz-Fernández, 2017, p. 28). Mientras que, el uso ilimitado de WhatsApp con relación al ámbito académico no presenta una asociación negativa, pues una investigación determinó que:

Los estudiantes con una calificación de 10 recibieron en promedio 533 mensajes diarios; seguidos de los estudiantes con calificación de 8, con 476 mensajes; $y$, las calificaciones de 9 y 7 , con 446 y 358 mensajes, respectivamente. (Rodríguez-Martínez et al., 2016, p. 22).

Por el contrario, la aplicación de WhatsApp también es una vía rápida para el acoso, pues la Revista Iberoamericana de Psicología y Salud explica que "El discurso de los agresores fue coincidente con el de las víctimas, confirmando la agresión por WhatsApp" (Giménez-Gualdo et al., 2014, p. 126). Por otra parte "Instagram ofrece un 


\section{5}

conjunto de potencialidades que permiten a los usuarios 1) gestionar su perfil, 2) publicar fotos y vídeos y comentarlos; y 3 ) compartir historias" (Pérez \& Cassany, 2018, p. 84). Asimismo, la variable del género "muestra que tanto los hombres como las mujeres más extrovertidas de la muestra tienden a seguir a más usuarios en Instagram, aunque los hombres publican más que las mujeres" (Casado-Riera \& Carbonell, 2018, p. 28).

Además, en el ámbito educativo "Instagram se ha convertido para las universidades privadas españolas en un canal de comunicación del que se puede obtener información de la institución académica cultural y, en ocasiones, social" (Alcolea-Parra et al., 2020, p. 128). Mientras que, en el Ecuador "Instagram es el medio social con menor uso por parte de las universidades del país, pues solo 15 de las 51 Instituciones de Educación Superior (IES) tienen una cuenta en esta red" (Abendaño-Ramírez et al., 2018, p. 6).

\section{Adultos mayores y la complejidad digital}

Las redes sociales "integradoras de una persona con su entorno social” (Montes de Oca, 2005). Analizadas desde el punto de vista de los adultos mayores, obligan a realizar un estudio de uso y conocimiento sobre estas, debido a que el uso que le dan tiene un objeto que es "comunicarse, aprender y facilitar sus actividades diarias y de ocio" (Agudo et al., 2012). Dependiendo fundamentalmente de los "ingresos, nivel educativo y familia" (Peral-Peral et al., 2015 , p. 58). Pero al mismo tiempo las redes sociales "pueden ser una fuente de bendiciones mezcladas" (Rook, 2015, 


\section{6}

p. 47). Pues es un ejercicio en el cual los adultos mayores no están acostumbrados a ejercer, pero de igual forma necesitan ser vistos como personas participes de una sociedad.

En la actualidad, hay un número escaso de redes sociales destinadas a los adultos mayores y por tal motivo "Los sitios web podrían empezar a considerar en serio a los usuarios senior y crear herramientas pensadas para esta población” (Admin, 2019). Y esta implementación podrá causar efectos positivos en ellos como menciona la CENIE (2018) "habilidades cognitivas mejoradas, disminución de la soledad, entretenimiento y nuevas oportunidades" de igual forma indica Barroso y Aguilar (2016).

El uso de redes sociales por parte de los adultos mayores varía y depende de la accesibilidad de cada usuario "Pew Research, un centro de investigación de Estados Unidos, afirma que hay más de 39 millones de usuarios de Facebook, Twitter y Skype que superan los 65 años" (Rubí, 2019, p. 182). Pero con respecto a la accesibilidad en Facebook, la Universidad Nacional de la Patagonia Austral realiza estudios considerando propiedades ligadas a la calidad y usabilidad de estos medios, con el objetivo de evaluar la experiencia del usuario manifestando que:

La falta de conocimiento sobre algunas funcionalidades específicas de la red social, dificultades al subir imágenes y falta de práctica son barreras de uso. Además, una preocupación es en cuanto a su privacidad, temen que sus perfiles sean usados para publicaciones que ellos no realizaron, o que cuando aceptan un sitio comercial o público se viole su privacidad. (Miranda et al., 2014, p. 132) 
Y varios testimonios acompañaron otras investigaciones, pues aportando al ámbito de usabilidad mencionaron que "no pudieron realizar y entre las dificultades señaladas, aparece "No lo encontró" como causa principal y "Se desorientó" y "No lo entendió" como otras causas no $\tan$ frecuentes" (Cardoso et al., 2017, p. 16).

Pero es necesario reconocer que a pesar de esto, muchos adultos mayores se arrojan a la aventura que experimentan en las diferentes redes sociales, y "Facebook también les gusta porque les permite mantenerse vinculados a intereses y aficiones y porque es una red que facilita las relaciones intergeneracionales" (Aquino, 2017). También la Revista Comunicar realiza un estudio y plantea los siguientes resultados:

El 51,2\% de los mayores de la muestra había utilizado una red social, de los cuales, el $77,6 \%$ tenían creado un perfil. El $44,1 \%$ tenían perfil en una sola red, el $14,2 \%$ en dos y $5,1 \%$ en tres. [...] el 93,1\% usaba Facebook, el 26,7\% Twitter y un 22,7\% usaba otras redes sociales". (Peral-Peral et al., 2015, p. 61)

Analizando estos resultados nos permite dar cuenta de que "no existen dudas acerca de que Internet y la Web no solo significan un gran avance tecnológico, sino que también un cambio cultural, que correctamente adaptado puede contribuir a la inclusión social de los adultos mayores" (Cardoso et al., 2017, p. 16). Y sobre todo entender que "El acercamiento de las tecnologías con la tercera edad puede disminuir la creciente brecha generacional entre ellos y las nuevas generaciones" (Muñoz, 2013). 


\section{Metodología}

Esta investigación se fundamenta en un análisis crítico de enfoque cualitativo-deductivo con un diseño metodológico etnográfico, utilizando la observación directa y entrevistas como instrumentos de recopilación de datos. Cuyo objetivo general es identificar el uso de las redes sociales en jóvenes y adultos mayores cuencanos, teniendo en cuenta los siguientes objetivos específicos: 1) Determinar las dificultades digitales que tienen los jóvenes y adultos mayores en Facebook; 2. Descubrir el nivel de conocimiento que tienen los jóvenes y adultos mayores en Instagram; 3. Comparar los resultados de jóvenes y adultos mayores cuencanos sobre el uso de WhatsApp. Para llevar a cabo la construcción de las entrevistas se tomó en cuenta las diferencias de edad y conocimiento de la muestra en este estudio para así justificar su objetivo.

En este sentido, se realizaron entrevistas compuestas por 7 preguntas que parten desde las redes sociales como eje general, hacia las específicas que son Facebook, Instagram y WhatsApp. Estas se estructuraron a partir de 2 preguntas generales, para introducir el tema a los participantes, la primera de conocimiento y la segunda de opinión, además de 5 preguntas estructurales y específicas para responder a los objetivos anteriormente planteados, estas tienen la finalidad de determinar el grado de conocimiento, demostrar las diferencias tanto en tiempo como en habilidad y entender los distintos puntos de vista. 
De la población cuencana se seleccionó una muestra de 50 personas y se realizó un muestreo no probabilístico por conveniencia. Con lo que respecta a los instrumentos de recolección de datos, la observación se realizó de forma participativa y estructurada; además, las entrevistas se aplicaron a 25 personas jóvenes, desde la edad de 15 años hasta los 25 y 25 adultos mayores desde los 60 años en adelante. De las 50 entrevistas, 35 se establecieron de forma online o vía telefónica y los 15 restantes de forma presencial, en un determinado tiempo de 6 días desde el 3 de julio hasta el 8 de julio.

\section{Resultados}

En esta sección se analizó las respuestas de las entrevistas, obteniendo resultados que reflejan lo siguiente:

\section{Dificultades digitales en la red social Facebook}

De los 25 jóvenes entrevistados, se determinó que el $4 \%$ no cuenta con esta red social, el otro $8,33 \%$ indica que esta aplicación tiene un rango de dificultad intermedio, debido a que Facebook cuenta con muchas herramientas y varias funcionalidades, además recalcan que no tienen buena relación con la tecnología y el $88 \%$ restante manifiesta que esta red social no presenta alguna dificultad, pues mencionan que la cotidianidad y costumbre de uso permite tener el conocimiento básico, añadiendo que Facebook tiene herramientas indicadoras, presenta un interfaz amigable y sus actualizaciones sencillas generan espacios a más usuarios. 
100

En lo que se refiere a los adultos mayores, el $36 \%$ no tiene Facebook, al 56,25\% le resulta difícil operar esta red social pues la utilizan poco tiempo y mencionan que esta aplicación no se adapta a su edad, indicando que sus funcionalidades están destinadas para las personas jóvenes; finalmente, el 7\% restante menciona que no les parece difícil, ya que le dedican tiempo a publicar imágenes, revisar comentarios y ver noticias haciendo fácil su uso.

Descubrir el nivel de conocimiento que tienen los jóvenes y adultos mayores en Instagram

Para descubrir el nivel de conocimiento de los jóvenes se analizó que, de los 25 jóvenes entrevistados, 24 tienen la red social de Instagram y un amplio conocimiento sobre esta; mientras que, solo uno no cuenta con esta red social, pero sí comprende el uso de esta red. Asimismo, en los adultos mayores se demostró todo lo contrario, pues de los 25 entrevistados solo 2 personas cuentan con esta aplicación y los 23 restantes no tienen Instagram ni tampoco conocen para qué funciona, ni cómo usarla.

Los jóvenes y adultos mayores mencionaron las diferentes actividades que permite realizar esta red social; por lo que, en la siguiente tabla se detallará los aportes obtenidos. 
101

\section{Tabla 1}

\section{Indicadores del nivel de conocimiento de los entrevistados}

\begin{tabular}{|l|l|l|}
\hline Entrevistados & \multicolumn{1}{|c|}{ Tiene conocimiento } & \multicolumn{1}{c|}{ No tiene conocimiento } \\
\hline Jóvenes & $\begin{array}{l}\text { Entre los cometarios } \\
\text { mencionados, el 100\% } \\
\text { demuestra tener cono- } \\
\text { cimiento, a través de los } \\
\text { siguientes comentarios: } \\
\text { "Instagram permite reali- } \\
\text { zar videos, directos, subir } \\
\text { y ver fotos personales o de } \\
\text { personas famosas, tam- } \\
\text { bién permite chatear con } \\
\text { amigos mediante audios, } \\
\text { fotos o mensajes y sobre } \\
\text { todo es una aplicación } \\
\text { que se usa mucho para } \\
\text { crear publicidades y cono- } \\
\text { cer tiendas virtuales". } \\
\text { Y el único entrevistado } \\
\text { que no tiene esta red so- } \\
\text { cial menciona si conocer } \\
\text { qué actividades se pueden } \\
\text { realizar en esta. }\end{array}$ & \\
\hline $\begin{array}{l}\text { Es necesario recalcar que } \\
\text { el 8\% de los participantes } \\
\text { tiene un conocimiento } \\
\text { limitado, pues indicaron } \\
\text { que: "Instagram permite } \\
\text { ampliar información y } \\
\text { saber de farándula". }\end{array}$ & $\begin{array}{l}\text { El 92\% de los entrevistados } \\
\text { indica no tener conocimiento, } \\
\text { pues nombran lo siguiente: } \\
\text { "No conozco, yo no sé nada de } \\
\text { eso, es nuevo para mí, no ten- } \\
\text { go idea, esas cosas son hechas } \\
\text { para la juventud y ni si quiera } \\
\text { he escuchado esas cosas". }\end{array}$ \\
\hline
\end{tabular}

Fuente: Elaboración propia 
102

Comparar los resultados de jóvenes y adultos mayores cuencanos sobre el uso de WhatsApp

En esta parte se comparó los resultados de las 50 personas entrevistadas, obteniendo que el 100\% de los jóvenes sí tienen esta aplicación; mientras que, en los adultos mayores el $56 \%$ cuenta con esta red social y el $44 \%$ no la tiene. Adicionalmente, se analizó el uso que le dan a WhatsApp y se extrajo que lo jóvenes lo utilizan para chatear con amigos o familia, realizar llamadas o videollamadas de forma rápida y sencilla, efectuar actividades laborales y sobre todo académicas; por el contrario, los adultos mayores que sí tienen WhatsApp lo usan para comunicarse con familia cercana al igual que con los que están en otro país y los que no usan, señalaron que no entienden, no saben utilizar y que no les gusta la aplicación.

Se identificó el tiempo que los entrevistados usan WhatsApp, definiendo que el $28 \%$ de jóvenes usa un máximo de 2 horas diariamente, el otro $40 \%$ utiliza de 3 a 4 horas diariamente y el $32 \%$ restante usa más de 4 horas al día; en cambio, de los 14 adultos mayores el 52\% usa un rango menor a 1 hora y el $8 \%$ utiliza más de 2 horas diariamente. La siguiente figura representa el número de horas que usan la mayoría de jóvenes y adultos mayores. 
103

\section{Figura 1}

Representación del promedio de horas que usan la mayoría de jóvenes y adultos mayores en WhatsApp

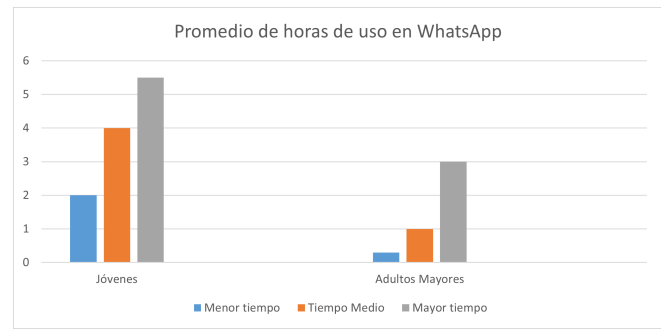

Fuente: Elaboración propia

\section{Conclusiones}

De lo anterior, se puede concluir que existe una evidente desigualdad en el uso de las diferentes aplicaciones por parte de los adultos mayores en comparación a los jóvenes. El análisis de las dificultades digitales en Facebook demuestra que ningún joven presenta problemas al manejarla, mientras que los adultos mayores un 56\% presentan complejidad en esta; además, se concluyó que el nivel de conocimiento de los adultos mayores en Instagram es escaso, dado que solo el $8 \%$ comprende su funcionalidad y en los jóvenes el 100\% demuestra conocer esta aplicación en su totalidad; por último, se comparó que el $100 \%$ de jóvenes tiene WhatsApp en sus celulares y que su uso es superior al de los adultos mayores, pues solo el 56\% cuenta con esta aplicación, en consecuencia se establece que el uso 
104

de WhatsApp, Facebook e Instagram de los adultos mayores es inferior al de los jóvenes.

Se constata que en este estudio los jóvenes tienen mayores facilidades para usar Facebook, WhatsApp y un amplio conocimiento de Instagram, pero los adultos mayores no. Por lo que, el entorno familiar debe incentivar al adulto mayor a no permanecer en la ignorancia solo por su edad, pues ahora las nuevas tecnologías facilitan la comunicación a distancia, dado que es un fundamento importante; asimismo, los jóvenes necesitan encontrar un equilibrio en el uso de las redes sociales debido a que la frecuencia de uso que tienen debe buscar su beneficio.

Esta investigación presentó algunas limitaciones, primero la falta de documentos sobre las redes sociales en jóvenes y adultos mayores cuencanos, impidió que se usara la documentación como técnica de recolección de datos; también, es necesario recalcar que estas entrevistas fueron realizadas en época de cuarentena por lo que tuvieron que ser aplicadas vía online; este fue un obstáculo debido a que los adultos mayores no podían utilizar con eficiencia este medio, obligándonos a realizar estas entrevistas por vía telefónica y de forma presencial. Del mismo modo, algunas entrevistas se aplicaron a personas de más de 85 años, las cuales no tuvieron la capacidad de responder, pues la edad en este caso sí era un limitante.

Finalmente, para las futuras investigaciones se recomienda que, este estudio sea realizado con un enfoque cuantitativo para obtener resultados con escala de actitudes; a la 


\section{5}

par, es necesario ampliar esta investigación a todo el territorio ecuatoriano para conocer los datos de cada región y que estos sean analizados, dependiendo de las zonas rurales como urbanas para así definir si esto representa un cambio.

\section{Bibliografía}

Abendaño-Ramírez, M., Velásquez-Benavides, A., Duque-Rengel, V., \& Rodríguez-Castillo, J. (2018). Relación entre el uso de medios sociales de las universidades del Ecuador vs. el consumo de los millennials. https://bit. ly/2CVD6Y2

Admin. (22 de febrero de 2019). Los adultos mayores, un público emergente en las redes sociales [Mensaje en un Blog]. https://bit.ly/32o6bnV

Agudo, S., Pascual, M.A., \& Fombona, J. (2012). Usos de las herramientas digitales entre las personas mayores. Comunicar, 39(20), 193-201. http://dx.doi.org/10.3916/ C39-2012-03-10

Alcolea- Parra, M.A., Barba, D.R., \& Fernández, V.N. (2020). El uso corporativo de Instagram en las universidades privadas españolas. Estudio comparativo de 35 universidades. Ámbitos. Revista Internacional de Comunicación, (47), 109-134. https://doi.org/10.12795/ambitos.2020.i47.06

Barroso, J., \& Aguilar, S. (2016). Las personas mayores y las redes sociales. un análisis de la situación actual. Aula de Encuentro, 1(18), 228-250. https://bit.ly/3hwEks2

Cardoso, C., Martin, A., \& Saldaño, V. (2017). Los adultos mayores y las redes sociales: analizando experiencias para mejorar la interacción. Unpa, 9(2), 1-29. http://dx.doi. org/10.22305/ict-unpa.v9i2.244.

Casado-Riera, C., \& Carbonell, X. (2018). La influencia de la personalidad en el uso de Instagram/The influence of personality on Instagram use. Aloma: Revista de Psicología, 


\section{6}

Ciències de l'Educació i de l'Esport, 36(2). http://orcid. org/0000-0002-9714-1568

Castaño, J., Duart, J., \& Sancho-Vinuesa, T. (2015). Determinantes del uso de Internet para el aprendizaje interactivo: un estudio exploratorio. New approaches in educational research, 4(1), 25-34. http://dx.doi.org/10.7821/ naer.2015.1.93

CENIE (31 de Julio de 2018). Las redes sociales y los adultos mayores [mensaje en un Blog]. https://bit.ly/34y2yOE

Del Barrio-Fernández, Á., \& y Ruiz-Fernández, I. (2017). Hábitos de uso del Whatsapp por parte de los adolescentes. Revista Internacional de Psicología del Desarrollo y la Educación, 2(1), 23-30. https://doi.org/10.17060/ijodaep.2017.n1.v2.915

Giménez-Gualdo, A. M., \& Maquilón-Sánchez, J. J., \& Arnaiz-Sánchez, P. (2014). Acceso a las tecnologías, rendimiento académico y ciberbullying en escolares de secundaria. Revista Iberoamericana de Psicología y Salud, 5(2), 119-133. https://bit.ly/3hzyEgY

Guaña-Moya, J., Quinatoa-Arequipa, E., \& Larrea-Torres, L. (2018). Estudio preliminar del uso de las redes sociales en los jóvenes ecuatorianos. Revista PUCE, (106), 224234. http://dx.doi.org/10.26807/revpuce.v0i106.137

Miranda, M., Martin, A., Saldaño, V., \& Gaetan, G. (2014). Usabilidad y accesibilidad en las redes sociales, una experiencia de usuarios adultos mayores en Facebook. UNPA, 6(2),

118 -140. http://dx.doi.org/10.22305/ict-unpa.v6i2.98.

Montes de Oca, V. (2005). Redes comunitarias, género y envejecimiento. UNAM.

Muñoz, F. (2013). Red social para integración de personas de la tercera edad (Tesis de grado). https://bit.ly/2EyC1Gg

Palao-Pedrós, L., \& Baez-Devesa, V. (2020). El futuro crecimiento de las redes sociales: Instagram, Facebook y Tiktok. Repositorio Institucional de la Universidad de Alincante, 42-47. 


\section{7}

Peral-Peral, B., Arenas-Gaitán, J., \& Villarejo-Ramos, A. (2015). From digital divide to psycho-digital divide: Elders and online social networks. Comunicar, 23(45), 57-64. doi:10.3916/C45-2015-06

Rodríguez-Martínez, M.C., Valerio-Ureña, G., Cárdenas-Anaya, C.A., \& Herrera-Murillo, D.J. (2016). Percepción y realidad del uso de WhatsApp en estudiantes universitarios de ciencias de la salud. FEM: Revista de la Fundación Educación Médica, 19(3), 118-124. https://bit. $\mathrm{ly} / 3 \mathrm{aV} 142 \mathrm{~h}$

Rook, K. (2015). Las redes sociales en la tercera edad: sopesando los efectos positivos y negativos para la salud y el bienestar. Current Directions in Psychological Science, 24(1), 45-51. https://bit.ly/2YAiUm9

Rubí, M. (29 de marzo de 2019). El uso de las redes sociales en la tercera edad [Mensaje en un Blog]. https://bit. ly/3b0ajOD

Pérez-Sinusía, M., \& Cassany-Comas, D. (2018). Escribir y compartir: prácticas escritas e identidad de los adolescentes en Instagram. Aula de Encuentro, 20(2), 75-94. https:// dx.doi.org/10.17561/ae.v20i2.5

Torres-Toukoumidis, A., \& De Santis, A. (2020). YouTube y la comunicación del siglo XXI. Ciespal.

Valerio-Ureña, G., \& Serna-Valdivi, R. (2018). Social networks and psychological well-being of college students. Revista Electrónica de Investigación Educativa, 20(3), 19-28. https://dx.doi.org/10.24320/redie.2018.20.3.1796 



\section{Capitulo $\mathrm{V}$ \\ Lenguaje cuencano en las redes sociales}

Evan Arias-Sánchez

Universidad Politécnica Salesiana, Ecuador https://orcid.org/0000-0002-7105-5522

\section{Resumen}

Con la llegada de las nuevas tecnologías y con ellas las nuevas formas de comunicación, esta última parece estar cambiando la manera de interactuar de los seres humanos. El lenguaje contiene cultura, está dependiendo del lugar en el que se hable. Si bien el uso de estas plataformas digitales es opcional, pero ¿hasta qué punto pueden influir las redes sociales en la cultura de un grupo de personas? Esta investigación tiene como fin analizar dos factores, el coloquialismo o idiolecto de los cuencanos como también el uso del spanglish. El idiolecto sería el conservar la cultura mientras que el spanglish sería la amenaza de la misma. Para su observación, hemos optado por un modelo de estudio cualitativo de análisis del discurso por significación 
110

con una muestra de casi cien mil comentarios, por parte de los cuencanos, vertidos en la red social Facebook. El análisis corrobora la presencia del coloquialismo y spanglish en las redes, también la presencia de errores al momento de redactar un escrito. Este trabajo incide a ampliar el campo de estudio e incluir otras plataformas digitales para de esta manera teorizar de manera más contundente el impacto de las redes sociales en el lenguaje y por ende la cultura de un grupo de personas.

Palabras clave: Medios sociales, internet, coloquial, spanglish, Facebook, dialecto, cultura, tecnología, digital, transición.

\section{Abstract}

With the arrival of new technologies and with them new forms of communication, the latter seems to be changing the way human beings interact. Language contains culture, it is depending on where it is spoken. While the use of these digital platforms is optional, but how far can social networks influence the culture of a group of people? This research aims to analyze two factors, the colloquialism or idiolect of Cuenca people as well as the use of spanglish. The idiolect would be to preserve culture while the Spanish would be the threat of it. For its observation, we have opted for a qualitative study model of analysis of discourse by significance with a sample of almost one hundred thousand comments, by Cuenca people, posted on the social network Facebook. The analysis corroborates the presence of colloquialism and spanglish in the networks, also the 
111

presence of errors the time of drawing up a writing. This work aims to broaden the field of study and include other digital platforms in order to theorize more forcefully the impact of social networks on the language and therefore the culture of a group of people.

Keywords: Social media, Internet, colloquial, spanglish, Facebook, dialect, culture, technology, digital, transition.

"Uno de los rasgos más característicos de la identidad del habitante azuayo - y, obviamente, cuencano- es el llamado cantado o canto. Es decir, su peculiar sistema de entonación de las frases y las palabras" (Vásquez, 2018, p. 282). También posee una gama de vocablos y términos que se ha formado en el transcurso del tiempo, que ha surgido de habitantes bilingües (español-quichua), es decir, de la mezcla del idioma nativo con el de los colonos. Sabemos que lo que determina el habla particular es el contexto sociocultural, el lenguaje cuencano, al igual que el norteño (norte ecuatoriano), junto con el costeño, tiene su peculiaridad, no obstante, como lo dijo Vásquez (2018) "De las tres formas de entonación, ciertamente la que más llama la atención, es la azuaya o cuencana, y de ahí la opinión generalizada de que los cuencanos cantan" (p. 282).

Las redes sociales, son en la actualidad el medio de comunicación más usado, esta nueva forma de comunicación, ofrece a los usuarios un lugar común para desarrollar comunicaciones constantes a nivel global, la misma que ha tomado relevancia al punto de ser indispensable para; 
112

el negocio, el emprendimiento, el estudio y sobre todo, el entretenimiento.

Con la globalización de la comunicación también hay una globalización del lenguaje. Según Piaget e Inhelder (1976) el lenguaje se forma gradualmente y según Skinner (1957) el lenguaje se forma mediante el condicionamiento. Esta nueva manera de comunicación, como son las plataformas virtuales, con sus nuevas condiciones ha modificado el lenguaje. Hoy en día el hombre puede comunicarse con tan solo una imagen, emoticón, stickers, o gifs, y su receptor, hable o no su idioma, lo entenderá porque las redes sociales han creado, y lo siguen haciendo, su propio lenguaje, un lenguaje universal.

\section{Lenguaje en redes sociales}

Según la Infobae (2016) el español es la segunda lengua más usada en Facebook y Twitter. Y como lo dijo Silvia Ramírez G. en una entrevista para la Infobae, que la lengua es una entidad con vida propia y como tal esta crece, se transforma y adopta nuevos términos (Infobae, 2016). Nuevos términos aparecen cada cierto tiempo debido a las nuevas necesidades de los hablantes o en nuestro caso, los internautas. Un ejemplo de esto son los "hashtags" que de tanto en tanto crean tendencia a nivel mundial, por consiguiente, estos términos creados para el momento, no siempre mueren, muchos se hicieron tan comunes que, hasta el día de hoy, aún se mantienen como lo son las siguientes palabras: "followers", "podcast", "selfie", "throwback" y la lista continúa. Si bien la RAE es la entidad con autoridad 
para crear conceptos y palabras, en más de una vez se ha visto obligada a adoptar ciertos términos e incluirlos en su diccionario. Otra manera de comunicarse en estas plataformas es mediante los "memes" que pueden ser imágenes, expresiones, videos, "gifs", etc. ... que son compartidos entre los usuarios de manera viral.

\section{Tabla 1}

Redes sociales más usadas en el mundo

\begin{tabular}{llll}
\hline Red Social & Usuarios activos por mes & Hombres \% & Mujeres \% \\
\hline Facebook & 2449 millones & 44 & 56 \\
YouTube & 1600 millones & & \\
WhatsApp & 1600 millones & 49,6 & 50,4 \\
$\begin{array}{l}\text { Instagram } \\
\text { TikTok }\end{array}$ & $\begin{array}{l}1000 \text { millones } \\
800 \text { millones }\end{array}$ & & \\
\hline
\end{tabular}

Fuente: (Kemp, 2020). Elaboración: Autor.

Nota. ${ }^{\text {abc }}$ YouTube, WhatsApp y TikTok no registran el sexo a sus usuarios, por lo que no es posible saber su porcentaje.

\section{Lenguaje por los jóvenes en redes sociales}

"Es un hecho que vivimos en una sociedad digital, y por tanto, las nuevas generaciones pertenecen ya a lo que se ha denominado "nativos digitales", ya que es el mundo en el que se desenvuelven continuamente" (Marín-Días et al., 2019). El estudio Digital 2020 Global Digital Overview que fue realizado por las empresas We are Social y Hootsuite, indica que más del 50\% de usuarios de Facebook e Instagram están en el rango de edad de 18-34 años. Twitter, por el contrario, la mayoría de sus usuarios están en el rango de 35-49 años de edad. 


\section{4}

Como podemos apreciar, también existe una inclinación a ciertas plataformas virtuales entre los cibernautas, es de esperarse que no encontremos muchos usuarios del rango de edad de 35-49 en TikTok, puesto que esta es una red social que está emergiendo y sus funciones se ajustan a usuarios jóvenes.

Desde el punto de vista de las diferencias en función del sexo, las chicas tienden a utilizar más los recursos de comunicación de los que están provistas las redes sociales, y los chicos a jugar de forma online en las diferentes plataformas que hay para ello (Holtz \& Appel, 2011; IAB Spain, 2017; Fernández-Montalvo et al., 2015).

Tal como lo dijo Silvia Ramírez G. "la lengua es una entidad viva", el idioma es adaptable. Hoy los jóvenes inundan las redes sociales con caritas, stickers, memes, videos, gifs. Su comunicación no es mediante el significante o el significado, sino su referente y estas pueden tener varias acepciones al mismo tiempo. También se los encuentran usando sus "tmb" (también), sus "ntp" (no te preocupes), sus "tuitear", "googlear", "guasapear", "logear" entre otros. La tecnología ha creado cosas nuevas y con ello, vacíos en la lengua. Y ante todo esto, el diccionario ya acepta su propia renovación.

\section{Lenguaje en redes sociales en Ecuador}

"El lenguaje como creación cultural establece los principios constitutivos de la identidad del individuo y de los grupos sociales" (Araque, 2005). El lenguaje abarca el idioma, habla, dialecto, y modismos. Entre los modismos 
ecuatorianos están: "Calentar las orejas", "clavarle el diente", "coger de pato", "creerse la última cola en el desierto", "cuy de vivo", "cuy gara", "bajarle los humos a alguien", "bien mal", ¿a cómo?, "aguar la fiesta".

Como se ha visto, existe entre los jóvenes la tendencia a modificar los nuevos términos que por lo general son anglicismos, con una misma finalización gramatical que es la primera conjugación verbal "ar" por ejemplo: "chatear", "postear". En Ecuador no ha sido la excepción, puesto que es una tendencia a nivel hispanohablante.

\section{Tabla 2}

Uso de dispositivos móviles, internet $y$ redes sociales en Ecuador

\begin{tabular}{lccc}
\hline Población total & $\begin{array}{c}\text { Dispositivos } \\
\text { Móviles }\end{array}$ & $\begin{array}{c}\text { Usuarios de } \\
\text { internet }\end{array}$ & $\begin{array}{c}\text { Usuarios activos en } \\
\text { redes sociales }\end{array}$ \\
\hline 17510 millones & 15650 millones & 12000 millones & 12000 millones \\
\hline
\end{tabular}

Fuente: Kemp, 2020.

Elaboración: Autor.

\section{Lenguaje en redes sociales en Cuenca}

La idiosincrasia cuencana, en cuanto a su cultura, arquitectura, arte y la literatura, pero, sobre todo, en aspectos comunicativos es notable. Como lo dijo Vásquez (2018): "De las tres formas de entonación, ciertamente la que más llama la atención, es la azuaya o cuencana". Sin embargo, su particularidad puede verse amenazada, dicho en sus propias palabras: 


\section{6}

Creemos que debido a la movilidad de la población y, sobre todo, a la gran penetración de los medios masivos de comunicación en las últimas décadas, se habrá reducido mucho más la zona del cantado, no tanto como zona, sino como número de hablantes que canten. (...). Otro aspecto que debe señalarse es que el migrante (el austro es una zona de alta tasa de migración), (...) deja el dialecto tonal rápidamente y se mimetiza con los hablantes del medio. (pp. 284-285)

Otro fenómeno que ha dado lugar las redes sociales y que está cambiando gradualmente la lengua morlaca juvenil es el ya conocido fenómeno del spanglish que según Libedinsky (2003) es un mestizaje lingüístico, no sólo un intercambio de fonemas y morfemas sino de identidades. Actualmente en las plataformas digitales como Twitter e Instagram se puede ver este fenómeno. Stavans (2000), nos dice al respecto de este fenómeno lingüístico que la lengua no se está destruyendo, sino, es una transformación necesaria debido a las nuevas necesidades.

Un ejemplo de esto lo vemos en un post en la cuenta de Instagram de Nikole Salinas, vigente reina de Cuenca:

(...) GANA DOS ENTRADAS GOLDEN BOX A SEBASTIAN YATRA 3 simples pasos a seguir: 1.- Dale like (...). (Salinas, 2019)

El lenguaje cuencano en las redes sociales está cambiando debido a las nuevas necesidades y objetivos que poseen estas plataformas digitales y también los jóvenes cuencanos para comunicarse. La generación Z está expuesta desde muy temprana edad a términos que no figuran en 
el dialecto cuencano y los están adoptando como su nuevo dialecto normal. A esto se lo denomina "Successive Early Bilingualism" Según Meisel (2009) esto consiste en que el niño aprende una segunda lengua o L2, a medida que va hablando, a pesar que ya tiene una lengua materna o L1. A través de las clases de un segundo idioma, músicas en otro idioma, series con actores y actrices con diferente dialecto, todo esto de manera consciente o inconsciente modifica el lenguaje de los jóvenes cuencanos, como bien, se puede constatar hasta el día de hoy en las redes sociales. Si bien aún existen círculos que mantienen su idiolecto, existen otros que están relegando su modismo y adoptando modismos extranjeros como el "ñaño" por el "bro", "chendo" por el "sorry", "no te miento" por el "cero joda", "amigo" por el "wey”, o el "púchica” por el "joder” español.

\section{Metodología}

Objetivo general: Este estudio pretende analizar la presencia del lenguaje cuencano en las redes sociales, al mismo tiempo descubrir si éste se ve amenazado a desaparecer o por el contrario, si puede mantenerse a pesar de la nueva forma de comunicación.

\section{Objetivos específicos}

Con el fin de obedecer al objetivo general se buscará determinar el modismo o coloquialismo cuencano en las redes sociales. También examinar el uso del spanglish por parte de los jóvenes en las redes sociales. 
118

El enfoque que se aplicará en este estudio será "cualitativo-deductivo", se realizará un sondeo en las redes sociales del lenguaje cuencano de manera general para de esta manera identificar el modismo o coloquialismo cuencano y también identificar el spanglish. El diseño del estudio es Análisis del discurso-significación, por lo que analizaremos el lenguaje en general y también el aporte de la palabra para la persona.

Las herramientas de recopilación que se utilizará para esta investigación serán de "Observación y Documentación” dado que se analizará las reacciones por parte de los cuencanos a documentos, fotografías, videos que circula en las redes sociales exceptuando los chats personales por supuesto.

Los criterios de significación que se usará en esta investigación son el coloquialismo y el spanglish presentes en la interacción por parte de los usuarios cuencanos, mediante el lenguaje escrito vertidos en las plataformas digitales. Se precederá a examinar las reacciones en forma de comentarios a las diferentes publicaciones hechas por páginas propiamente cuencanas.

El coloquialismo hace referencia a la idiosincrasia de un grupo de personas en el ámbito del lenguaje. El spanglish se puede interpretar de diferentes maneras, Alfredo Ardila lo describe como un dialecto anglicizado en español. Es decir, se trata de un intercambio de elementos léxicos y gramaticales entre el español y el inglés. 
119

Es fundamental aclarar lo siguiente, que a pesar de las diversas plataformas que usan los cuencanos como Instagram, Twitter, TikTok, entre otros, la red social Facebook es la que más lo usan, de modo que en esta red se encuentra la muestra en la que se ha analizado la presencia de coloquialismos morlacos y también el uso del spanglish en la interacción en forma de comentarios vertidos en la red social por parte de los habitantes de Cuenca.

Para el análisis se han seleccionado cuatro páginas de Facebook de las cuales, la primera página pertenece a una entidad gubernamental, la siguiente a un medio de comunicación de la ciudad, la tercera se trata de una fan-page de Cuenca y finalmente una página de Facebook con contenido característico del lenguaje cuencano. Facebook, en la actualidad, es la red social con la cantidad de usuarios más grande que otras redes sociales, al mismo tiempo cuenta con internautas con edades muy variadas. Por lo que cada página que se ha seleccionado cuenta con un grupo de usuarios singulares y diferentes al grupo de usuarios de otra página. Debido a lo cual, se busca estudiar los objetivos tanto a los adolescentes, jóvenes adultos y adultos mayores. En la página que pertenece a la entidad gubernamental se espera estudiar a un público con adultos mayores, mientras que en la página que pertenece al medio de comunicación, un grupo de usuarios variado entre jóvenes adultos y adultos mayores. En la fan-page de Cuenca y en la página con contenido de humor y coloquialismo cuencano, se espera tener un grupo de usuarios adolescentes y jóvenes adultos. De ninguna manera se afirma la no diversidad de edades dentro de las páginas, pero sí su mayoría. 
120

El análisis de la muestra se ha realizado desde el 14 de julio de 2020 al 18 de julio de 2020. La muestra seleccionada para el estudio, ha sido extraída de las publicaciones difundidas entre el 1 de julio de 2020 al 7 de julio de 2020 . La muestra se refiere a las reacciones en forma de comentarios por parte de los seguidores de dichas páginas.

\section{Resultados}

\section{Municipio de Cuenca}

Cuenta con 124880 seguidores.

En las publicaciones pertenecientes a dicha fecha se han encontrado 140 fotografías y 30 videos en los cuales se ha realizado 1542 . A continuación, se graficará la presencia del coloquialismo cuencano y también la presencia del spanglish.

Figura 1

Coloquialismo 16; Spanglish 5

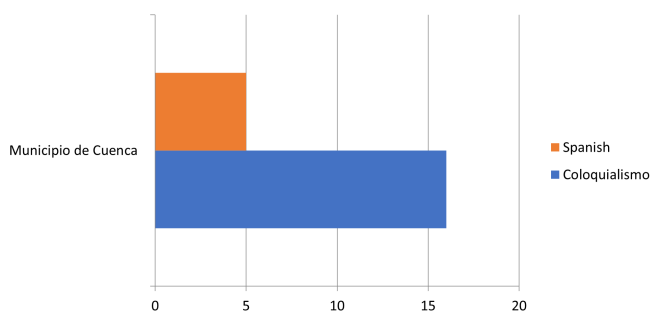

Elaboración propia 
Como se puede observar, la presencia del coloquialismo y spanglish es mínima teniendo en cuenta la cantidad general de comentarios. La mayor cantidad de personas que interactúan en esta red son personas adultas por lo que el spanglish es mínimo. Algo a recalcar es que lo que abunda son las faltas ortográficas. A continuación, unos ejemplos: Coloquialismo: "un disque", "esta tapiñado", "se aguanta", "a chupar”, etc.

Spanglish: "el show", "la web”, “en google”, etc.

La Voz del Tomebamba

Cuenta con 350855 seguidores.

$\mathrm{Al}$ igual que con la página "Municipio de Cuenca" se ha realizado un análisis en las publicaciones difundidas del 1 de julio de 2020 al 7 de julio de 2020 .

En dichas publicaciones se ha localizado 205 fotografías y 72 videos. En las cuales se ha realizado 2578 comentarios. De igual manera se procederá a graficar la presencia tanto del coloquialismo cuencano, como del spanglish. 


\section{2}

Figura 2

Coloquialismo 11; spanglish 5

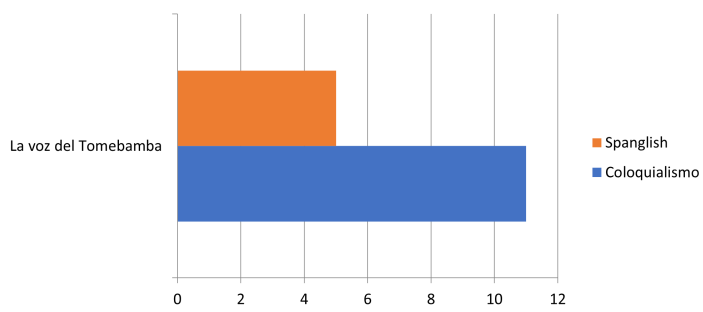

Elaboración propia.

Teniendo en cuenta los 2578 comentarios, el coloquialismo y el spanglish presentes en los comentarios es muy poco. Quizá el poco interés por parte de la juventud, que son los que mayor presencia tienen en las redes sociales, dé como resultado una presencia nula del spanglish. Y el hecho de manejar un lenguaje escrito, disminuya el coloquialismo. A continuación, algunos ejemplos recopilados:

Coloquialismo: "los peludos", “alcoliten", "bola de rateros", "parece mi garita", etc.

Spanglish: "en Marketplace”, "hay en el Mall del Rio”, "un manager", etc.

Cuenca 4 Ríos

Cuenta con 154362 seguidores.

Realizando un análisis a publicaciones difundidas entre el 1 de julio de 2020 al 7 de julio de 2020, se han 


\section{3}

encontrado con 72 fotografías y 6 videos. Cabe resaltar que, de las páginas analizadas, esta ha sido la página que más ha recibido interacción como comentarios, con un total de 88109 comentarios. Se ha seleccionado 2 videos y 5 fotografías debido a que algunas publicaciones cuentan con miles de comentarios. Esto se debe a que ciertas publicaciones han sido temas controversiales.

Figura 3

Coloquialismo 21; Spanglish 9

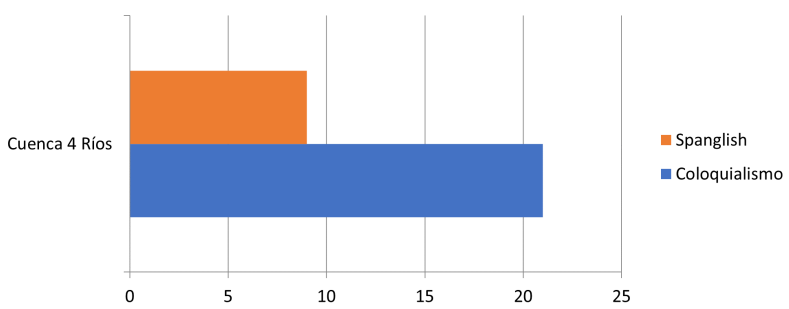

Elaboración propia.

Fantasy Channel

La razón por la que se analizó esta página es que sus contenidos se caracterizan por tener presente el coloquialismo cuencano. Esta página cuenta con 108334 seguidores.

Para el análisis de este canal se ha escogido 4 videos del 1 de julio de 2020 al 7 de julio de 2020, que cuentan con 688 comentarios. 
124

Figura 4

Coloquialismo 30; Spanglish 8

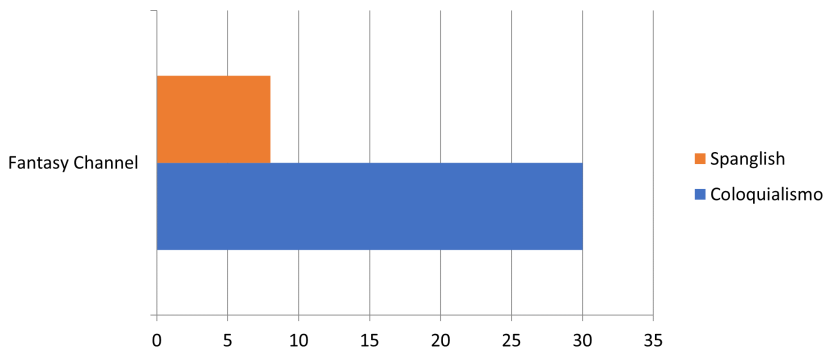

Elaboración propia

Se ha podido apreciar que, en esta página, la presencia del coloquialismo, destaca de las anteriores, y es que esta cuenta con un público juvenil y muchos de ellos mantienen su idiolecto. A continuación, algunos coloquialismos y uso del "spanglish" vertidos en los comentarios:

Coloquialismo: "Buen show", "den enviando", “darán escribiendo", "no shunsho", "que bestia”.

Spanglish: "algunos mails", "varios tickets", "garage”, entre otros.

\section{Conclusiones}

Después de finalizar la investigación y de revisar los resultados, datos que de alguna manera nos dan una imagen de lo que ocurre en las redes sociales dentro de la zona geográfica de Cuenca, es que, en efecto, sí existe tanto el 


\section{5}

coloquialismo como el spanglish en la interacción de los cuencanos en las plataformas digitales. Lo que se ha pretendido con este estudio es saber si los cuencanos son fieles a su idiolecto y, por otro lado, si emplean el spanglish en su interacción en las plataformas digitales. A su vez se ha podido observar que la presencia de coloquialismo es claramente muy poca, el spanglish aún menos. Con lo cual el lenguaje cuencano y por ende su cultura, de momento, no se ve amenazada, no al menos en esta generación.

La investigación sugiere que el modismo cuencano tiene mayor presencia en la interacción mediante el lenguaje oral, no escrito. Mientras que el spanglish está presente a la hora de describir o nombrar algo puntual como nombres de lugares, cosas que tienen que ver con la tecnología o con la comunicación.

En mi opinión, con la llegada de las nuevas tecnologías, la población se ha visto sesgada, no podemos olvidar que hay personas que no manejan una red social. También está el hecho de que para un análisis profundo se requiere analizar las diferentes plataformas digitales. Estos dos factores que influyeron en la investigación hacen que los resultados sean muy diferentes a lo que sucede en la cotidianeidad de la población cuencana. Por lo que para futuras investigaciones se recomienda ampliar el estudio a otras plataformas, las mismas que tienen más presencia e interacción de otros públicos. 


\section{6}

\section{Bibliografía}

Araque, O.L. (2005). El lenguaje como configuración funcional de la identidad y la cultura. Cuadernos de Lingüística Hispánica, (6), 113-127. https://bit.ly/3hw94cp

Holtz, P., \& Appel, M. (2011). Internet Use and Video Gaming Predict problem Behavior in Early Adolescence. Journal of Adolescence, 34, 49-58.

https://doi. org/10.1016/j.adolescence.2010.02.004

Infobae (2016). El impacto de las redes sociales en el lenguaje. https://bit.ly/32pV91r

Kemp, S. (2020). Digital 2020. https://bit.ly/3hIu2os

Libedinsky, J. (2003). Una controversia que crece. ¿Es el spanglish un idioma?: el nacimiento de una lengua. https://bit. ly/34GH7LH

Marín-Díaz, V., Vega-Gea, E., \& Passey, D. (2019). Determinación del uso problemático de las redes sociales por estudiantes universitarios. RIED. Revista Iberoamericana de Educación a Distancia, 22(2), 135. https://doi. org/10.5944/ried.22.2.23289

Meisel, J. (2009). Second Languaje Acquisition in Early Chilhood. Zeitschrift für Sprachwissenschaft, (28)1. https:// doi.org/10.1515/ZFSW.2009.002

Nikole.salinas (17, octubre, 2019). ¡El post íntegro [SORTEO!! GANA DOS ENTRADAS GOLDEN BOX A SEBASTIAN YATRA 3 simples pasos a seguir: 1.- Dale like a la publicación y comenta esta publicación con quien quisieras ir 2.- Comparte está publicación en tu historia]. https://bit.ly/3jeafOj

Piaget, J., \& Inhelder, B. (1976). Génesis de las estructuras lógicas elementales: clasificaciones y seriaciones. Editorial Guadalupe.

Skinner, F. (1957). Conducta verbal. ProQuest.

Stavans, I. (2000). Spanglish para millones. Casa de América.

Vásquez, O.E. (2018). La lengua morlaca. Don Bosco. 


\title{
CAPítulo VI Influencers en la ciudad de Cuenca
}

\author{
Viviana Calle-Salinas \\ Universidad Politécnica Salesiana, Ecuador \\ https://orcid.org/ 0000-0003-4222-6035 \\ Ximena Méndez-Calle \\ Universidad Politécnica Salesiana, Ecuador \\ https://orcid.org/0000-0002-8451-1689
}

\section{Resumen}

El creciente poder de los influencers en su red social, se ha convertido en un nuevo lugar de comunicación para las marcas. Este estudio desarrolla en el marco de la metodología cualitativa el papel de los influencers en Cuenca, quienes actualmente son considerados líderes de opinión en línea y marketing, asimismo, se aplicó una exploración de sus perfiles. Los datos resultantes del trabajo de campo se sistematizaron y procesaron para facilitar su análisis e interpretación. Metodológicamente, se trata de un estudio de caso con aproximación netnográfica en la que se utilizan herramientas cualitativas como la observación de per- 
files, permitiendo reconocer la eficacia de las estrategias de comunicación por parte de los influencers en el análisis de las nuevas figuras publicitarias y el comportamiento de sus interacciones en redes sociales.

Palabras clave: Influencers, marcas, marketing de influencia, redes sociales, contenido, Instagram, YouTube, prescriptores, Cuenca.

\section{Abstract}

The growing power of influencers in their social network has become a new place of communication for brands. This study develops, within the framework of the qualitative methodology, the role of influencers in Cuenca, who are currently considered online opinion and marketing leaders. An exploration of their profiles was also applied. The data resulting from the field work were systematized and processed to facilitate their analysis and interpretation. Methodologically, this is a case study with a netnographic approach in which qualitative tools such as profile observation are used, allowing the recognition of the effectiveness of communication strategies by influencers in the analysis of new advertising figures and the behaviour of their interactions in social networks.

Keywords: Influencers, brands, influence marketing, social networks, content, Instagram, YouTube, prescribers, Cuenca.

Desde la existencia de las redes sociales, el mundo de estas plataformas ha llegado a conseguir poder en la socie- 


\section{9}

dad, si tú también te has subido a este tren de redes sociales tu vida ahora es pública. Todas tus vacaciones, tu música favorita, la marca de ropa que usas y por supuesto tus fotos. De la misma forma que tú compartes tu vida, descubres más personas que comparten sus opiniones.

Las redes sociales son el fin de los influencers en Cuenca, que por sus diferentes razones o ya sea por compartir sus aficiones y sus habilidades a la hora de editar videos o fotografías, comparten sus conocimientos de un tema o simplemente la creatividad de hacernos sonreír con su humor o sus opiniones por marcas, productos o ropa, de esta forma logran conseguir un gran número de seguidores, fieles a sus contenidos.

Los influencers o también llamados "chicos populares" tienen gran acogida en Cuenca, cuentan con mucha aceptación en el internet y por sus distintas facetas que utilizan, determinan la participación dentro de la comunicación estratégica, cuya opinión cambia o genera decisiones de compra mediante medios digitales que inspiren a sus fans a ser fieles en el contenido que suben diariamente a sus perfiles.

Sus experiencias, gustos y opiniones, permite interactuar de manera directa con sus seguidores, estos se identifican por ser personajes con gran acogida en internet y su participación dentro de la comunicación de una marca. Sin embargo, más allá de ser personajes icónicos en plataformas digitales, se convierten en amigos y no personajes actuados detrás de una pantalla. No obstante, a medida 
que aumenta la presencia de influencers en colaboración con marcas, más se sospecha sobre su profesionalismo y su reconocimiento. No sólo se ha puesto en duda que deban de obtener una remuneración por colaborar con marcas, sino que también, se pone en duda que no son profesionales de este sector.

De hecho, la elaboración de este trabajo, pretende comprobar la efectividad de los influencers y la manera en la que actúan y emplean sus redes sociales, por esta razón la investigación analiza todo este fenómeno denominado influencer, y la manera en la que conquistan tendencias en redes sociales, con una exploración de los tipos de influencers que existen en Cuenca y sus relaciones e interacciones en las diferentes plataformas e incluso como muestran su credibilidad en la plataforma Instagram que es el medio digital de preferencia por parte de los activos en las redes sociales.

Las redes sociales son canales de relaciones, las relaciones son negocios disfrazados. Los jóvenes han encontrado en las redes sociales el espacio perfecto para informar y estar informados. Sin embargo, solo unos pocos tienen la capacidad de influir en las decisiones de compra, estilo de vida o preferencias del resto. Los llamados influenciadores sociales se han convertido en una parte activa de la comunicación de una marca, especialmente aquellas dedicadas a la moda (Brown \& Hayes, 2008), sin embargo, menciona que las redes sociales en línea han establecido plataformas virtuales que permiten a las personas expresar sus opiniones, intereses y pensamientos en una variedad de contextos 
y dominios para difundir su contenido, por lo tanto, estableciendo así las bases para medir su influencia social.

En particular, existe la necesidad de una mejor comprensión de la confianza social basada en el dominio para mejorar y expandir el proceso de análisis y determinar la credibilidad (Brown \& Hayes, 2008), sin embargo, la opinión que sostiene el crecimiento exponencial en el uso de las redes sociales no solo ha impactado la forma en que las personas se comunican e interactúan, sino que también ha abierto nuevas vías para varios dominios incluidos el marketing y el comercio electrónico (Torres-Toukoumidis \& De Santis, 2020).

El contenido compartido en las plataformas de redes sociales se vuelve popular y posteriormente viral cuando es compartido y propagado por un público más amplio a un ritmo más rápido. Las organizaciones están aprovechando este poder de las redes sociales, sin embargo, también nos menciona que los jóvenes han encontrado en las redes sociales el espacio perfecto para informar y estar informados (Uzunoglu \& Kip, 2014), a pesar de ello, solo unos pocos tienen la capacidad de influir en las decisiones de compra, estilo de vida o preferencias del resto. Los llamados influenciadores sociales se han convertido en una parte activa de la comunicación de la marca. Los influencers son nuestros referentes que interactúan en las redes sociales inspirando a sus fans (Cáceres et al., 2017).

Para comenzar el término influencer se define como la creación de marcas personales de los usuarios de redes 
sociales, estos son una herramienta utilizada para aumentar la notoriedad de la marca, que forman parte de los líderes en Cuenca y que permiten que las marcas creen, publiquen y compartan contenido con aquellos que tienen intereses similares (Brown \& Hayes, 2008); su poder en la sociedad es generar decisiones de compra y confianza, siendo así los dos factores más importantes para la evolución de la credibilidad del mensaje y la falta de la misma en las comunicaciones logrando que los consumidores busquen información en otras fuentes como en recomendaciones de amigos, pues consideran que obtienen información en otras fuentes como en personas que conocen que la de los anunciantes a los que se los percibe con un interés financieros (Brown \& Hayes, 2008).

\section{Metodología}

Este trabajo se origina a partir de una interactividad sistemática de las fuentes de información oficial disponibles en sus redes sociales. No está demás destacar que la investigación parte de la recolección, organización, análisis e interpretación de información proveniente de fuentes electrónicas.

Objetivo general: Demostrar el método estratégico que poseen los influencers para facilitar el progreso en el mundo publicitario.

Objetivos específicos: Explicar el surgimiento de estas nuevas figuras publicitarias capaces de generar notoriedad en la ciudad; Examinar cómo un influencer puede 
llegar a convertirse en un prescriptor para una marca; Demostrar el efecto que generan en sus seguidores mediante sus redes sociales como Instagram.

\section{Enfoque de estudio}

La investigación se desarrolla en un contexto cualitativo para exponer y deducir las interacciones del público con los influencers, para demostrar mediante un análisis a profundidad diez influencers de la ciudad de Cuenca y su gran alternativa de marketing que representan, mediante investigaciones en la web y un análisis crítico de la información adquirida, para solventar la necesidad de publicidad en línea. Estas nociones metodológicas permiten lograr los objetivos planteados en la presente investigación.

Este proyecto basa su estudio en un diseño netnográfico, que permita analizar y explorar perfiles junto con el comportamiento de incidencia que tiene un influencer en la sociedad en general y las redes sociales en particular, el marketing de influencia se ha convertido en una estrategia para las marcas, especialmente cuando se dirigen a jóvenes.

La recopilación de datos que utilizaremos en la investigación se da a partir de una exploración de perfiles exhaustiva, que permitan recoger específicamente su frecuencia en publicaciones de las diferentes plataformas como Instagram, Facebook, YouTube. Identificando a fondo las diferentes reacciones sistemáticas que existe por parte de los seguidores, y así mismo saber cuál es la temática 
o temas que utilizan en sus perfiles con temas tales como; moda, comida, maquillaje y respecto a esto identificar a qué público se dirigen sus posts logrando un análisis profundo de la percepción subjetiva de la muestra de recopilación de datos frente al objeto de estudio.

\section{Resultados}

Los resultados de esta investigación respecto a los tres objetivos planteados, extrae la información de los diez influencers analizados en Cuenca, quienes se desempeñan en sus diferentes temáticas utilizadas en sus perfiles, estos datos obtenidos y analizados durante el 25 de abril hasta el 18 de julio de 2020, se caracteriza por ser un estudio cualitativo, ya que contiene conceptos e ideas que surgen a partir de los análisis realizados en los perfiles.

A continuación, se hará una breve reseña de las indagaciones de los influencers en Cuenca y se expondrán los resultados adquiridos en base a la exploración realizada en los perfiles de Instagram, el 14 de junio hasta el 16 julio, con su respectivo análisis, teniendo presente la pregunta de investigación: ¿Demuestran un método estratégico para facilitar el progreso en el mundo publicitario?

\section{Tabla 1}

Porcentajes de respuesta a la pregunta ¿método estratégico para facilitar el progreso en el mundo publicitario?

\begin{tabular}{|l|l|}
\hline Relación con las marcas & Porcentajes \\
\hline Incentivar a la venta de productos & $48 \%$ \\
\hline Instruir sobre el uso del producto & $32 \%$ \\
\hline
\end{tabular}




\section{5}

Encaja los influencers con los valores de la marca

Fuente: Elaboración de las autoras.

En este gráfico evidenciamos los resultados de la pregunta. ¿Utiliza un método estratégico para facilitar el progreso en el mundo publicitario? Los social media, en Cuenca se basan más en utilizar sorteos e interacciones mediante IGTV con recomendaciones y demostrando la efectividad de los productos que enseñan para promocionar las marcas, logrando aumentar la audiencia con una mayor credibilidad con un 32\%. El 48\% de los influencers, demuestran liderazgo en ser prescriptores para las marcas, mientras que en un porcentaje comprendido por el $20 \%$ revela que sus publicaciones o tipos de contenidos no encaja con la relación de marcas que tienen.

\section{Figura 1}

Análisis de su poder de influencia en base

a sus comunidades

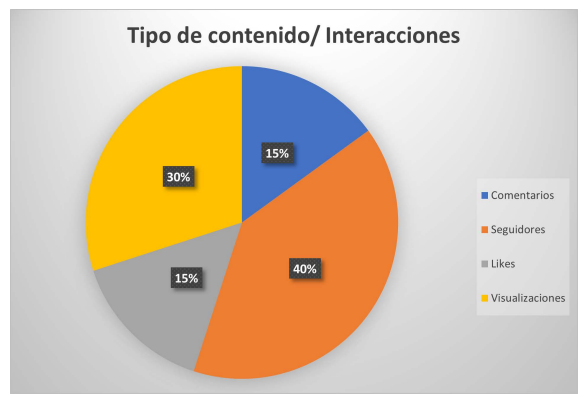

Fuente: Elaboración de las autoras 
Tal y como se puede evidenciar en la Figura 1, se analizó una muestra aleatoria de 20 publicaciones a partir de un seguimiento en la plataforma Instagram, medio oficial de los influencers en Cuenca, se comenzó analizando la cantidad de seguidores que tienen los 10 influencers y se evidenció los datos entre el $15 \%$ en likes y el $15 \%$ en comentarios, lo que revela el menor porcentaje en el no uso de estas estrategias de asistencia, sin embargo, sus habilidades sociales logran que tenga un $30 \%$ de visualizaciones.

Por otro lado, la mayoría de los seguidores los siguen, en este caso, a influencers pertenecientes al campo de la moda, siendo este el ámbito en que este tipo de marketing tiene mayor impacto. Por todo esto, el alto porcentaje de ellos se ven influidos por estas figuras y evidencia su efectividad comercial, sin embargo, gran parte de las personas consulta previamente la opinión, comentarios y valoraciones de los influencers sobre un determinado producto antes de comprarlo. Por este motivo muchas veces son ellos, con sus aportaciones en cada comentario, esto a su vez se considera el papel importante en la sociedad, esto se debe a los resultados que están obteniendo y a los miles o millones de seguidores que les siguen de cerca y que les preguntan por sus opiniones acerca de un tema, en este caso, la moda.

Al llevar a cabo este proyecto, notamos muchas inconsistencias al contar con muchos seguidores en desproporción con sus pocos likes y comentarios, pero sus publicaciones suelen brillar por su originalidad y capacidad de inspiración, por esta razón encontramos campañas que 
los utiliza para enseñar sus marcas. Los espectadores están viviendo menos la televisión: el público se está moviendo cada vez más a los dispositivos móviles, con un $50 \%$ de usuarios a través de la pantalla más pequeña, y los espectadores están exigiendo clips más cortos, incluso Netflix se ha dado cuenta de que el 78\% de sus sesiones de visualizaciones en dispositivos móviles tenían menos de 10 minutos.

\section{Conclusiones}

El estudio cualitativo realizado permite iniciar una revisión a profundidad, la utilización de influencers en Instagram como una estrategia de marketing y la forma en la que pueden influir en las decisiones de compra, para introducirnos en esta investigación. Según De Veirman, Cauberghe y Hudders (2017) expresan que: Instagram continúa siendo una de las redes sociales de más rápido crecimiento, hasta el punto de superar en número de usuarios a los 467 millones de Linkedln, los 313 millones de Twitter, y los 150 de Pinterest o Snapchat. Sólo le ganaba su ya empresa matriz, Facebook, con su imbatible cifra de 1790 millones de usuarios mensuales. En este sentido, y como se observó en los resultados, la red social Instagram permite que aquellas empresas que desean seguir el impacto de la publicidad, les brinden diferentes estadísticas que ayudará a evaluar y mejorar el impacto de las publicaciones, y conocer a los seguidores. Por lo tanto, los resultados de este estudio, con respecto a los objetivos planteados, da como evidencia que existe una interacción limitada en cuestión de likes y comentarios que resulta complicado la recolección de datos, pero aportan estrategias de marketing para acoger más seguidores y 
colocan una alternativa didáctica que es el IGTV. Hay que destacar que tras la realización de los análisis pertinentes, no se han alcanzado los resultados planteados, ya que, los influencers no han sabido relacionar su contenido con el tipo de marcas que presentan.

Para finalizar con este trabajo de investigación acerca de cómo afectan los influencers de Instagram en la decisión de comprar de los jóvenes, plantearemos la siguiente implicancia al problema planteado

Desde nuestro punto de vista, hay que reconocer que la publicidad online está creciendo, sin embargo, creemos que todavía no se debe dejar de lado a los medios masivos, como la televisión ya que aún no hay número que indique que los medios digitales superan a los medios masivos tradicionales. Con respecto a Instagram, es una red social nueva y dinámica. A la hora de mostrar y medir nuestros resultados notamos que es una red óptima para los influencers de Cuenca porque es visiblemente atractiva, por los post que se suben diariamente a sus perfiles, permitiendo que aquellas empresas de indumentaria, que hacen uso de esta red lo hagan para publicitar de mejor manera su producto.

Para futuras investigaciones se recomienda lo siguiente: Investigar si las marcas ya sean de moda, comida, maquillaje tienen incidencia o no dentro de los contenidos posteados por los influencers; porque en esta investigación se pudo constatar que el contenido que postean los influencers no favorece a las marcas, ya que no hay una 
interacción de comentarios interesados por parte de sus seguidores con respecto a las marcas posteadas. Investigar, qué es más importante para las diferentes marcas al momento de contratar a un influencer, si la cantidad de seguidores que tienen cada uno de ellos, esto nos va a permitir tener más claro el panorama al momento de dar un criterio al respecto. Investigar cómo poder categorizar a los influencers, que puede ser por la cantidad de seguidores. Sin embargo, consideramos que esta investigación contribuyó para aumentar el conocimiento sobre los influencers en Cuenca y de los contenidos de los posteos sobre el marketing utilizado dentro de Instagram y que este estudio se pueda llevar a desarrollar en futuras investigaciones sobre influencers cuencanos.

\section{Bibliografía}

Brown, D., \& Hayes, N. (2008). Marketing de influencia. Routledge. Cáceres, G., Perea da Silva, T., Vázquez, M., \& Torres, M.G. (2017). El impacto de los influencers de Instagram en la decisión de compra de indumentaria de los jóvenes. Universidad Argentina de la Empresa.

De Veirman, M., Cauberghe, V., \& Hudders, L. (2017). Marketing through Instagram influencers: the impact of number of followers and product divergence on brand attitude. International Journal of Advertising, 36(5), 798-828. http://dx.doi.org/10.1080/02650487.2017.1348035

Torres-Toukoumidis A., \& De Santis, A. (2020). Cuando los instagrammers son los adultos. Abya-Yala.

Uzunoğlu, E., \& Kip, S. M. (2014). Building relationships through websites: A content analysis of Turkish environmental non-profit organizations'(NPO) websites. 
Public Relations Review, 40(1), 113-115. http://dx.doi. org/10.1016/j.pubrev.2013.06.001 


\section{Capítulo VII \\ Cultura cuencana y redes sociales}

Freddy Parra-Sigüencia

Universidad Politécnica Salesiana, Ecuador https://orcid.org/0000-0002-0952-2548

Johny Cabrera-Ruiz

Universidad Politécnica Salesiana, Ecuador https://orcid.org/0000-0002-0374-5193

Paolo Romero-Arévalo Universidad Politécnica Salesiana, Ecuador https://orcid.org/0000-0003-4829-5066

\section{Resumen}

En esta investigación, se indaga cómo se transmite la cultura cuencana por medio de las redes sociales, en este caso Facebook, también se busca determinar cuál es su grado de influencia en ámbitos como el turismo, el entretenimiento y conocimiento, y cuáles son las herramientas más útiles para alcanzar esos fines planteados. Se parte la investigación desde páginas ya creadas con anterioridad, 
que se dedican a esas labores de compartir sobre la cultura de Cuenca, que en su mayoría son personas adultas (mayores de 31), pero ¿qué piensan los jóvenes sobre utilizar una aplicación (Facebook) que está destinada al ocio para darle un fin educativo y cultural? ¿Están dispuestos a indagar y compartir en sus redes sobre temas relacionados a Cuenca? ¿Con qué frecuencia lo han hecho? Quiénes son más activos dentro de Facebook con relación a la cultura ¿los jóvenes que tienen más apego a las redes sociales? $\mathrm{O}$ ¿los adultos que tienen más apego y amor a la cultura? Se sondea los resultados para conocer por qué es más factible impartir la cultura y qué herramientas facilitaría su percepción, dejando de lado los textos largos y aburridos para evolucionar al mass media, mediante contenido multimedia, que ha sido muy favorable para dejar en alto a Cuenca y los cuencanos como lo ha venido haciendo, favoreciendo a la llegada de extranjeros y siendo galardonada en distintas ocasiones. Pero se encuentra con un grave problema, ¿qué tan fácil es encontrar publicaciones concisas sobre cultura, que llame la atención de todos para proceder a compartir?

Palabras clave: Cultura, actividades socioculturales, cambio cultural, cultura popular, turismo, contenido de la educación.

\section{Abstract}

In this research, the study investigates how the culture of Cuenca is transmitted through social networks, in this case Facebook, and also seeks to determine its degree of influence in areas such as tourism, entertainment and 
knowledge. The research starts from previously created pages, which are dedicated to these tasks of sharing about the culture of Cuenca, which are mostly adults (over 31), but what do young people think about using an application (Facebook) that is intended for leisure to give it an educational and cultural purpose? Are they willing to investigate and share in their networks about issues related to Cuenca? How often have they done it? Who are the most active within Facebook in relation to culture, the young people who are most attached to social networks? Or the adults who are more attached to and love culture? The results are polled to find out why it is more feasible to impart culture and what tools would facilitate its perception, leaving aside long and boring texts to evolve the Mass media, through multimedia content, which has been very favorable to leave Cuenca and the Cuencanos high as it has been doing, favoring the arrival of foreigners and being awarded on several occasions. But it encounters a serious problem, how easy is it to find concise publications on culture, which attract the attention of everyone to proceed to share?

Keywords: Culture, socio-cultural activities, cultural change, popular culture, tourism, educational content.

El hombre es un ser básicamente cultural y la cultura es una construcción del ser humano. Cada uno de nosotros nacemos en una cultura o también llamada comunidad de vida, al interior de la cual interiorizamos unas maneras de pensar, sentir y actuar muy particulares. Al mismo tiempo que la cultura nos constituye como seres humanos, somos nosotros los que hacemos que esa cultura se trasmita, se 


\section{4}

conserve o se transforme. Esto se produce por la acción comunicativa que se da al interior de cada comunidad de vida (Garzón-Vera, 2014, p. 24).

La cultura ha sido tornadiza con el tiempo, obligando a nuestros antepasados a adaptarse a los cambios y de igual manera sucede en la actualidad, vivimos en trance de adaptación y evolución. La cultura es la herencia que nos han transmitido nuestros predecesores, y de la misma manera nos ocuparemos de sembrar en nuestros sucesores la avidez de preservar el patrimonio tangible e intangible de la Atenas del Ecuador.

Al hablar de que la cultura ha sido tornadiza, hacemos mención a los cambios que se han registrado hasta el momento, cambios para bien y para mal, este contexto se inclina a los cambios que han hecho que la cultura evolucione y que trascienda de lo presencial a lo virtual, se ve reflejado la influencia de las redes sociales no solamente para conocer y hablar con personas; sino también para aprender y compartir lo aprendido (Herrán-Gómez et al., 2019).

Cuenca no se ha quedado atrás, ha tenido una transformación muy sustancial que se ve reflejado en su cultura, en su gente y sus tradiciones. Un claro ejemplo que se testifica es en la dirección de cultura o el municipio cuando lanzaban un libro sacaban cierta cantidad finita, y quien no adquiría el compendio a buena hora se quedaba sin poder conocer lo que esconde sus textos, ahora, la diferencia es que si se acaban encontrarás un ejemplar virtual abierto a todo el mundo de manera gratuita. Lo mismo sucede en el 
campo artístico y teatral, hace algunos años los actores realizaban sus obras dentro de un teatro, luego las obras pasaron a ser en las calles y hemos visto que tales actividades se mudaron a las redes sociales, podemos gozar aquellas obras desde la comodidad de nuestra casa. En las ventas artesanales hemos evidenciado que lo que se comercia en la Plaza Rotary, Casa de la Mujer y similares, comerciantes han optado por ofrecer su orfebrería por plataformas de venta en línea, los sombreros, actividad principal de comercio en el siglo XX en Cuenca tampoco han sido la excepción, al momento de optar por los lineamientos virtuales.

Se han tomado estos ejemplos los cuales se extenderán en el desarrollo del capítulo, demostrando cómo ha sido este trance existente en varios ámbitos, que se ha centrado en la cultura, en Cuenca y en los cuencanos.

En esta crisis debido a la pandemia se ha acrecentado los campos virtuales en trabajo, educación, actividades deportivas y recreativas entre ella la cultura y con esto hemos evidenciado que los cuencanos sí estamos capacitados para dar este siguiente paso, en fin, si los cuencanos se encuentran competentes para esta evolución cultural, pero no queremos decir que esté al alcance de todos. Nuestro objetivo general será descubrir si la migración de la cultura a las redes sociales tiene una gran aceptación de los cuencanos, exteriorizar cuáles son sus predilecciones dentro de ellas y quiénes son sus mayores activistas.

La cultura cuencana es un tema que cuando se menciona, parece interesar solamente a personas mayores afi- 
146

nes al tema, descuidando el interés juvenil que puede existir allí detrás. En cambio, cuando hablamos de redes sociales inclinamos la balanza hacia los jóvenes descuidando el afecto que existe por parte de las personas mayores, pero ¿qué pasa si se une la cultura con las redes sociales?

Para conseguir los datos pertinentes que validen nuestra investigación, se ha recurrido a una herramienta de recolección de datos muy eficaz para el tema propuesto a abordar, empleando encuestas con escala de Likert utilizando una muestra equivalente 50:50 entre menores de 30 años (jóvenes) y mayores de 30 (adultos), se llevó a cabo un cuestionario con diez preguntas multivariantes politómicas con el fin de aseverar si las personas mayores (31 años en adelante) son más activos en la divulgación de la cultura cuencana en Facebook.

De los encuestados, el 51,5\% fueron hombres y $48,85 \%$ mujeres, dividimos las encuestas de manera parcial y equilibrada, el $50 \%$ de los encuestados fueron menores de 30 años, lo que en la investigación denominamos como jóvenes. El otro 50\% fueron personas mayores de 31 años, que en la investigación se les designó como adultos. 


\section{Figura 1}

¿Con qué regularidad usa Facebook para indagar sobre la cultura cuencana?

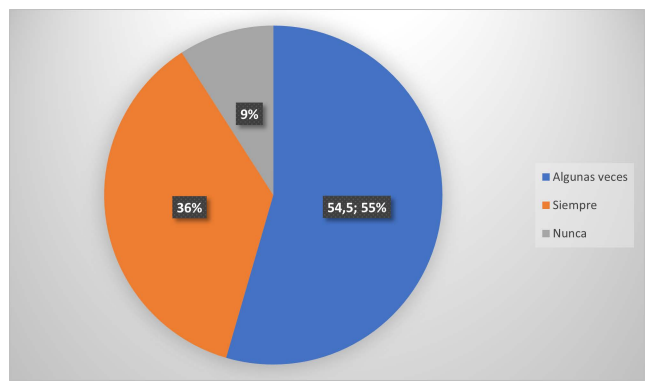

Fuente: Elaboración propia.

Facebook se define a sí misma como una herramienta social que te conecta con personas a tu alrededor. Esta red social sirve para conectarnos con amigos, compartir información, también es usada como pasatiempo y para hablar con personas de cualquier parte del mundo. Pero, al tener acceso a todo esto y mucho más ¿existen personas que lo usen para nutrirse culturalmente? El 54,5\% de los encuestados respondieron usarlo algunas veces para indagar sobre cultura. Diversas opciones de Facebook que fueron muy usadas en su inicio han quedado obsoletas, porque han emergido nuevas aplicaciones que han sustituido funciones en los últimos años dejando la plataforma libre para aventurarse en nuevas ideas, un claro ejemplo son los medios de comunicación independientes, así mismo, la cultura ha tomado un gran impulso, y Cuenca no es la excepción, por ende, el 36,4\% de los encuestados men- 
cionan indagar regularmente sobre la cultura de la ciudad en esta red social.

\section{Figura 2}

¿Cuáles son los motivos que usted considera importantes para publicar sobre la cultura de Cuenca?

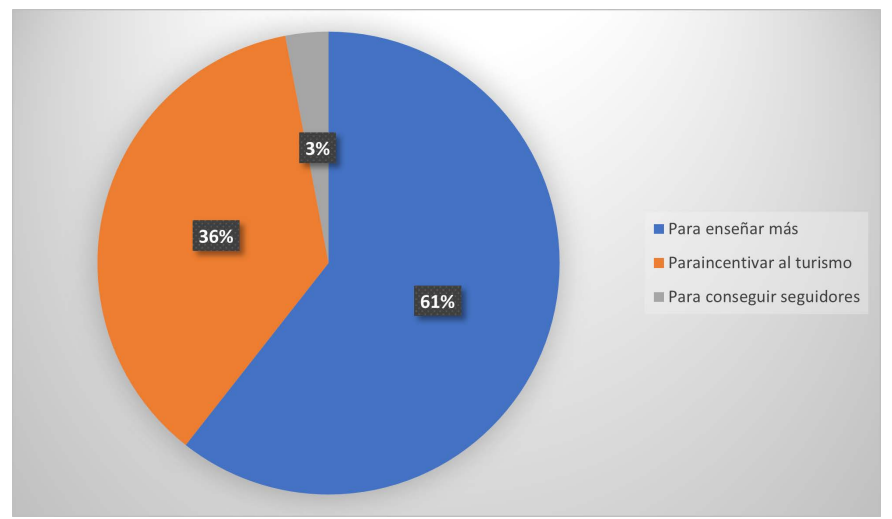

Fuente: Elaboración propia.

Facebook:

Esta red no está diseñada para educar como tal, pero sí es un medio que genera mucho más aprendizaje, debido a que es una herramienta online que está al alcance de cualquier persona sea por medio de una Laptop, un Smartphone o Tablet. (Vargas, 2005, p. 48)

Los usuarios de Facebook consideran que el motivo principal para compartir sobre la cultura de Cuenca, está reflejado en la enseñanza debido a que existe datos extras que no son impartidos en las escuelas, colegios o encuentran una forma más sencilla de transmitir y recibir datos. 


\section{Figura 3}

¿Con qué frecuencia ha encontrado publicaciones con referencia a la cultura cuencana?

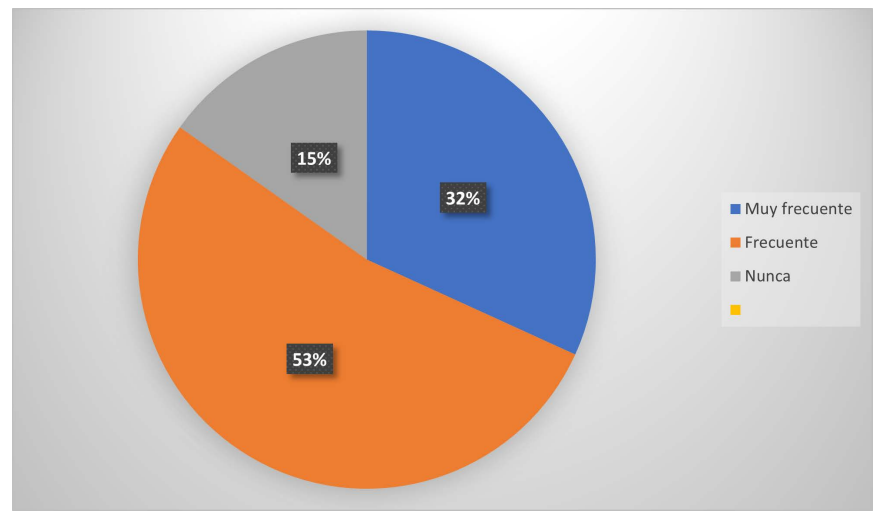

Fuente: Elaboración propia.

Se ha evidenciado la frecuencia con la cual se usa Facebook para compartir sobre la cultura, debido a que hay mayores activistas encargados de impartir su conocimiento.

Existen dos grupos representativos dedicados a la publicación de contenido sobre la cultura cuencana. La primera es Cuenca: "La Arcadia de los Andes y La Atenas del Ecuador" creada por el Dr. Andrés Tola, hasta la fecha contiene 2035 miembros, con mucha actividad diaria y el $80 \%$ de sus participantes activos son personas mayores a los 31 años. Otro grupo significativo es: "Cuenca, Memoria y Testimonio" creado por Adriano Augusto Merchán Aguirre, hasta el día de hoy tiene 5303 miembros, cabe recalcar que muchos de los que forman parte de este grupo, también son activos en el otro ya mencionado. 
Asimismo, hay varias páginas dedicadas a la misma actividad, como: "La Cuenca de Antaño" y "Cuenca Patria Chica" del Dr. Felipe Durán Alemán o cuentas personales como la de Piotr Zalamea Zielinski, miembro del Colectivo Artístico del Teatro Barojo, en donde presencialmente dan las llamadas "rutas de leyendas" que en conjunto con la Arquidiócesis de Cuenca presentan actuaciones en la que imitan a personajes importantes dentro de la historia cuencana, no obstante, por el confinamiento migraron del teatro a las plataformas virtuales, en este caso Facebook, con transmisiones diarias en vivo, narrando historias y cuentos tradicionales.

\section{Figura 4}

¿Está de acuerdo que la cultura cuencana sea impartida por Facebook?

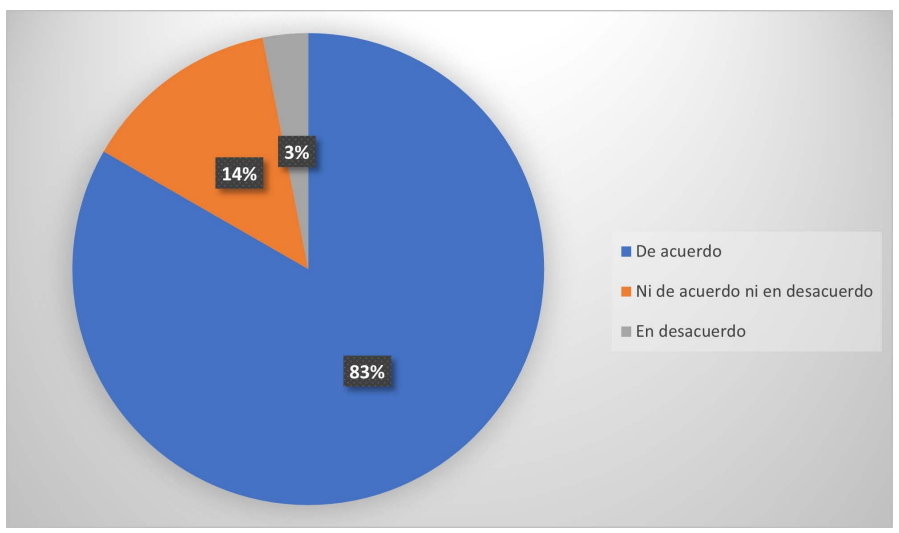

Fuente: Elaboración propia. 
151

Existen diversas maneras de impartir información, rudimentariamente podemos hablar de libros, películas, artículos de revista, pero si el objetivo es llegar a los jóvenes, estas formas ya no se les hace muy llamativas, por lo que se debería innovar.

Es lo que se ha hecho con la cultura cuencana, y ha dado resultados muy buenos aparte de ahorrar costos es más viable para llegar a diversas personas.

Un claro ejemplo es el lanzamiento de compendios, cuando es físico se invierte en el local, en lo que van a servir a los invitados y obviamente en la impresión del libro (cantidades finitas), pero ahora el panorama sanitario nos ha obligado a tomar medidas repentinas, como los lanzamientos que se han realizado virtualmente, evitando los costes ya mencionados, el libro se lo libera en internet y de esta manera todos tienen acceso al mismo, los enlaces del compendio son publicados en Facebook (en donde se encuentra la mayoría de jóvenes). Es por eso que en la encuesta realizada el $83,3 \%$ aduce que la cultura debe ser impartida por las redes sociales, y este cambio significativo que se está dando seguirá evolucionando, por ende, en el futuro los jóvenes se guiarán y construirán su bagaje cultural de acuerdo a lo que encuentran en sus redes sociales (en este caso Facebook) por ser más accesible y cómodo. 
152

Figura 5

¿Ha publicado en su perfil de Facebook

sobre la cultura cuencana?

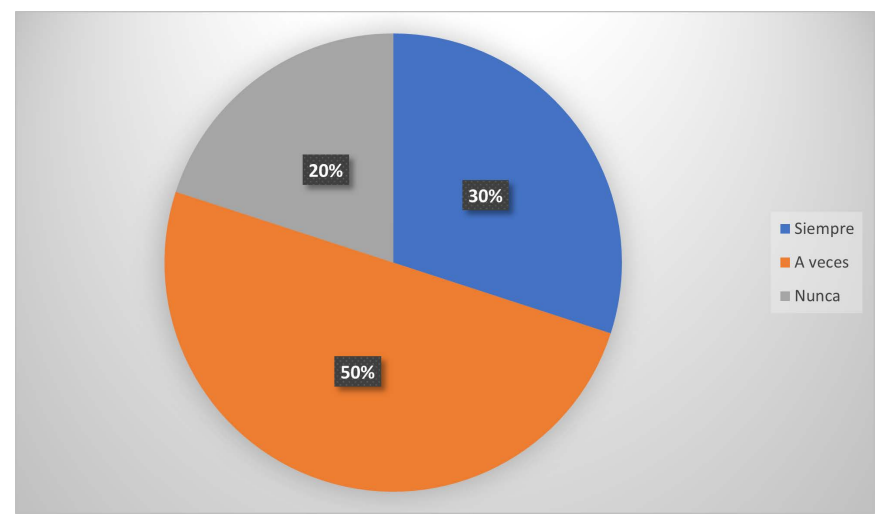

Fuente: Elaboración propia

Son pocas las páginas sobre cultura cuencana, de esa minoría su contenido se inclina más a las imágenes que contienen pequeñas referencias, que las hacen llamativas por su simpleza y concreción. El 45,5\% de los sondeados, mencionan haber compartido algunas veces en sus perfiles de Facebook sobre Cuenca y su cultura, porque se han dejado llevar por las fotografías antiguas, que evidencian su arquitectura emblemática que caracteriza a Cuenca al pasar de los años. 


\section{3}

\section{Figura 6}

¿Cree que se incentiva al turismo a Cuenca compartiendo información sobre su cultura en Facebook?

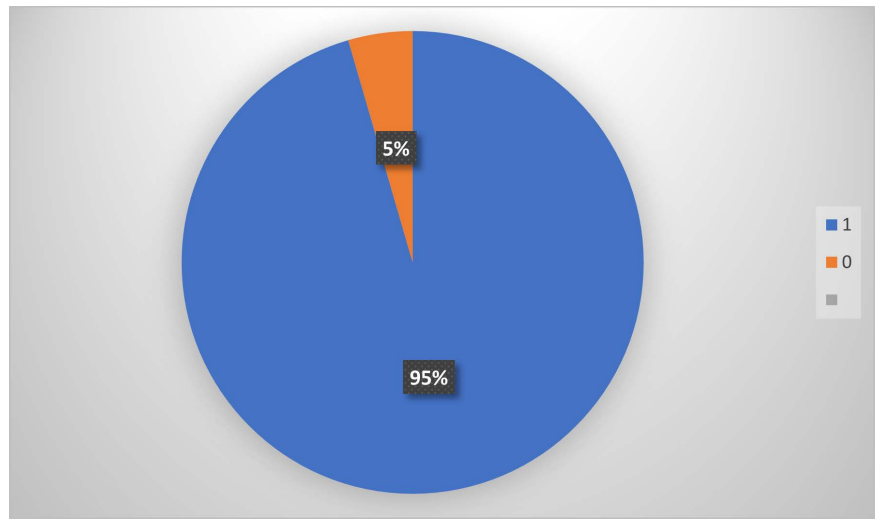

Fuente: Elaboración propia.

El 95,5\% de los encuestados asumen la importancia de publicar sobre la cultura para incentivar el turismo. Cuenca ha participado en los World Travel Awards siendo ganadora por tres veces consecutivas $(2017,2018,2019)$ con el premio "Mejor Destino de Vacaciones Cortas de Sudamérica", la competición y los ganadores son elegidos por el público en la plataforma de organización en la que participan varios expertos en turismo, empresarios y viajeros. 
154

\section{Figura 7}

¿Cree que la cultura se puede transmitir de una manera más eficaz mediante contenido audiovisual?

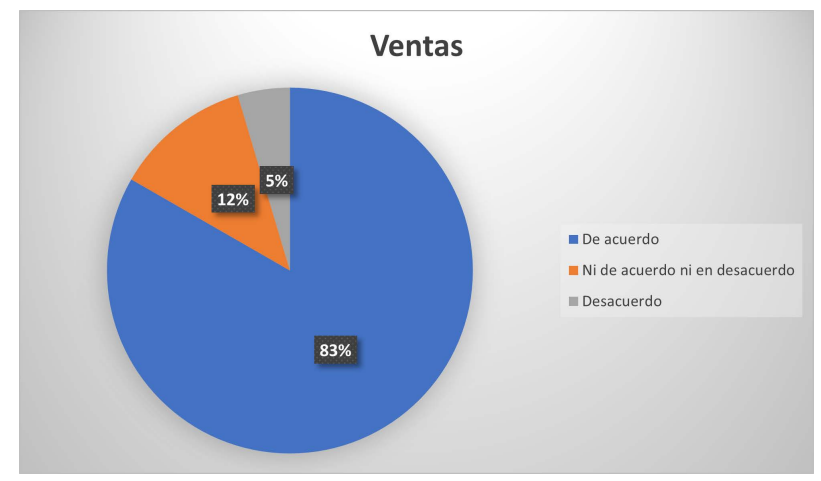

Fuente: Elaboración propia.

El contenido multimedia se ha apoderado de la industria de la información, que ha modificado hábitos tradicionales como la lectura colocándoles en nuevos escenarios como lo son los medios masivos de comunicación.

En consecuencia, en la era de los mass media donde prevalece la cultura de la imagen, la lectura ha sufrido un desplazamiento, más manifiesto aún en las nuevas generaciones, a la vez de grandes cambios: ya sea en la manera de aproximarse a ella, en el material que se escoge, en la forma en que se hace, en los medios que se eligen y, por, sobre todo, en el tiempo que se le dedica. 
155

\section{Figura 8}

¿Qué dificultad tiene usted para encontrar artículos de la cultura cuencana en Facebook?

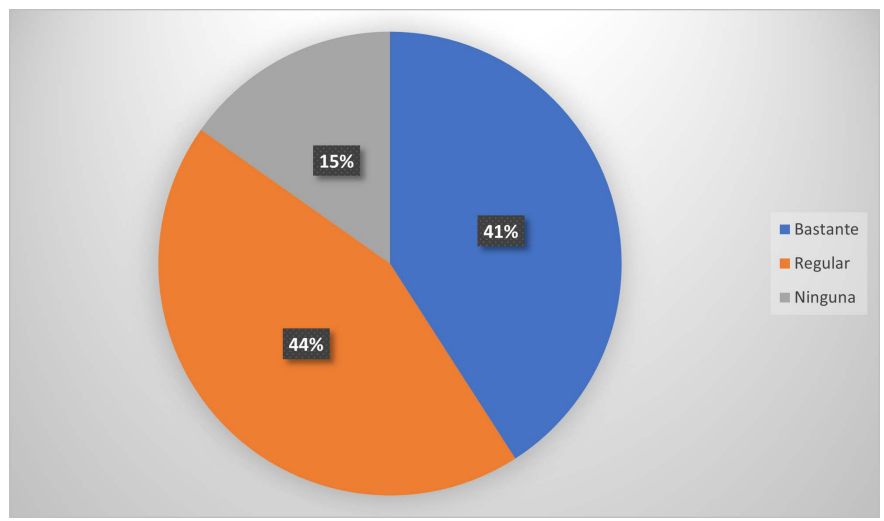

Fuente: Elaboración propia.

Por medio de la encuesta, se ha evidenciado una dificultad grande en relación a encontrar artículos en Facebook que hablen sobre la cultura cuencana, más del $40 \%$ menciona tener bastante inconvenientes, debido a cómo se mencionó en los análisis anteriores quienes comparten lo hacen, pero en los grupos de Facebook (que son cerrados) y las páginas son reducidas. Otro inconveniente a la hora de encontrar artículos de cultura es que se espera a que en el panel de inicio nos aparezca de forma imprevista para posteriormente compartirlo, no obstante, eluden el buscador para encontrar artículos de su interés. 
156

\section{Figura 9}

¿Cuál es el grado de importancia que le atribuye la cuencana a las redes sociales?

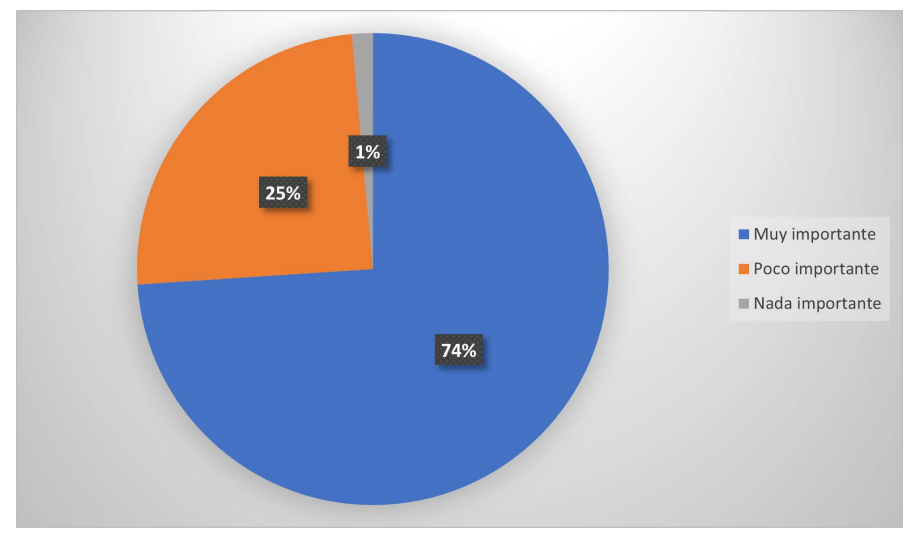

Fuente: Elaboración propia.

Tras el sondeo realizado, el 72,7\% de los encuestados califican de muy importante la cultura en redes sociales, como ya se ha manifestado, el carácter siempre se inclina al aprendizaje, más aún de las añoranzas personales, como en este caso es la cultura y la ciudad de natalicio.

Cuando se mediatiza la enseñanza, se convierte en un bien común al alcance de todos, por lo que, el grado de importancia aumenta, para eso debe ir acompañado de información verificada, porque al estar subido en una red tiene mucho alcance $y$, por ende, también existe información no validada que puede ser confundida y compartida siendo apreciada como real. 
157

\section{Conclusiones}

La investigación sobre la cultura cuencana se llevó a cabo en el mes de julio, debido a las adversidades coyunturales se hizo imposible la recolección de datos de manera presencial, no obstante, recurrimos a los beneficios que nos brinda la tecnología para llevar a cabo el experimento de manera virtual obteniendo de manera satisfactoria los resultados esperados.

Tras una larga investigación, encuestas y análisis de lo planteado en la hipótesis, se logró conglomerar los resultados ya planteados, en donde se evidencia el afán de los jóvenes (menores de 30 años) por adquirir más información sobre la cultura de Cuenca, pero por medio de las redes sociales (Facebook), en donde la mayoría concuerda su importancia pero haciendo hincapié a que se debe compartir de una forma más innovadora, es decir, dejar atrás los textos largos y ambientarlos a un modelo visual, donde prime lo multimedia con una información corta y precisa sobre temas específicos.

Los más activos en compartir información, fotografías antiguas y en llevar los grupos de Facebook, son personas mayores (31 años en adelante), los cuales no le prestan atención a la realización de contenido multimedia, enfrascándose solo en la escritura de artículos que relatan la procedencia de las imágenes antiguas de la ciudad.

Los jóvenes muestran su avidez por adquirir conocimiento, demostrando que ya no solo son los mayores quienes usan las redes para impartir la cultura. Las redes y 
158

los jóvenes muestran más afinidad por la cognición, porque muy aparte de querer informar quieren incentivar a un mejor desarrollo turístico en la ciudad, tanto así, que ha mostrado buenos resultados en los tres años anteriores en la que galardonaron a Cuenca con el óscar de ciudad turismo de Sudamérica.

Con el avance de la tecnología, la cultura será conocida por todas aquellas personas con acceso a internet y una cuenta de Facebook, bastará con poner en el buscador el tema sobre el cual se desee indagar, para que se despliegue una lista de contenidos sobre cultura y otros temas más, ya no solamente escrito por personas mayores, sino por jóvenes quienes con contenido audiovisual compartirán la información requerida de manera minuciosa y concreta.

Existió limitaciones debido a la crisis sanitaria por la que el mundo está pasando, las encuestas no se pudieron realizar físicamente, y se optó por sondeos virtuales, llegando así a concluir con los resultados planteados.

Para aquellos que deseen continuar con la investigación, deben centrarse más en la evolución cultural dentro de Facebook, partiendo desde el contenido cultural/multimedia actual enfocándose en cuál es su plan a futuro sin dejar de lado las nuevas herramientas y aplicaciones que hacen posible su interacción con los jóvenes y adultos.

\section{Bibliografía}

Herrán-Gómez, J., Torres-Toukoumidis, Á., \& Afonso-Gallegos, A. (2019). Efecto de la territorialidad en la identidad 


\section{9}

andina: caso Ecuador. Revista Estudios del Desarrollo Social: Cuba y América Latina, 7(1), 68-87. https://bit. ly/32wtUST

Vargas, M.E. (2005). Libro versus audiovisual: Reconciliar la antinomia para una formación de calidad en el ámbito universitario. Facultad de Diseño y Comunicación-Universidad de Palermo, 1(6)

Garzón-Vera, B. (2014). Comunicación intercultural en la ciudad de hoy. Utopía, 18(82), 24. 



\title{
CAPítulo VIII \\ El comercio cuencano y las redes sociales
}

\author{
Jhonathan Cuesta-Cuesta \\ Universidad Politécnica Salesiana, Ecuador \\ https://orcid.org/0000-0002-8111-4223 \\ Esteban Calderón-Méndez \\ Universidad Politécnica Salesiana, Ecuador \\ https://orcid.org/0000-0003-4258-4318
}

\section{Resumen}

El comercio a nivel de nuestro país cumple un rol vital en el desarrollo económico, es importante recalcar que a nivel de la Sierra se encuentra la mayor producción de divisas para el país, Cuenca sin duda es una de las ciudades que a lo largo de su historia ha experimentado grandes cambios y transiciones, tanto a nivel social, económico y sin duda tecnológicamente, lo que ha permitido su evolución, en lo que respecta al comercio en sus distintas modalidades. Para esta investigación se aplicó una metodología de tipo cuantitativa, que permitió analizar estadísticamente los negocios locales y compradores en redes sociales y la 
transición que se ha dado en los últimos años. Los resultados obtenidos nos han permitido tener una idea muy clara del avance y la evolución del comercio en nuestra ciudad, ya que estas actividades se realizan diariamente por estos medios. Esta investigación permitió determinar que el desarrollo comercial ligado a las redes sociales en Cuenca avanza significativamente, lo que sin duda marca un precedente en el desarrollo y avance de la economía cuencana.

Palabras clave: Comercio, redes sociales, investigación, resultados, público.

\section{Abstract}

Trade at the level of our country plays a vital role in economic development, it is important to emphasize that at the level of the Sierra is the largest production of foreign currency for the country, Cuenca is undoubtedly one of the cities that throughout its History has undergone great changes and transitions, both socially, economically and undoubtedly technologically, which has allowed its evolution, regarding trade in its different modalities. For this research, a quantitative methodology was applied, which allowed us to statistically analyze local businesses and buyers on social networks and the transition that has occurred in recent years. The results obtained have allowed us to have a very clear idea of the progress and evolution of commerce in our city, since these activities are carried out daily by these means. This research allowed us to determine that commercial development linked to social networks in Cuenca is progressing significantly, which undoubtedly 
sets a precedent in the development and advancement of the Cuenca economy.

Keywords: Commerce, social networks, research, results, public.

El presente trabajo va a profundizar acerca del comercio en Cuenca, la transición que ha sufrido el mismo gracias a la intervención de las redes sociales desde los medios tradicionales en la actualidad. Para tener un concepto claro acerca del tema se presentarán conceptos y situaciones del comercio en el Ecuador y en la Sierra, hasta tener una guía clara de su manejo en Cuenca y las redes sociales y su funcionamiento, de este último sabemos que se ha convertido en un medio que lo utilizamos a diario, tanto en nuestra vida profesional y emocional.

\section{El comercio en el Ecuador}

El comercio del Ecuador se presenta de manera histórica en tres etapas, las mismas que han definido las estructuras del sector externo ecuatoriano. La primera etapa es en la época colonial donde los principales productos de comercialización son los metales como oro y plata y productos agrícola como el cacao, estos productos eran los más comercializados tanto fuera como dentro del país, la segunda etapa del comercio ecuatoriano se presenta desde 1890-1930, dados los hechos negativos que sucedieron en el país, la economía basada en los burgueses y sus negocios fue insertada en la economía internacional y el Ecuador comercializa una diversidad de productos como textiles, 
sombreros de paja toquilla, tabaco y caucho, continuando con la comercialización de los productos de la primera etapa (Ordóñez, 2016).

La última, la tercera etapa transcurre desde 1921, Ecuador se caracteriza por basar su comercio en productos agrícolas y siendo la región Costa la principal generadora de esta oferta a nivel de exportación y la Sierra siendo la principal proveedora de consumo nacional. A partir de esta década empiezan las empresas petroleras con trabajos de exploración y hasta la década de los 70 y luego de varias concesiones a empresas extranjeras se empieza con la gran extracción del crudo en el Ecuador y el crecimiento de esta actividad (Ordóñez, 2016).

\section{El comercio de la Sierra}

Cabe recalcar que el intercambio económico entre zonas del país es activo, en cuanto a productos agrícolas, la sierra en su mayor parte se encarga de la producción agrícola y textil.

En la Sierra ecuatoriana está ubicada la provincia de Pichincha con su capital, Quito es la ciudad que más aporta en el comercio y de manera económica al país en su PIB, generando la mayor cantidad de impuestos, considerando así a la Sierra como la zona más importante comercialmente. La economía en esta zona se da en pequeña y gran escala, podemos encontrar comerciantes de productos agrícolas, desde sus pequeños productores que comercializan sus productos en una esquina de manera directa con el consumidor. 
Hasta grandes empresas dedicadas a la exportación de productos agrícolas, comprando sus huertas a los pequeños agricultores, sucede lo mismo con productos como las flores, el famoso "Panama Hat" que se da su elaboración desde pequeños obreros hasta grandes productores que se dedican a su distribución.

\section{Comercio en Cuenca}

La industria textil, muebles, cerámica, minería y turismos son los sectores más desarrollados en el cantón Cuenca, estas son las bases del comercio que se realiza en esta zona. La actividad artesanal es importante dada su claridad y variedad, un gran porcentaje de la población se dedica a esta actividad, elaborando artículos en oro, plata, tejidos y bordados.

El comercio se presenta especialmente en lugares o centros de abastos, donde los comerciantes ofrecen sus productos de manera directa, en la ciudad existe una variedad de locales destinados a comercializar todo tipo de productos y servicios, la variedad económica no es ajena a esta realidad, en este último tiempo el comercio se da de diferentes maneras.

\section{Redes sociales y su influencia en el comercio cuencano}

Conocidas también como estructuras sociales que puede representar de manera gráfica una persona, entidad o cosa, en los cuales se presenta a un grupo definido o infinito. 
Entre este grupo están artistas y la interacción con su público. Las relaciones en estas redes sociales pueden ser de distinto tipo, económicas, sociales, afectivas y las interacciones pueden ser conversaciones, juegos, foros, entre otros agrupando a personas con intereses en común (Gariboldi, 1999).

Este concepto es el más cercano a la realidad de las redes sociales que manejamos a diario en Cuenca. Facebook, Instagram, Twitter y WhatsApp son las plataformas más utilizadas por la sociedad cuencana, estas plataformas han presentado grandes cambios en las relaciones interpersonales, se han convertido en un medio para conocer personas, presentar productos y servicios y en este caso realizar transacciones comerciales.

Facebook cuenta con su propio centro comercial virtual "marketplace" en el cual se permite publicar variedad de productos y servicios, ya sea desde una página personal o página comercial. Este cambio que nos presentan las plataformas no se han dado de manera instantánea, esta se ha ido dando poco a poco, con una gran desventaja detrás, muchas empresas o personas no se dan cuenta que no es únicamente la creación de una nueva plataforma de venta, si no es un nuevo canal de comunicación. Lo que no se comunica no existe y lo que no avanza se pierde.

\section{Metodología}

Objetivo general: Identificar el uso comercial que se da a las redes sociales tanto por parte de los comerciantes como de los compradores. 
Objetivos específicos: Conocer las plataformas con más uso en la sociedad cuencana con el fin comercial; Establecer la importancia que le dan los usuarios a estas plataformas; Conocer el vínculo entre redes sociales y usuarios.

Métodos teóricos: se aplica para explicar los resultados de la investigación, es decir para fundamentar la aplicación y por otra parte las acciones que no pueden ser observadas a simple vista y esta es orientada a la acción aplicación de lo presentado.

Se requiere poner atención en la percepción de los conceptos de comercio y redes sociales y como sea presentado dicha transición en la ciudad de Cuenca, para tener esta apreciación la metodología será tanto cuantitativa como cualitativa.

Rodríguez Peñuelas (2010, p. 32), señala que el método cuantitativo de alcance exploratorio se centra en los hechos o causas del fenómeno social, con escaso interés por los estados subjetivos del individuo. Este método utiliza el cuestionario, inventarios y análisis demográficos que producen datos, los cuales pueden ser analizados estadísticamente para verificar, aprobar o rechazar las relaciones entre las variables definidas operacionalmente, además regularmente la presentación de resultados de estudios cuantitativos viene sustentada con tablas estadísticas, gráficas y un análisis numérico.

Dentro de esta investigación se aplicó una metodología cuantitativa, que permitió analizar de una manera estadística los negocios locales y compradores, en redes 
168

sociales, permitiendo probar hipótesis y a la vez realizar el seguimiento de la fuerza y dirección de los efectos de las redes sociales dentro del comercio de nuestra ciudad.

Para Stanton et al. (2004) una encuesta es una exploración que se realiza sobre una muestra de personas que representa un colectivo mucho más grande. De la misma forma se obtuvo una muestra heterogénea en la aplicación de la encuesta en compradores, tanto en género como en edad, siendo claros que la decisión de compra está en una persona con el poder adquisitivo.

\section{Resultados}

Con un total de 100 encuestas aplicadas, $50 \%$ a comerciantes, entre servicios y productos y a compradores entre hombres y mujeres, se procedió a realizar un análisis comunicacional, donde se puede observar que, dentro de nuestra ciudad, las plataformas o redes sociales son de uso normal y cotidiano para realizar actividades comerciales, lo que significa un gran avance y sobre todo una gran transición entre las maneras tradicionales de comercializar y las nuevas que van de la mano con las plataformas virtuales. 
169

\section{Figura 1}

Promedio entre compradores y comerciantes

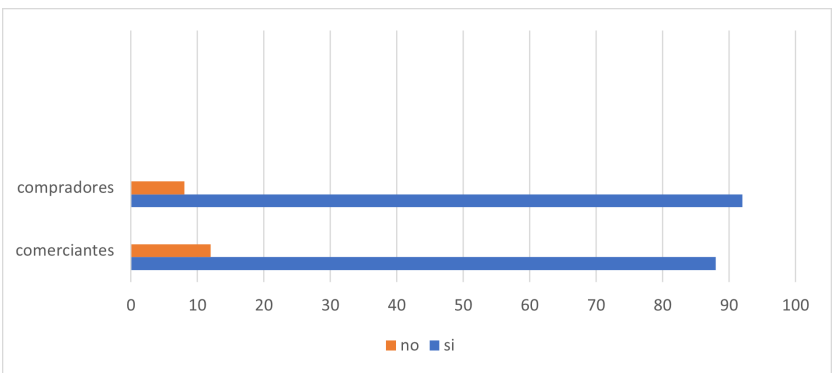

Fuente: Elaboración propia.

La columna presentada con respuesta afirmativa implica que la mayoría de los comerciantes y compradores interactúan mediante el uso de las redes sociales para acceder a productos y servicios en Cuenca, es decir la sociedad se adaptó a su uso para actividades diarias permitiéndole generar mayor accesibilidad durante la pandemia.

Figura 2

Porcentajes de ventas dentro de las redes sociales

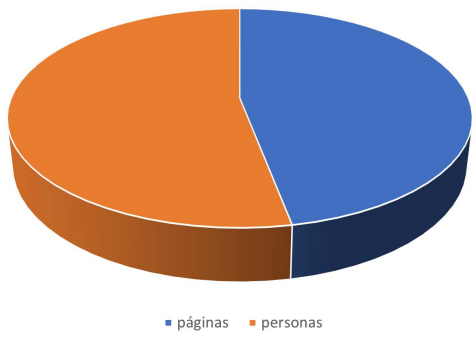

Fuente: Elaboración propia. 


\section{0}

Contar con una página 47\% (azul) dedicada únicamente a las ventas para los compradores no tiene mayor relevancia, estos compran de manera similar a personas 53\% (naranja) que ofrecen sus productos. Plataformas como Facebook brindan la opción de Marketplace, que es un espacio brindado únicamente para la comercialización de productos o servicios, sin costo alguno de publicidad y se puede realizar desde una página personal.

\section{Conclusiones}

Como conclusiones del presente trabajo damos a conocer que nuestro público en el caso de comerciantes fue homogéneo en cuanto a bienes y servicios, su ubicación es de manera principal en la zona urbana de la ciudad. Más del $80 \%$ ofrecen sus productos por redes sociales, a pesar de no tener una página comercial o web dedicada al mismo un $70 \%$ tiene fan page.

Facebook es la plataforma con más medios para publicitar y por lo tanto con un 59,5\% es el medio que los comerciantes utilizan para promocionar sus productos, contradictoriamente no consideran que las redes sociales son importantes para el comercio, claro está que sus clientes prefieren comprar por este canal y que ellos han tenido un porcentaje alto en cuanto a su éxito de ventas. Estas plataformas brindan comodidad y esta es la misma razón en su mayoría para que los usuarios realicen sus compras por estas plataformas. 


\section{1}

Para concluir se puede observar que el comercio en Cuenca ha tenido un gran cambio, ya que en los últimos años y cabe recalcar que en los últimos meses con mayor intensidad se ha dado a través de redes sociales o plataformas semejantes. Es importante destacar que estos medios brindan la seguridad necesaria para poder comercializar $\mathrm{y}$ adquirir todo tipo de producto; sin duda alguna se han convertido en una parte fundamental de nuestro diario vivir, haciendo más ágil, amenas y efectivas todas nuestras compras y ventas.

Las redes sociales se convirtieron no únicamente para Cuenca, sino para el mundo en un medio para llevar a cabo las labores diarias dentro de un entorno mas en el cuál tenemos un fin en común, es decir dentro de nuestros perfiles obtenemos más información, acerca de temas que a nosotros nos interesan, coincidiendo con Gariboldi (1999) la información brindada a nuestras redes sociales se forma en personas con intereses similares. En el caso del comercio, al buscar compradores interesados en nuestros productos, o productos que sean de nuestro interés o sacie nuestras necesidades.

En Cuenca el comercio ha sido modificado para bien, ya que la inmediatez está presente, obtenemos lo que deseamos en el menor tiempo posible y con la seguridad de una plataforma que nos ayuda a "conocer", a quién está detrás de un servicio o producto.

Investigaciones como esta, dentro de la ciudad han sido nulas, se encuentran estudios acerca de la influencia 
de las redes sociales en la vida cotidiana, más no de manera directa como interfiere en el comercio de la ciudad. Investigaciones de esta índole se encuentran en la ciudad de Quito y Guayaquil.

Esta investigación en Cuenca, deja sentado un precedente para estudios futuros, acerca del comercio y cómo han intervenido las redes sociales en el mismo, con bases desde un modelo de muestra para comerciantes y compradores, que en conjunto nos brindan información valiosa, para saber cómo gira este entorno y cuáles son las debilidades comunicacionales que tiene. Claro está que existe una posición favorable para las redes sociales y su funcionamiento dentro de los usos comerciales, en una época donde la comodidad y la agilidad son un factor importante para llegar al público.

\section{Bibliografía}

Gariboldi, G. (1999). Comercio electrónico: conceptos y reflexiones básicas. BID-INTAL.

Ordóñez, P. (05 de abril de 2016). Análisis del intercambio de bienes desde la colonia hasta la actualidad. El Comercio. Rodríguez-Peñuelas, M.A. (2010). Diseño de proyectos. En Métodos de Investigación (p. 32). Universidad Autónoma de Sinaloa.

Stanton, W. J., Etzel, M.J., \& Walker, B.J. (2004). Fundamentos de marketing. McGraw-HillInteramericana. 


\section{Capítulo IX \\ Los cuencanos en el exterior y las redes sociales}

Wendy Pugo-Arévalo

Universidad Politécnica Salesiana, Ecuador https://orcid.org/0000-0002-1149-2173

Melissa Mora-Gordillo Universidad Politécnica Salesiana, (Ecuador) https://orcid.org/0000-0001-7375-4530

\section{Resumen}

La migración es un proceso humano vinculado a la expansión de las personas y esta tiene gran relación con el funcionamiento de las redes sociales. Este trabajo busca mostrar la relación de las redes sociales con la migración presente en familias cuencanas y sus familiares estadounidenses. Se basa en el análisis cualitativo que fue realizado a través de 20 entrevistas como técnicas de recopilación de datos y se aplicó a una muestra de 10 familias migrantes y 10 familiares cercanos. Este análisis presenta la interacción y porqué las familias deciden mantener contacto e infor- 


\section{4}

marse del país en el cual están sus familiares; reflejando la necesidad de las redes sociales para mantener una posible unión entre ellos.

Palabras clave: Migración, redes sociales, interacción, comunicación, familias.

\section{Abstract}

Migration is a human process linked to the expansion of people and this has a great deal to do with the functioning of social networks. This work seeks to show the relationship of social networks with migration present in families in Cuenca and their relatives in the United States. It is based on the qualitative analysis that was carried out through 20 interviews as data collection techniques and was applied to a sample of 10 migrant families and 10 close relatives. This analysis presents the interaction and why families decide to maintain contact and get information about the country in which their relatives are; reflecting the need for social networks to maintain possible links between them.

Keywords: Migration, social networks, interaction, communication, family.

El trabajo pretende segmentar el enfoque dentro de la temática actual y ser tratada a profundidad desde una perspectiva migratoria que acontece al país, con respecto a la migración de Estados Unidos, con Cuenca-Ecuador, por medio de un estudio que permitirá conocer el estado de las personas adultas de quienes han migrado, y dar a conocer 


\section{5}

las redes sociales que son intervenidas por los migrantes, y el uso como herramienta de información que son proporcionadas, por medio de la red social, y cuál es el manejo que se interviene para comunicarse con la familia; y luego analizar por qué los migrantes escogieron las redes sociales como medio de comunicación y tercero descubrir por dónde reciben la información los migrantes sobre su país del cual migraron, y así permitir integrar características individuales y el conjunto de relaciones sociales que son aspectos importantes al abordar el fenómeno migratorio desde las redes sociales considerando que la persona ha experimentado su movilización para tener buena estabilidad económica, social, familiar, y para una buena educación que ha podido componerse de un estado íntegro dentro del manejo de las redes comunicacionales.

En ese sentido, el objetivo de este trabajo fue el análisis de los motivos y qué redes sociales usan aquellos ecuatorianos que migran o han migrado a los Estados Unidos y la situación actual de los migrantes que han retornado al país, específicamente el caso de Cuenca-Ecuador, con el propósito de diagnosticar el problema y conocer los factores que inciden sobre las redes sociales.

La migración se ha convertido en un fenómeno que abarca a muchos ciudadanos y con ellos consecuencias amplias, tanto para el país al que migran como el país que dejan, pues este fenómeno no es reciente, sino que acarrea muchos años y sucesos "la migración internacional constituye a una estrategia de supervivencia y de reproducción social hace más de treinta años" (Herrera, 2005). De igual 


\section{6}

forma esta manifestación sigue creciendo y en este estudio se centra en la población ecuatoriana con respecto a Estados Unidos, ya que la mayoría de sociedad migra por problemas económicos, falta de trabajo o por cuestiones de supervivencia.

Este fenómeno que se da en todas las ciudades ecuatorianas, por lo tanto, también en Cuenca genera cambios en el ámbito laboral como el social y estos no tienen un equilibrio de las futuras consecuencias, de allí que los movimientos migratorios en Ecuador generan configuraciones en la movilidad que van provocando efectos cambiantes en la labor social y laboral (Ramírez \& Ramírez, 2005).

Según estudios indican que la población está mayormente situada en la ciudad de Nueva York "En total Nueva York y sus alrededores estaría concentrado al 64.3\% de toda la población ecuatoriana en Estados Unidos" (Herrera, 2005, p. 9). Realmente comprender el porqué de este fenómeno es difícil ya que hay un fin de razones e incentivos y así lo menciona, Eguiguren (2017) ingresos o productividad de la tierra, que impulsaron a los individuos a buscar otros destinos. Esto está ligado con el campo de estudios del desarrollo, entendido entonces como desarrollo económico. Pero al momento de no estar en el mismo lugar que sus seres queridos la comunicación se vuelve esencial al igual que medios que permitan esto, es decir las redes sociales pues generan nuevas costumbres y colocan a las personas en distintos conjuntos ya que "transforman las relaciones sociales y crean nuevos grupos de identidad, solidaridad y desigualdad" (Pérez, 2003, p. 89). 
177

Los ecuatorianos constituyen uno de los grupos migratorios más grandes localizado en la ciudad de Nueva York.

Algunos migrantes pudieron contar con préstamos obtenidos de sus parientes, especialmente, de algún pariente cercano radicado ya en los Estados Unidos; otros tuvieron que conseguir el dinero de mano de 'prestamistas', individuos que imponen sus propios intereses dentro de una economía informal. (De Miguel-Luken, 2006, p.56)

De alguna manera se encuentran constituidos por círculos que les ayudan a beneficiarse a través del contacto con familiares radicados, mejorando así su situación económica laboral (Monterosas, 2003).

"Los movimientos migratorios en Ecuador generan configuraciones en la movilidad que se va desarrollando en trabajadores de los Estados Unidos y las densidades que provocan efectos cambiantes en la labor social y lo laboral" (Jofre, 2002, p. 3), se producen cambios en la búsqueda de las oportunidades y el bien moral en las relaciones que en su mayoría logran colectividades sociales en un fenómeno migratorio y que cada vez se componen de obstáculos en su logro. Las manifestaciones realizadas por parte de personas radicadas en Estados Unidos en su integración social que se encuentra mediante los trabajos en un cambio que genera las oportunidades para los ecuatorianos.

La migración fue explicada por los mayores incentivos, tales como ingresos o productividad de la tierra, que impulsaron a los individuos a buscar otros destinos. Esto está ligado con el campo de estudios del desarrollo, 


\section{8}

entendido entonces como desarrollo económico. (Rivera \& Valdéz 2016, p. 121)

La economía migratoria está basada en los cambios productivos que se van generando al desempeñarse como sujeto que busca ser incentivado, al desarrollo que produce estos cambios y ser la principal economía que se atraviesa.

La toma de conciencia, por parte del migrante, de que ha llegado a un límite, sea porque ha logrado el éxito o porque ya no es posible recibir mayores ingresos, lo coloca en una disyuntiva donde tiene que evaluar nuevamente costos y beneficios económicos, sociales, culturales y familiares. El migrante cuenta con un nuevo capital humano y social que puede utilizar tanto para quedarse o como para regresar a su país de origen.

Actualmente hay muy poca migración a los Estados Unidos desde Cuenca-Ecuador por la pandemia que se dio alrededor del mundo; se ha disminuido la migración en muchos países, en especial en Estados Unidos, se han cerrado las fronteras, aun así, hay personas que desean migrar porque en Cuenca-Ecuador se ha dado recorte salarial, y de personal en muchos trabajos. La gente busca migrar porque los sueldos son bajos y no les alcanza cubrir las necesidades básicas del hogar.

\section{Metodología}

Esta investigación tiene un enfoque cualitativo para deducir la relación de la migración y las redes sociales, con un diseño etnográfico el cual usará observación no par- 
179

ticipativa y entrevistas para responder al objetivo general que es analizar las redes sociales con respecto a la migración de Estados Unidos con Cuenca y así respectivamente responder estos objetivos específicos. Primero identificar qué red social usan los migrantes para comunicarse con la familia; segundo analizar por qué escogieron las redes sociales como medio de comunicación y tercero descubrir por dónde reciben la información los migrantes sobre su país de procedencia.

Para realizar este estudio se eligió a una población estadounidense y cuencana realizando un muestreo no probabilístico por conveniencia a una muestra de 20 personas migrantes al igual que a sus familiares; en este sentido se realizaron como técnicas de recolección de datos la observación y entrevistas de opinión y conocimiento, con 6 preguntas 3 generales en el ámbito de la migración y 3 estructurales sobre la relación de la migración con las redes sociales.

Con respecto a las entrevistas 13 fueron destinadas a personas migrantes que viven en Estados Unidos y 7 a familias cuencanas que tienen familiares en ese país, todas estas entrevistas, fueron realizadas de forma telefónica o vía internet y en un tiempo establecido de 2 días, todo el día, desde el 21 de julio hasta el 22 de julio y estas fueron analizadas los mismos días con respecto a los objetivos anteriormente ya planteados. 
180

\section{Resultados}

Las entrevistas realizadas a familiares cercanos que han migrado de Cuenca, arrojaron los siguientes resultados:

Se identificó que las redes sociales que más usan los migrantes para comunicarse con sus familiares es WhatsApp en un $100 \%$ de su uso, Messenger igual en un 100\% y FaceTime en un $100 \%$. También se dio a conocer que los mensajes de textos son muy usados, tanto para mantener contacto con su familia lejana y la cercana, por tal razón de alguna manera escogieron estas redes de comunicación porque les facilita la interacción; para ser abordados con los resultados obtenidos mediante las redes que, en su mayoría, dieron a conocer en un $100 \%$ el uso que se maneja.

Figura 1

Porcentajes de las redes sociales más utilizadas por migrantes y sus familiares

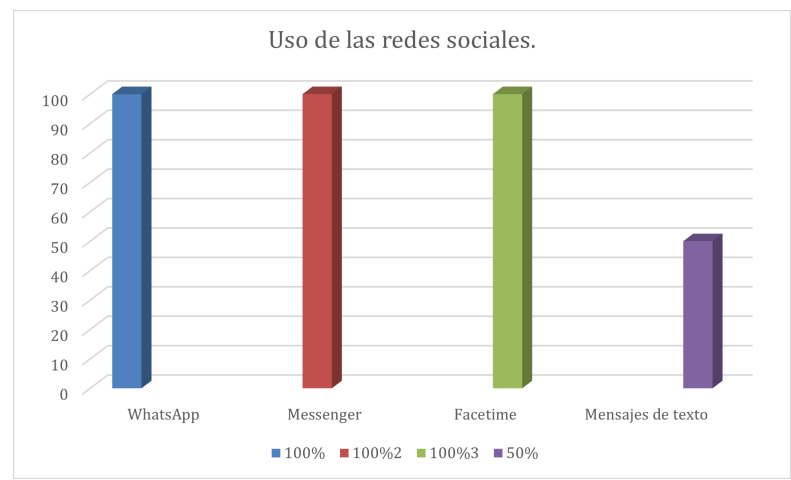

Fuente: Elaboración propia. 
181

Además se analizó por qué escogieron las redes sociales como medio de comunicación y se determinó que 20 personas, es decir el 100\% de los entrevistados eligieron las redes como WhatsApp, Messenger y FaceTime y un 50\% de ellos mencionó que en estos tiempos usa la aplicación de Zoom, ya que estas son fáciles de usar, también que los familiares tienen las mismas aplicaciones, pues son muy conocidas alrededor del mundo. Además, mencionaron que estas aplicaciones la usan porque son muy claras y te puedes comunicar con cualquier persona de otro país; y en el caso de FaceTime (IPhone) ya que se pueden hacer llamadas de celular a celular y así mejorar la comunicación.

Asimismo, analizando el medio por el cual reciben información los migrantes, sobre su país de procedencia, se indicó que de los 20 entrevistados 5 mencionan que usan Twitter, otros 4 mencionan que usan YouTube y los 10 restantes mencionan que usan Facebook y la persona restante usa una aplicación llamada TuneIn Radio que sirve para escuchar las noticias que se da en su ciudad de procedencia, también por medio de noticias y de post que hacen en las redes sociales como Facebook y Twitter.

La información obtenida por parte de las personas migrantes es la siguiente: el 50\% usa Facebook para obtener información por medio de post al igual que 32\% en Twitter, el 15\% usa la información audiovisual que brinda YouTube y el $4 \%$ usa TuneIn. Por lo tanto, se elabora un gráfico para indicar estos porcentajes. 


\section{2}

\section{Figura 2}

\section{Redes sociales por las cuales los migrantes se informan} sobre su país de procedencia

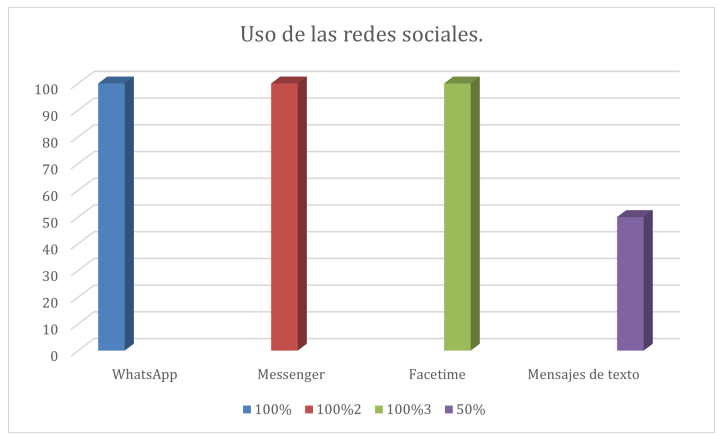

Fuente: Elaboración propia

\section{Conclusiones}

Se puede concluir que hay un total uso de redes sociales por parte de los migrantes al igual que de sus familiares, es decir una relación permanente en estos dos aspectos, pues se demostró que los migrantes usan WhatsApp, Messenger y mensajes de texto para comunicarse con sus familiares; así mismo esta fue la razón por la cual los entrevistados escogen WhatsApp para conocer sobre el país procedente.

Las redes sociales aportan un beneficio que permite la comunicación con familiares que han migrado y es importante reconocer el manejo que las redes tienen para mantenernos comunicados, en el uso de Facebook, WhatsApp que es de alguna manera más interactiva y favorable en el 
183

crecimiento que aportan estas redes. Y en nuestra opinión las entrevistas están muy bien planteadas, ya que obtuvimos respuestas muy claras y breves sobre la migración de Cuenca-Ecuador a Estados Unidos.

Una respuesta que llamó mucho la atención fue que por esta pandemia los migrantes usaron una aplicación llamada Zoom utilizado para hacer reuniones, rezar, etc.; otra aplicación que nos llamó mucho la atención fue TuneIn Radio que es para escuchar las distintas noticias provenientes del Ecuador.

Como limitaciones, se tuvo la falta de tiempo al realizar las entrevistas, también algunos entrevistados ni siquiera respondían a las preguntas y algunos que sí respondían brindaban respuestas escasas, pues al momento de analizar y redactar los resultados nos hizo falta información impidiendo que se llegue con claridad a resolver los objetivos, por lo tanto se infirió en varias respuestas.

Por último, como sugerencias para futuras investigadores es que este estudio se realice con un enfoque cualitativo para así analizar cuestionarios y usar las escalas de actitudes conociendo distintas opiniones $y$, finalmente, que estas entrevistas sean realizadas con más tiempo y respondiendo a las preguntas específicas para así conocer con detalle la información de los migrantes con las redes sociales.

En ese sentido, para alcanzar dicho ajuste óptimo de la investigación se desarrollaron formas para ser probadas y criticadas mediante las situaciones de los migrantes con relación a Cuenca, y se ha intervenido las redes sociales 


\section{4}

como bases principales para la realización de las entrevistas. El proceso de estas entrevistas es conocer de manera simultánea la cotidianidad que maneja la migración mediante la intervención de las redes sociales.

Para concluir se puede observar que la relación migratoria ha tenido un gran cambio que está orientado a la situación económica, que en su mayoría busca mitigar mediante el uso de redes sociales. Es importante recalcar que los migrantes pueden acceder a las redes y comunicarse con sus familiares cuencanos.

\section{Bibliografía}

Eguiguren, M.M. (2017). Los estudios de la migración en Ecuador: del desarrollo nacional a las movilidades. Íconos. Revista de Ciencias Sociales, (58), 59-81. https://doi. org/10.17141/iconos.58.2017.2497

Herrera, G. (2005). La migración ecuatoriana: transnacional ismo, redes e identidades. La Pradera.

Jofre, A. (2002). Las redes de relaciones sociales y las migraciones de baleares a Argentina. Mayurqa, 28, 93-110. https:// bit.ly/32vquQf

De Miguel-Luken, V. (2006). Migración y redes sociales de apoyo. Revista hispana para el análisis de redes sociales, 11(2). https://doi.org/10.5565/rev/redes.96

Monterosas, P.M. (2003). Las redes sociales de la migración emergente de Veracruz a los Estados Unidos. Migraciones internacionales, 2(1), 136-160.

Ramírez, J., \& Ramírez, F. (2005). La estampida migratoria ecuatoriana: Crisis, redes transnacionales y repertorios de acción migratoria. Clacso. https://bit.ly/2YET7sW

Rivera, Ó., \& Valdéz, G. (2016). "Crisis humanitaria: El rol de las redes sociales en el proceso migratorio. Humanidades, 6(1), 1-48. https://doi.org/10.15517/H.V6I1.25119 


\section{Capítulo X Los emigrantes en Cuenca y las redes sociales}

Mishell Jiménez-Pineda

Universidad Politécnica Salesiana, Ecuador https://orcid.org/0000-0002-7928-3191

Cristopher Pesantez-Maxi Universidad Politécnica Salesiana, Ecuador https://orcid.org/0000-0003-4619-1239

\section{Resumen}

Esta investigación tiene como finalidad dar a conocer sobre la cantidad de migrantes que han sido recibidos en Cuenca y el uso que le dan a las redes sociales, mediante una encuesta realizada con base a la información sobre la migración, mostrando la cifra de residentes permanentes de otros países que se quedaron en la ciudad, no solo para mejorar su situación económica, sino para superarse y salir adelante es sus estudios, incrementando el uso del internet en varios sectores, generando un intenso uso de las redes sociales, también para conocer el por qué es importante 
conocer sobre la migración en Ecuador, el porcentaje de usuarios migrantes que utilizan las redes sociales, ya sea para ver noticias, para realizar sus tareas, un pasatiempo, o utilizarlo como una herramienta más de trabajo para su diario vivir.

Palabras clave: Migración, emigración, inmigración, migración de retorno.

\section{Abstract}

The purpose of this research is to publicize the number of migrants they have received in the city of Cuenca and the use they make of social networks, through a survey based on information on migration, showing the number of permanent residents from other countries that will stay in the city, not only to improve their economic situation, but to improve themselves and get ahead in their studies, increase the use of the internet in various sectors, generate intense use of social networks, also to know the why it is important to know about migration in Ecuador, the percentage of migrant users who use social networks, whether it be to watch news, to carry out their tasks, for a time, or to use it as one more work tool for their daily life.

Keywords: Migration, emigration, immigration, return migration.

Las migraciones son muy comunes y se vienen dando desde hace muchos siglos atrás, ya sean voluntarias o forzadas. Testimonios y hechos; niños, niñas, mujeres embarazadas y ancianos migran por un bien común por causas de po- 
lítica o pérdidas en sus salarios o sustentar a su familia, pero lo más común de las migraciones es la crisis económica. A nivel mundial existen millones de migrantes y a través de las redes sociales han podido solventarse ya que es una gran ayuda, y para ello se ha realizado una encuesta que ayuda a obtener datos específicos sobre cómo las personas utilizan los medios sociales para obtener información acerca de los migrantes, siendo ahora el caso en Cuenca.

\section{Migrante ecuatoriano y redes sociales}

La migración es entendida como desplazamiento de la población desde una mirada global, "se destacan las crecientes brechas entre los países de origen y de destino en el nivel de renta, en la calidad de vida, en las oportunidades y servicios y en la garantía del disfrute de derechos" (Lotero-Echeverri \& Pérez-Rodríguez, 2019, p. 146). Por ello existen diversas variables que provocan la migración, unas de ellas "sugieren que el nivel salarial no puede explicar por sí solo la decisión de migrar, sino que depende una gran medida del empleo disponible en las regiones disectoras" (Alvarado-López et al., 2017, p. 112). El proceso migratorio provoca que los lazos interactivos y comunicacionales se vean afectados, por lo que:

El internet extiende la posibilidad de establecer una red de contactos a nivel local y global. Las cuentas de Facebook de migrantes funcionan como lazos débiles porque se sostienen con menor intensidad, pero con mayor conectividad. La creación de redes no funciona sólo a nivel práctico y técnico, sino que se encuentra en el imaginario de estos migrantes. Ellos descubren la posi- 


\section{8}

bilidad e impulsan el objetivo de crear vínculos. (Melella, 2016, p. 83)

Por lo cual, este medio no solo contribuye a la necesidad de comunicarnos, sino que de acuerdo a la Universidad de Guayaquil explica que:

Con la ayuda de las redes sociales se darían a conocer la información que requieren los migrantes previo al retorno debido a que la necesidad de informar y guiar a cada una de estas familias es vital, con esto se evitarán gastos innecesarios, estafas. (Delgado-Sabando, 2016, p. 44)

En los trayectos de migración se da explicación de cómo se puede influir por convivencia dada en redes sociales:

Las organizaciones de migrantes desde sus orígenes han sido de sobrevivencia y por comunidad, que solo se vinculan convencionalmente con otras similares de la misma región para mantener su identidad sociocultural, pero no desarrollan proyectos conjuntos de mayor cobertura, como lo hacen las lucrativas que establecen relaciones cada vez más extensas con el exterior y tienden más hacia la adquisición de elementos políticos y socioculturales urbanos. Estas organizaciones no indígenas centran sus actividades socioeconómicas y políticas en las gestiones ante las instituciones oficiales y otros organismos nacionales e internacionales, realizando marchas, mítines, denuncias y otros eventos sociopolíticos para lograr sus demandas. (Ramos-Pioquinto, 2008, p. 6) 


\section{Percepción en redes sociales sobre la migración venezolana}

Con el concepto que se usa en el contexto de la economía y las finanzas públicas y que tiene que ver con la capacidad de los factores productivos para trasladarse de un mercado a otro. La movilidad del trabajo está relacionada con las diferentes habilidades que requiere las industrias que existen en un lugar específico y con la facilidad de traslado de los trabajadores de una localidad a otra, o de un país a otro. (Echeverry-Hernández, 2011, p. 16)

Se distingue que la migración venezolana se sitúa en diferentes países, así extendiendo sus búsquedas por salir de la crisis de su país, siendo así un flujo de migración masiva, por lo cual, los países tienen una presión de receptores sobre materialización de salud, educación de migrantes, aplicando en ser impulsadores de nuevas oportunidades.

Analizando las perspectivas de la migración como fuentes de ingresos o crisis de los países se da a conocer que:

Debido a estos nuevos movimientos poblacionales en la frontera colombo venezolana, se han identificado tres tipos de situaciones distintas a las ya conocidas. Un primer tipo referido a personas que cruzan la frontera durante la noche y regresan a territorio colombiano durante el día para trabajar; un segundo a personas que usan como tránsito el cruce de frontera, saliendo de sus lugares de origen para entrar nuevamente por otros pasos que les representen mayor seguridad; y un tercer tipo de personas que cruzan la frontera y desean quedarse en territorio venezolano en condición de refugiados. (Álvarez de Flores, 2004, p. 9) 
190

\section{Metodología}

El análisis de esta investigación se basa en un estudio crítico con un enfoque deductivo y un diseño etnográfico además se utilizará la observación participativa y estructurada, con el fin de responder al objetivo general, a la vez la aplicación de entrevistas como herramientas de recopilación de datos. El objetivo general es analizar el uso de las redes sociales por parte de la migración venezolana.

Los objetivos específicos son: contextualizar la información con la realidad territorial acerca de la migración y diagnosticar el uso de las redes sociales en relación con las personas migrantes.

Las entrevistas están compuestas por seis preguntas, la primera de opinión y formato general, la segunda de opinión y formato estructurada, la tercera es de conocimiento con formato estructurada, la cuarta es de opinión y de formato estructurado, la quinta de conocimiento con formato estructural y la última pregunta, de opinión y formato estructural. La primera y la quinta pregunta se utilizaron para responder el objetivo general, la segunda, tercera, cuarta y sexta se utilizaron para responder los objetivos específicos.

De la población local se eligió una muestra de 72 personas y a estas se aplicó un muestreo no probabilístico por conveniencia, las entrevistas fueron aplicadas a 50 cuencanos desde la edad de 15 a 18 años y 22 entrevistas a migrantes desde la edad de 15 en adelante, estas 72 entrevistas se aplicaron de forma online, el periodo empleado 
191

para realizar las entrevistas fue un estimado de 4 días, desde el 15 al 18 de julio de 2020.

Para ello se han utilizado algunos métodos para realizar la encuesta, se han subido las preguntas a una plataforma y enviado a varias personas para que estas las respondan, también se ha utilizado Instagram y Facebook para la misma encuesta, que fue realizada en diferentes días de la semana, para que no sean las mismas personas las que contestaran, recolectando así varias respuestas que nos servirán para los resultados de la investigación. Las encuestas realizadas fueron hechas en base de que las personas tengan el mayor conocimiento posible sobre la migración y las redes sociales, siendo un total de 72 personas, que gracias a su colaboración se han obtenido dichos resultados que se verán a continuación.

Se recolectó la información mediante la técnica de una encuesta en el cual su instrumento fue la guía de preguntas. Esta entrevista a pesar de los datos cualitativos permitió que la interpretación del investigador sea desde una perspectiva cualitativa puesto que las opciones de respuestas a las preguntas eran desde el nivel de percepción y satisfacción del encuestado. La encuesta fue realizada a 72 personas de los dos géneros, entre 18 a 25 años de edad, sacando un porcentaje exacto sobre cómo utilizan las redes sociales y la importancia de saber sobre la migración en Cuenca. El objetivo de la encuesta fue para conocer por qué medio se informan las personas acerca de la migración y su posición ante la misma. 


\section{2}

\section{Resultados}

Con relación a la pregunta sobre el uso de las redes sociales se puede distinguir que el $78 \%$ de las personas usan las redes sociales todos los días; el 17\% casi todos los días; el $4 \%$ ocasionalmente y el $1 \%$ nunca. Lo que nos lleva a interpretar que la mayoría de las personas constantemente se encuentra usando las redes sociales para una $\mathrm{u}$ otra actividad.

\section{Tabla 1}

¿Cuánto uso le da a las redes sociales?

\begin{tabular}{|c|c|}
\hline & Número de personas \\
\hline Todos los días & 56 \\
\hline Casi todos los días & 12 \\
\hline Ocasionalmente & 3 \\
\hline Casi nunca & 0 \\
\hline Nunca & 1 \\
\hline Total & 72 \\
\hline
\end{tabular}

Fuente: Elaboración propia.

En el gráfico 1, respecto a la pregunta acerca de cuánto conoce cada persona sobre la migración en el Ecuador se distinguió que: el $50 \%$ cree que es sumamente importante conocer esta información; el $45 \%$ lo considera algo importante; el $4 \%$ considera que es sin importancia alguna y el $1 \%$ lo ve ni importante, ni sin importancia. Por tal circunstancia se interpreta que la mayoría de las personas consideran que se debe conocer a cerca de esta información que acontece en el país. 


\section{3}

\section{Figura 1}

¿Cree que es importante conocer sobre la migración en el Ecuador?

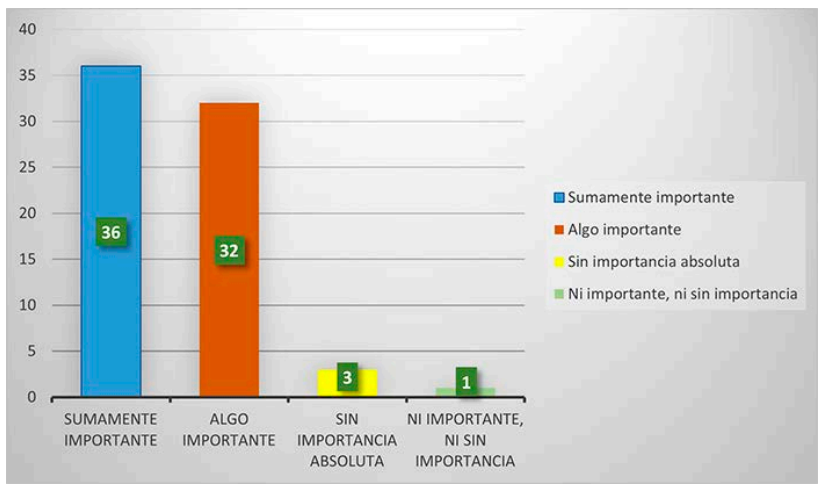

Fuente: Elaboración propia.

Tabla 2

¿Cree que es importante conocer sobre la migración en el Ecuador?

\begin{tabular}{lc}
\hline & Número de personas \\
\hline Sumamente importante & 36 \\
Algo importante & 32 \\
Sin importancia absoluta & 3 \\
Ni importante, ni sin importancia & 1 \\
\multicolumn{1}{c}{ Total } & $\mathbf{7 2}$ \\
\hline
\end{tabular}

Fuente: Elaboración propia.

En el gráfico 2 de acuerdo a la pregunta con la posición de cada persona frente a la llegada de migrantes en Cuenca los encuestados respondieron: el 53\% tiene su 


\section{4}

posición ni satisfecha, ni insatisfecha; el $26 \%$ se muestran poco satisfechos; el $14 \%$ un poco insatisfechos y el $7 \%$ muy satisfechos. Respecto a esta pregunta se comprende que la mayoría de los encuestados tiene una posición neutra ante la presencia de los migrantes en la ciudad y un 33\% se sienten satisfechos con la llegada de migrantes.

Figura 2

¿Cuál es su posición frente a la llegada de los migrantes a la ciudad de Cuenca?

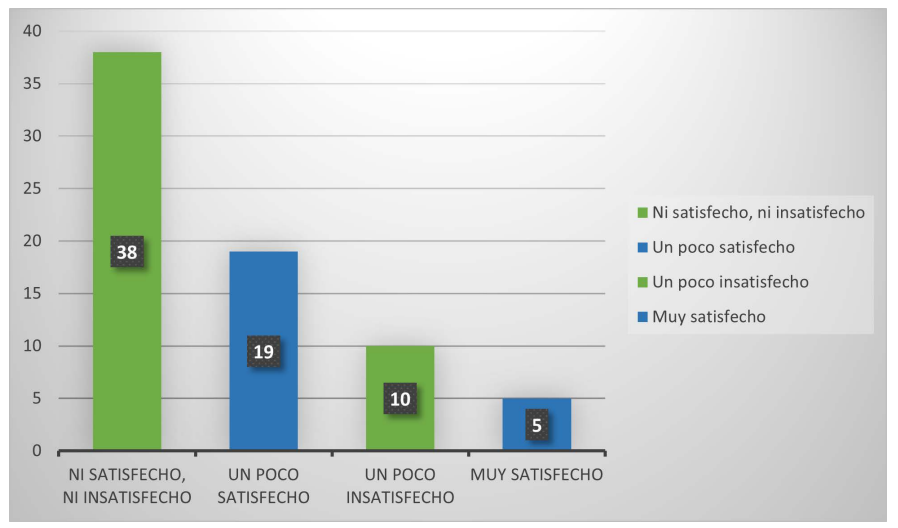

Fuente: Elaboración propia. 


\section{5}

\section{Tabla 3}

¿Cuál es su posición frente a la llegada de los migrantes a la ciudad de Cuenca?

\begin{tabular}{lc}
\hline & Número de personas \\
\hline Ni satisfecho, ni insatisfecho & 38 \\
Un poco satisfecho & 19 \\
Un poco insatisfecho & 10 \\
Muy satisfecho & 5 \\
$\quad$ Total & 72 \\
\hline
\end{tabular}

Fuente: Elaboración propia.

En el gráfico 3 respecto por cuál medio se informan las personas acerca de la migración se evidencia que: el $86 \%$ por medio de redes sociales; el $7 \%$ por la televisión; el $4 \%$ por comunicación directa con migrantes o vecinos y el 3\% por medio de la radio. Por tal motivo se interpreta que la mayoría de personas usa las redes sociales para informarse acerca de esta temática y medios de comunicación digitales.

\section{Figura 3}

¿Por cuál medio se informa acerca

de la migración de personas?

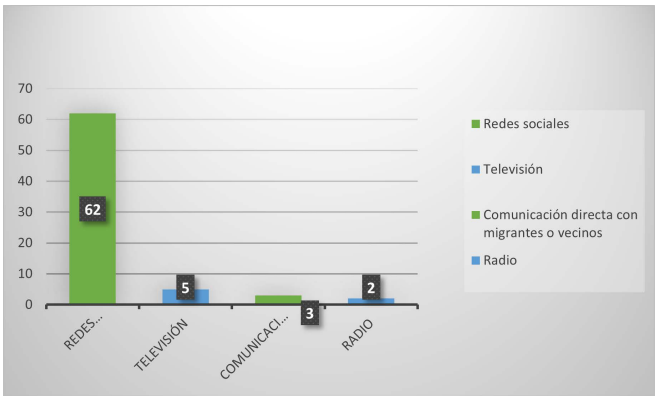

Fuente: Elaboración propia. 


\section{Tabla 4}

¿Por cuál medio se informa acerca

de la migración de personas?

Número de personas

\begin{tabular}{|c|c|}
\hline Redes sociales & 62 \\
\hline Televisión & 5 \\
\hline $\begin{array}{l}\text { Comunicación directa con migrantes } \\
\text { o vecinos }\end{array}$ & 3 \\
\hline Radio & 2 \\
\hline Total & 72 \\
\hline
\end{tabular}

Fuente: Elaboración propia.

En el gráfico 4 con respecto por cuál red social se informan de acuerdo a la pregunta del gráfico 4 se evidenció que: el $79 \%$ de los encuestados se informa a través de Facebook; el 14\% por medio del Twitter; el $4 \%$ por medio de Instagram y el $3 \%$ por medio de TikTok.

Figura 4

¿Cuál red social utiliza para informarse?

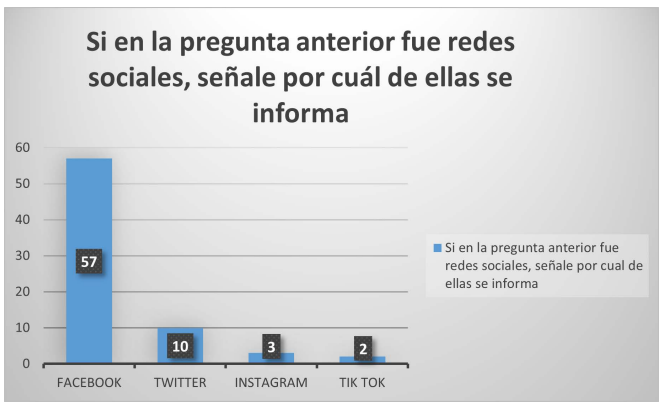

Fuente: Elaboración propia. 


\section{7}

\section{Tabla 5}

Si en la pregunta anterior fue redes sociales señale por cuál de ellas se informa

\begin{tabular}{|c|c|}
\hline Redes sociales & Número de personas \\
\hline Facebook & 57 \\
\hline Twitter & 10 \\
\hline Instagram & 3 \\
\hline TikTok & 2 \\
\hline Total & 72 \\
\hline
\end{tabular}

Fuente: Elaboración propia.

En el gráfico 5 de acuerdo a si las personas quieren conocer más sobre la migración por redes sociales se visualiza que el $90 \%$ de los encuestados sí desean y solo el $10 \%$ no; por tal razón se interpreta que la mayoría de personas sí desea informarse más y seguirlo haciendo por medio de esta herramienta.

\section{Figura 5}

¿Le gustaría conocer o informarse más acerca de la migración por redes sociales?

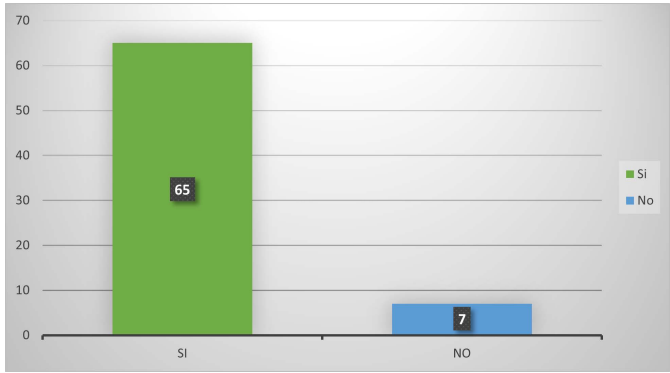

Fuente: Elaboración propia. 
198

\section{Tabla 6}

¿Le gustaría conocer o informarse más acerca de la migración por redes sociales?

\begin{tabular}{lcc}
\hline & Número de personas \\
\hline Sí & & 65 \\
No & Total & 7 \\
& & 72 \\
\hline
\end{tabular}

Fuente: Elaboración propia.

\section{Conclusiones}

En conclusión, se puede decir que 56 personas utilizan las redes sociales todos los días y la red que más utilizan es Facebook, 65 personas les gustaría saber acerca de las migraciones en Cuenca, a 36 personas les parece importante conocer acerca de la migración en el territorio ecuatoriano, 63 personas usan las redes sociales para mantenerse informados sobre las personas migrantes y 38 personas no están satisfechas ni insatisfechas por las llegadas de los migrantes a Cuenca.

En base a la investigación realizada se considera que es importante permitir conocer por dónde se informan las personas acerca de la migración. Así, en el desarrollo de la carrera profesional darle vital importancia como comunicador a la influencia que tiene estos medios para informar y saber cómo informar a través de los mismos. Los obstáculos presenciados en el desarrollo del proyecto es que quizás se pudo indagar de mejor forma con encuestas de forma personal ya que aquí se interactúa de manera direc- 
ta con el encuestado y se ve su reacción de comunicación corporal ante una pregunta.

En tal circunstancia como sugerencia para los próximos investigadores acerca de esta temática es importante tomar en cuenta que se puede utilizar más métodos de recolección de información tales como una encuesta para la interpretación de resultados y las preguntas elaboradas desde la escala de Iker ya que permiten el accionar cualitativo del investigador y se toma en cuenta el pensamiento, acción y reflexión personal de cada individuo encuestado, y además la exposición del producto puede ser a través de un video en donde se exponga las reacciones de la muestra investigada.

\section{Bibliografía}

Alvarado-López, J.R., Correa-Quezada, R.F., \& Tituaña-Castillo, M.D.C. (2017). Migración interna y urbanización sin eficiencia en países en desarrollo: evidencia para Ecuador. Papeles de población, 23(94), 99-123. http://dx.doi. org/10.22185/24487147.2017.94.033

Álvarez de Flores, R. (2004). La dinámica migratoria colombo-venezolana: evolución y perspectiva actual. Geoenseñanza, 9(2), 191-202. https://bit.ly/2D7Xbul

Delgado-Sabando, E.A. (2016). Análisis comunicacional sobre la información que reciben los migrantes ecuatorianos que deciden retornar a nuestro país. Repositorio Universidad de Guayaquil, 1-61. https://bit.ly/3b6JHf1

Echeverry-Hernández, A.A. (2011). Análisis de la migración venezolana a Colombia durante el gobierno de Hugo Chávez (1999-2011). Identificación de capital social y 
compensación económica. Revista Análisis Internacional, (4), 33-52. https://bit.ly/3b9u9Hh

Lotero-Echeverri, G., \& Pérez-Rodríguez, M.A. (2019). Migraciones en la sociedad contemporánea: Correlación entre migración y desarrollo. Retos Revista de Ciencias de la Administración y Economía, 9(17), 145-159. https:// doi.org/10.17163/ret.n17.2019.09

Melella, C.E. (2016). Migración y TIC: Identidades andinas en Facebook. La Trama de la comunicación, 20(1), 73-88. https://bit.ly/3js9aCF

Ramos- Pioquinto, D. (2008). Migración rural-urbana y redes sociales. El caso de la Sierra Norte de Oaxaca. El Cotidiano, 23(148), 95-104. https://bit.ly/3jnZitE 


\section{Capítulo XI \\ El futuro de las redes sociales en Cuenca}

Fabrizzio Sánchez-García Universidad Politécnica Salesiana, Ecuador https://orcid.org/0000-0001-8891-1009

Nicolás Moscoso-Loaiza Universidad Politécnica Salesiana, Ecuador https://orcid.org/0000-0002-9440-2486

\section{Resumen}

En esta investigación se va a analizar el impacto que tendrán las redes sociales dentro de Cuenca-Ecuador, siendo así, uno de los temas de estudio la aceptación que tuviera el turismo mediante las redes sociales, también se analizó como creen los expertos que la publicidad se pudiera dar en estas y si esto ayudará a que las empresas y los emprendimientos logren maximizar su marca; este estudio se realizó a 15 expertos dentro de las redes sociales para saber las opiniones que tengan sobre el tema, siendo los expertos estudiantes de los últimos años de las carreras de Comunicación 


\section{2}

y de Informática, quienes son los que están más cerca trabajando con redes sociales y que pueden darnos una retroalimentación más nueva sobre el tema.

Palabras clave: Informática, medios sociales, medios de comunicación de masas, medios de información, ciudad, sociedad futura.

\section{Abstract}

This research will analyze the impact that social networks will have within the city of Cuenca-Ecuador, being one of the topics of study the acceptance that tourism had through social networks, also analyzed as experts believe that advertising could be given in these and if this would help companies and enterprises to maximize their brand; This study was conducted to 15 experts within the social networks to know their opinions on the subject, being the experts students of the last years of the careers of Communication and Computer Science, who are those who are closer working with social networks and can give us newer feedback on the subject.

Keywords: Computing, social media, mass media, Future society, information media, city, future society.

Estamos ante una sociedad en la cual, las redes sociales han estado presentes en todo momento en el actuar y que en el futuro serán las que nos sigan ayudando en todo lo que se irá necesitando en nuestro día a día. Se tendría que seguir esperando que estas nos den un mejor soporte para cualquiera problema que se vaya generando, y Cuenca 
se adapte de una manera relativamente rápida a esta nueva tecnología haciendo uso de ella en las diferentes necesidades que la población vaya requiriendo, por ejemplo, los políticos se dan a conocer mediante videos y publicidades; a su vez lo cultural no se queda atrás, pues esto va creando contenido para que todo interesado en conocer algo nuevo de la cultura de Cuenca pueda hacerlo a través de la red social mediante pequeños videos y publicaciones que tienen alguna cita informativa; como también ofrecer una mejor información a la ciudad a través de videos en vivo, dando noticias al instante de la ciudad de Cuenca.

Esto también ayuda a personas de todas las edades a tener un mejor manejo de estas porque cada vez son más usuarios de diferentes edades que utilizan las redes sociales, y esto crea un beneficio en todo ámbito; en lo económico es crear nuevas oportunidades de empleo y más repercusión a empresas pequeñas, esto ocasiona que cada vez la sociedad vaya evolucionando de una manera mejor con la ayuda de estas.

Esta herramienta ha hecho que haya un cambio de cultura muy grande dentro de la ciudad y se adapten culturas de diferentes sociedades, ampliando el conocimiento de los ciudadanos, pero también tiene sus contras y es que con este cambio cultural se va perdiendo las tradiciones de la ciudad por adaptarse a nuevas costumbres.

Últimamente se tiene una peculiar utilización por parte de las autoridades, de las redes sociales como medio no solo para comunicarse con la ciudadanía, sino también 


\section{4}

para tomar decisiones directamente, relacionadas con su función pública (Rodríguez-Hauschildt, 2015). Con la situación actual se puede gobernar a través de internet y es una forma más eficaz de tener controladas a las masas, a través de sus dispositivos inteligentes que están conectados a estas redes, se puede saber la ubicación en la que encuentran y así tener una mayor información de cómo la sociedad está actuando, esto facilita a que los diferentes funcionarios públicos no se expongan tanto a esta situación.

El concepto de Red Social (RS) remite cada vez menos a la "red de vecinos que se autoorganizan en un barrio, de trabajadores en un sindicato, etc., y nos remite, cada vez más, a modos de organización mediados por instrumentos/espacios virtuales, lo cual, lejos está de ser un devenir natural" (Sforzin, 2016, p. 1). Una referencia de lo que empieza a pasar en el mundo es que todas las empresas, familiares, negocios entre otros, van siendo cada vez más dependientes de las redes sociales, ya que la comunicación de ahora ha cambiado con respecto a años anteriores, puesto que ahora para comunicarse con un empleado de la empresa ya no se le llama, sino que se le manda un mensaje mediante WhatsApp, que es hoy por hoy una de las más usadas en el mundo.

"Me gusta", "actualizar el muro", "tuitear", "etiquetame”, “¿tenés Facebook?”, “¿vi tus fotos en el Facebook?”, “te sigo en Twitter", y muchas otras frases parecidas se han vuelto parte de nuestro vocabulario y accionar cotidiano. Las redes sociales ya trascienden edades, clases sociales, profesio- 


\section{5}

nes. Estar en las redes es cada vez más estar pendiente de los demás y en contacto a la distancia (Gutiérrez, 2014).

Una herramienta para la expresión personal, con una capa que permita establecer conexiones con cierto nivel de control, y sin un modelo de negocio que pretenda espiarnos o imponernos una publicidad hipersegmentada en función de nuestra actividad (Dans, 2019).

Las redes sociales y unas pocas compañías digitales están tratando de controlar nuestro estilo de vida digital. Y ante esta situación, los Gobiernos de algunos países (Estados Unidos, Europa, China...) están creando nuevas leyes para gobernar el espacio digital, una situación bastante diferente de la idea original de un Internet sin fronteras. (Celaya et al., 2018)

Las redes sociales han modificado la forma y frecuencia en que los seres humanos se comunican, lo cual también ha originado una forma distinta de participación ciudadana (Ayala, 2014).

Es así cómo las redes sociales han venido transformando el mundo que conocemos, y a pesar de las brechas generacionales, nos han permitido integrarnos a una cadena que es sumamente dinámica y efectiva. "La verdadera revolución está teniendo lugar justo en este momento, y son las redes sociales" afirma Hütt-Herrera (2012, p. 126).

Por su parte, Islas-Torres y Carranza-Alcántar (2011) manifiestan que uno de los ámbitos donde podemos desarrollar el potencial de las redes sociales como parte de la 


\section{6}

educación es Facebook, ya que representa un espacio colaborativo, además de que ofrece una fuerte cantidad de recursos para ilustrar aplicaciones, proponer ejercicios de aplicación, optimizar la dinámica de la clase, entre otros, lo que brinda la posibilidad de conectar estudiantes entre sí en redes de aprendizaje

\section{Metodología}

Este artículo tiene un enfoque cualitativo-deductivo con un diseño de investigación-acción el cual usará Delphi que son entrevistas a expertos (estudiantes de los últimos años de las carreras de Comunicación e Informática) y observación participativa como técnicas de recolección de datos, con el fin de responder el objetivo general que es comprender cómo las redes sociales serán utilizadas en un futuro cercano ya que estas están en constante cambio, al igual que responder a los objetivos específicos que son: 1) demostrar las herramientas serán funcionales en las futuras redes sociales y las diferentes actualizaciones, 2) determinar si la publicidad implementada en las redes sociales será maximizada y utilizada en el futuro y por último, 3) analizar si el turismo virtual será utilizado dentro de Cuenca.

Las entrevistas se tomaron a la población cuencana con una muestra de 15 expertos, con un muestreo no probabilístico, de tipo bola de nieve y estas entrevistas se realizaron en un tiempo de 3 días a través de Zoom.

\section{Resultados}


Luego de analizar las respuestas de cada entrevista, se llegó al consenso de que todos los entrevistados consideran que en el futuro las redes sociales estarán más que presentes, teniendo así el 100\% de aceptación a lo largo del tiempo. Ronnie Urdiales uno de los individuos entrevistados menciona que, de esta forma serán implementadas las redes sociales en el futuro "tendrán identificaciones únicas para cada persona, evitando así las cuentas falsas, estafas, etc.”.

También se conoció que el 100\% de los individuos, consideran que mientras el tiempo siga cambiando será más accesible para todas las personas y haya cosas nuevas donde las redes sociales puedan mejorar sus herramientas; de esta forma se puede llegar a decir que los usuarios esperan que las redes sociales estén actualizando sus herramientas constantemente, para que de esta manera nos puedan ir ofreciendo cada vez más y mejores herramientas.

Con respecto al turismo en las redes sociales se analizó que el $45 \%$ de los entrevistados están totalmente a favor de este y mencionan que esta implementación es una excelente iniciativa pero en el turismo especialmente por su característica de interacción; mientras que, el $44 \%$ restante a pesar de estar a favor con esta iniciativa, mencionan que esta no será tan eficiente dado que, el turismo se caracteriza por la realidad y sobre todo la opción de poder salir a conocer de forma física el lugar y un $11 \%$ no está de acuerdo que se haga un turismo mediante redes sociales, debido a que se menciona que nunca se podrá reemplazar el turismo real. 


\section{8}

Figura 1

Análisis de aceptación del turismo en redes sociales

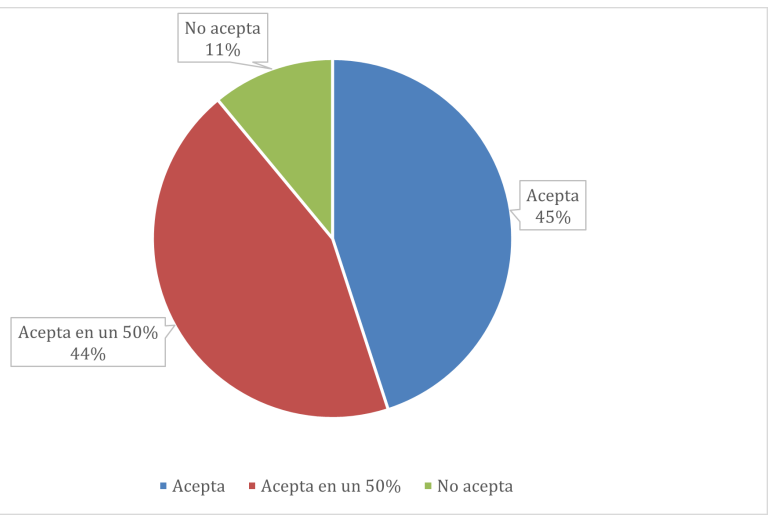

Fuente: Elaboración propia

En el ámbito de la publicidad en las redes sociales, el $100 \%$ considera que estas se van a maximizar por su uso, de esta forma las empresas, al igual que los emprendimientos deberán acoplarse a este nuevo método, permitiendo que su producto o mercancía llegue a varios destinos y así amplíe su mercado y los permita ser reconocidos, acreditando a esto Diego Orellana menciona que: "la publicidad crecerá, pues es la manera más fácil de llegar a la audiencia de manera personalizada", quien cree que las publicidades en las redes sociales serán personalizables de acuerdo al contenido que tenga el usuario.

Sebastián Bedoya afirma que las redes sociales: "tiene como aspecto positivo la automatización y como negativo los posibles robos de identidad o información mal 
utilizada"; es necesario recalcar que estas opiniones son escasas, puesto que otros entrevistados, sólo especificaron el lado bueno de las redes sociales indicando que estas empiezan poco a poco a tomar fuerza dentro de la sociedad en la que estamos, como es el caso de Diego Orellana, quien opina que: "las redes sociales harán bien, pues estamos en la era de la información y todo se lleva o se llevará de manera digital jugando un papel importante". No obstante, no pensó en lo que eso conlleva y todo lo malo que pueda pasar como dijo Sebastián Bedoya.

\section{Conclusiones}

Se demostró que según los análisis de expertos, las herramientas que se utilizarán en el futuro serán de una gran ayuda para la seguridad de la ciudad y también para la sociedad abriendo nuevas oportunidades en diferentes campos laborales, ayudando con actualizaciones que se espera mejoren a dichas herramientas; también se llegó a la conclusión que la publicidad podrá tener un aumento bastante grande en este medio y que se podrá aprovechar para nuevos emprendimientos y empresas que ya existan y estas busquen la mejor forma de maximizar sus ventas atrayendo al público con publicidades personalizadas para cada uno; y, por último, el turismo mediante las redes sociales servirá más que nada como un pequeño preámbulo donde se muestren las partes más emblemáticas de la ciudad, para que las personas se sientan motivadas a venir a conocer estos lugares en persona y de paso visiten toda la ciudad. 


\section{0}

Gracias a esta investigación se pudo concluir que el aumento del uso de las redes sociales servirá en un futuro para poder mejorar ciertos aspectos de la vida cotidiana de los ciudadanos, sin embargo también se verá afectada por casos puntuales que se podrán corregir con el pasar de los años; las limitaciones que se encontró al momento de realizar las entrevistas fue que algunos de los expertos seleccionados tenían poco tiempo para responder las preguntas y no nos pudieron dar las respuestas tan concisas como se esperaba. También el hecho de que se está atravesando una pandemia no se logró hacer entrevistas de manera presencial, que fue también uno de los causantes de que los entrevistados no se sintieran tan cómodos al momento de responder las preguntas; como sugerenciaplanteamos que este estudio se realice de manera cuantitativa para poder tener datos más seguros al momento de llegar a las conclusiones y también podemos sugerir que se realice una investigación más profunda sobre qué tipo de herramientas se considerarían mejores para que las redes sociales sea aún más efectivas.

\section{Bibliografía}

Ayala, T. (2014). Redes sociales, poder y participación ciudadana. Revista Austral de Ciencias Sociales, (26), 23-48. https:// bit.ly/34JIXLO

Celaya, J., Adzic, J., Cencerrado, L.M., Gervás, P., Menéndez, J.M., Neira, E., Yuste, E., Jimeno, D., Rodero, E., Tascón, M., \& Rodríguez, N., (2018). Anuario AC/E de cultura digital 2018: Tendencias digitales para la cultura. El lector en la era digital. Acción Cultural Española.

Dans, E. (06, octubre, 2019). Redes sociales y futuro. [Mensaje de un blog]. https://bit.ly/32y7SPv 


\section{1}

Gutiérrez, F.G. (2014). La "revolución" de las redes sociales: sociedad, educación y nueva profesión. Voces en el fénix, (40), 112-119. https://bit.ly/32DnOAb

Rodríguez-Hauschildt, V.M. (2015). Las redes sociales y su incidencia en la sociedad actual. Aequitas, 8(8). https://bit. ly/34FSLX2

Hütt-Herrera, H. (2012). Las redes sociales: una nueva herramienta de difusión social networks: a new diffusion tool. Reflexiones, (91), (121-128). https://bit.ly/32xqUpq

Sforzin, V. (2016). Redes sociales en Latinoamérica. De los usos a las estrategias colectivas. IX Jornadas de Sociología de la UNLP, 5 al 7 de diciembre de 2016 Ensenada, Argentina. Universidad Nacional de La Plata. Facultad de Humanidades y Ciencias de la Educación. Departamento de Sociología.

Islas-Torres, C., Carranza Alcántar, M. del R. (2011). Uso de las redes sociales como estrategias de aprendizaje. ¿Transformación educativa? Apertura, 3(2) https://bit. ly/2QFvBHT 

En conmemoración del Bicentenario de Independencia de Cuenca, la Universidad Politécnica Salesiana junto al Grupo de Investigación Gamelab-UPS y la dirección de Carrera de Comunicación -sede Cuenca- presenta la obra "Los morlacos y las redes sociales", la cual es el resultado de investigaciones cualitativas y cuantitativas realizadas por estudiantes de segundo ciclo en la asignatura "Investigación de la Comunicación". Los resultados demuestran que la ciudad de Cuenca y su población está inmersa en el uso de las redes sociales, denotando sus beneficios para la reactivación socioeconómica y cultural posterior a la pandemia.
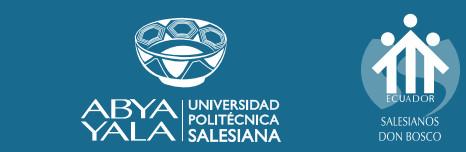